\title{
INVESTIGATION OF RADON AND HELIUM AS POSSIBLE FLUID-PHASE PRECURSORS TO EARTHQUAKES
}

H. Craig, Y. Chung, J.E. Lupton, S. Damasceno and R. Poreda

Scripps Institution of Oceanography University of California, San Diego La Jolla, California

USGS CONTRACT NO. 14-08-0001-18348 Supported by the EARTHQUAKE HAZARDS REDUCTION PROGRAM

OPEN-FILE NO.81-278

U.S. Geological Survey

OPEN FILE REPORT

This report was prepared under contract to the U.S. Geological Survey and has not been reviewed for conformity with USGS editorial standards and stratigraphic nomenclature. Opinions and conclusions expressed herein do not necessarily represent those of the USGS. Any use of trade names is for descriptive purposes only and does not imply endorsement by the USGS. 
TECHNICAL REPORT NO. 13

INVESTIGATION OF RADON AND HELIUM

AS POSSIBLE FLUID-PHASE PRECURSORS

TO EARTHQQUAKES

H. CRAIG, Y. CHUNG, J. E. LUPTON

S. DAMASCENO, AND R. POREDA

Scripps Institution of Oceanography University of California, San Diego

La Jolla, California

Sponsored by U. S. Geological Survey

Contract 非 USGS 14-08-0001-18348

Effective Date: October 1, 1979

Expiration Date: $\quad$ September 30, 1980

Amount of Funding: $\$ 91,625$

Government Technical officer: Karen Ward

SIO Refierence Number: $\quad 80-40$

December, 1980

The views and conclusions contained in this document are those of the authors and should not be incerpreted as necessariiy representing the official policies, efther expressed or implied, of the U.S. Goveinment. 


\section{TABLE OF CONTENTS}

Page

Abstract 1

1. Introduction $\quad 3$

2. S. California Network: Current Status 3

3. Arrowhead Hot Springs 7

3.1 Dissolved gases 7

3.2 Temperature and conductivity 13

4. Radon Variations at Hot Mineral We11 and Bashford's Bath We1i 18

5. Helium at Frink Hot Springs 18

6. General Data Sumnary 25

7. Temperature and Conductivity Variations 27

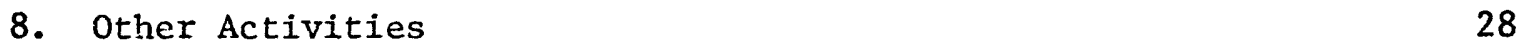

9. Collaborative Work with Chinese State Seismological Bureau, $\begin{array}{ll}\text { Peking } & 28\end{array}$

9.1 Research on Tibetan and Chinese geothermal areas 29

9.2 Proposal for a joint research program 32

List of previous technical reports 36

Appendix 1. Radon variations vs. time (graphs)

Appendix 2. Helium variations vs. time (graphs)

Appendix 3. Nitrogen variations vs. time (graphs)

Appendix 4. Methane variations vs. time (graphs)

Appendix 5. Temperature variations vs. time (graphs)

Appendix 6. Conductivity variations vs. time (graphs)

*Appendix 7. Southern California Network Liquid phase: radon, helium, and dissolved gases (Tables)

\section{TABLES}

Table 1. Primary Sampling Network $\quad 6$

Table 2: Tibet Gas Samples 30

Table 3. China Samples in 1720-Flasks 31

*Appendix 7 is a separate item; it is available at the USGS office. 


\section{FIGURES}

Page.

Figure 1. Location map for $\mathrm{Rn}$-He monitoring 5

F1gure 2. Current sample processing outline $\quad 8$

Figure 3. Radon variations at AROW-1P 9

Figure 4. Helium variations at AROW-1P 10

Figure 5. Nitrogen variations at AROW-1P 11

Figure 6. Methane variations at AROW-1P 12

Figure 7. Radon vs. helium variations at AROW-1P, for helium sampled in 1720-glass flasks 14

Figure 8. Helium vs. nitrogen variations at AROW-1P 15

$\begin{array}{lll}\text { Figure 9. Temperature variations at AROW-1P } & 16\end{array}$

Figure 10. Conductivity variations at AROW-1P 17

Figure 11. Radon variations at HMIN-2W 19

Figure 12. Radon variations at BASH-1W 20

Figure 13. Helium increases at FRNK-1P 21

Figure 14. Radon variations at FRNK-1P 22

Figure 15. Nitrcgen variations at FRNK-1P 23

Figure 16. $\mathrm{He}^{3} / \mathrm{He}^{4}$ vs. He at FRNK-1P $\quad 24$

Figure 17. Location of areas in China and Tibet sampled in MayJune, 1980

\section{SYMBOLS}

HELIUM A 1

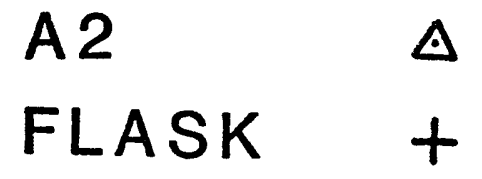


INVESTIGATION OF RADON AND HELIUM

AS POSSIBLE FLUID-PHASE PRECURSORS TO EARTHQUAKES

14-08-0001-18348

H. Craig, Y. Chung, J. E. Lupton

S. Damasceno and R. Poreda

Scripps Institution of Oceanography

University of California, La Jolla

La Jolla, California

(714) $452-3260$

ABSTRACT

This report includes new data on radon, helium, and other dissolved gases $\left(\mathrm{N}_{2}, \mathrm{Ar}, \mathrm{CH}_{4}\right)$ in thermal wells and springs along our Southern California network, for the period October, 1979, to September, 1980. Additionally, since this is an annual report, complete tables and graphs of data measured from 1975 to the present are included as appendices. Temperature and conductivity graphs are also shown for most sites.

Two sites, Arrowhead Hot Springs and Hot Mineral We11, at opposite ends of our S. California San Andreas network, have been of special interest during the past year. Arrowhead Hot Springs showed a large increase in radon and helium (plus all other gases) in early 1979, prior to the Big Bear earthquakes $(M=4.8)$. This increase, probably precursory, has been extensively discussed in TR 11 and TR 12, in which it was shown that the observed increases represent an increase in the "deep" component of gases in a two-component mixture with atmospheric gases dissolving into the exposed hot-spring surface water. By mid-1980, the radon and helium levels at Arrowhead had returned to normal baseline levels where they have remained since then.

At the south end of the San Andreas, in the Salton Sea geothermal area, Hot Mineral Well and Bashford's Baths We11, two $60^{\circ} \mathrm{C}$ hot wells in continual use, both showed $37 \%$ increases in radon concentration relative to previous baselines, beginning in February of this year. These increases may have been precursory to three small ( $M=3.3,3.0,3.3)$ earthquakes on April 6 and 7, which occurred $25 \mathrm{~km}$ south of these wells, on the fault trace. These increases were observed only in radon; helium, nitrogen, and argon showed no effect. The time interval prior to the earthquake was 66 
days in each case, somewhat longer than expected for such small seismic events. Two lower-temperature wells and Frink Spring, farther south and closer to the epicenter, showed no radon variations prior to the earthquakes.

Frink Spring has, however, undergone a steady increase in helium concentration since 1975 , approximately $5 \%$ per year over a five-year period. This $25 \%$ increase in helium is not matched by increases in radon, nitrogen, or argon. Nor, as we show in this report, has there been any change in the $\mathrm{He}^{3} / \mathrm{He}^{4}$ isotopic ratio during this time. The effects in this spring, including very unusual $\mathrm{N}_{2}$ and $\mathrm{Ar}$ concentrations, are quite complicated and are not yet understood. A significant component of mantle helium appears to be present, since the $\mathrm{He}^{3} / \mathrm{He}^{4}$ ratio is twice the atmospheric ratio and is probably higher than can be accounted for by tritium from nuclear weapons testing.

During May and June, H. Craig spent six weeks in China and Tibet, a visit occasioned by the Symposium on the Qinghai-Xizang (Tibet) Plateau organized by Academia Sinica, with a field trip across Tibet after the meeting. A preliminary plan for cooperative work in geochemical monitoring was laid out with the State Seismological Bureau in Peking, and seve-ral lectures on our work were given at the Bureau prior to the meeting.

In Tibet, $H$. and $V$. Craig returned to Lhasa after the field trip and carried out field work in the Yangbajin geothermal area to the north, collecting gases from hot springs and geothermal steam wells. This work was done with $\mathrm{Dr}$. Cai Zuhuang of the SSB, who is collaborating in the Tibetan study. The most important result to date has been the finding that the Tibetan helium is entirely "crustal", i.e. radiogenic in origin, with no evidence of a mantle component. The $\mathrm{H}_{2} 3 / \mathrm{He}^{4}$ ratio is, in fact, lower by a factor of 135 than the ratio in helium at Yellowstone Park (a mantle plume area)!

Joint work with the Peking SSB is continuing. Two Chinese scientists will visit our laboratory for one month during December, to study laboratory and field collection techniques. Then during early 1981, two of our group will work in the Yunnan geothermal area with SSB scientists, and carry out some further collections in the Peking area. A program for a very extensive study of crustal fluids throughout China is being developed as a joint long-term study involving helium, radon, other gases, stable isotopes, and chemistry, in a variety of tectonic regimes where significant earthquake hazards are present. 


\section{INTRODUCTION}

In this report, we present data on radon, helium, and other dissolved gases $\left(\mathrm{N}_{2}, \mathrm{Ar}, \mathrm{CH}_{4}\right)$ accumulated over the last twelve months, together with the previous data measured on our Southern California network since the beginning of our monitoring program in 1974. Measurements have been made at approximately monthly intervals on samples from thermal wells and hot springs along the Elsinore, San Jacinto, and San Andreas faults between San Bernardino and the Mexican border. Because this is an annual report, graphic presentations and a complete listing of the data, including temperature and conductivity, are given in the appendices. Sites of particular interest are discussed in separate sections. These include Arrowhead Hot Springs, in which significant variations were observed prior to the 1979 Big Bear earthquakes, Hot Mineral Well and Bashford's Bath We11, in which significant radon increases prior to nearby earthquakes in the Salton Sea area were observed this year, and Frink Spring, which has shown a systematic increase in helium concentrations over the past five years.

A preliminary plan for cooperative work in geochemical monitoring was formulat:d with the State Seismological Bureau in Peking, during H. Craig's visit to China and Tibet in May and June of 1980. Some results of the preliminary cooperative work and future plans are discussed in this report.

A paper on our current data accumulation will be presented at the 1980 Fall AGU annual meeting, in the Seismology session on "Geochemical precursors." The abstract is given in page 4 .

\section{S. CALIFORNIA NETWORK: CURRENT STATUS}

Figure 1 shows the present status of the network locations on the three major fault zones. The network now consists of 14 active sites: 8 springs and 6 thermal wells, sampled at regular monthly intervals. These primary sites are listed in Table 1; there are 3 on the Elsinore, 3 on the San Jacinto and 8 locations on the San Andreas-Mission Creek-Banning complex between San Bernardino and the east side of the Salton Sea. Two primary sites listed in Table 1 are currently inactive: ELSI-1W was damaged in January and no plan has yet been made to restore it or install a new pump since then. We are currently obtaining an estimate for the cost of 
FLUID- PHASE EARTHQUAKE PRECURSOR STUDIES IN SOUTHERN CALIFORNIA

H. Craig

Y. Chung, R. Poreda, J. Lupton, S. Damasceno (A1 1 at Scripps Institution of Oceanography, UCSD, La Jolla, CA 92093).

A monitoring network of 16 thermal wells and springs along the Elsinore, San Jacinto, and San Andreas faults, has been in operation for six years. Temperature, conductivity, radon, helium, and dissolved $\mathrm{N}_{2}, \mathrm{Ar}$, and $\mathrm{CH}_{4}$ are measured at monthly intervals. Other measurements at less frequent intervals include total $\mathrm{CO}_{2}$, carbon, hydrogen, oxygen, and nitrogen isotope ratios, $\mathrm{Ra}-226$ and $\mathrm{Pb}-210$ activities, and $3 \mathrm{He} / 4 \mathrm{He}$ ratios. We have established a two-component mixing model for dissolved gases in which compositional variations in thermal springs reflect mixing of an ascending deep component with a "surface" component within the spring. $\mathrm{Rn}$ and He variations due to these effects, and to cavitation loss in two-phase systems, are normalized by use of $\mathrm{N}_{2}$ and Ar variations. Helium isotope ratios show proportions of "mantle" to "crustal" helium throughout the network, and $\mathrm{Rn}$ to $\mathrm{Pb}-210$ activity ratios $\left(\sim 10^{3}\right.$ to $10^{5}$ ) show effects of lead scavenging and local radon addition.

Large changes in $\mathrm{Rn}$ and He in Arrowhead Hot Springs occurred in May, 1979, $60 \pm 15$ days prior to the Big Bear earthquake swarm $(M=4.8)$ in the San Bernadino mountains. $\mathrm{Rn}$ and He increased $72 \%, \mathrm{CH}_{4}, \mathrm{Ar}$, and $\mathrm{N}_{2}$ increased by $60 \%, 25 \%$, and 17\%. All concentrations returned to baseline by 1ate 1979. This appears to be a definite precursory event, in which the "deep" component increased relative to the surface component and gas concentrations were less diluted by downward convective mixing. No dilatancy effects were involved. At Frink Spring in the Salton Sea area, He has increased $5 \%$ per year since early 1976, with no increase of other components; no reason is yet known. 

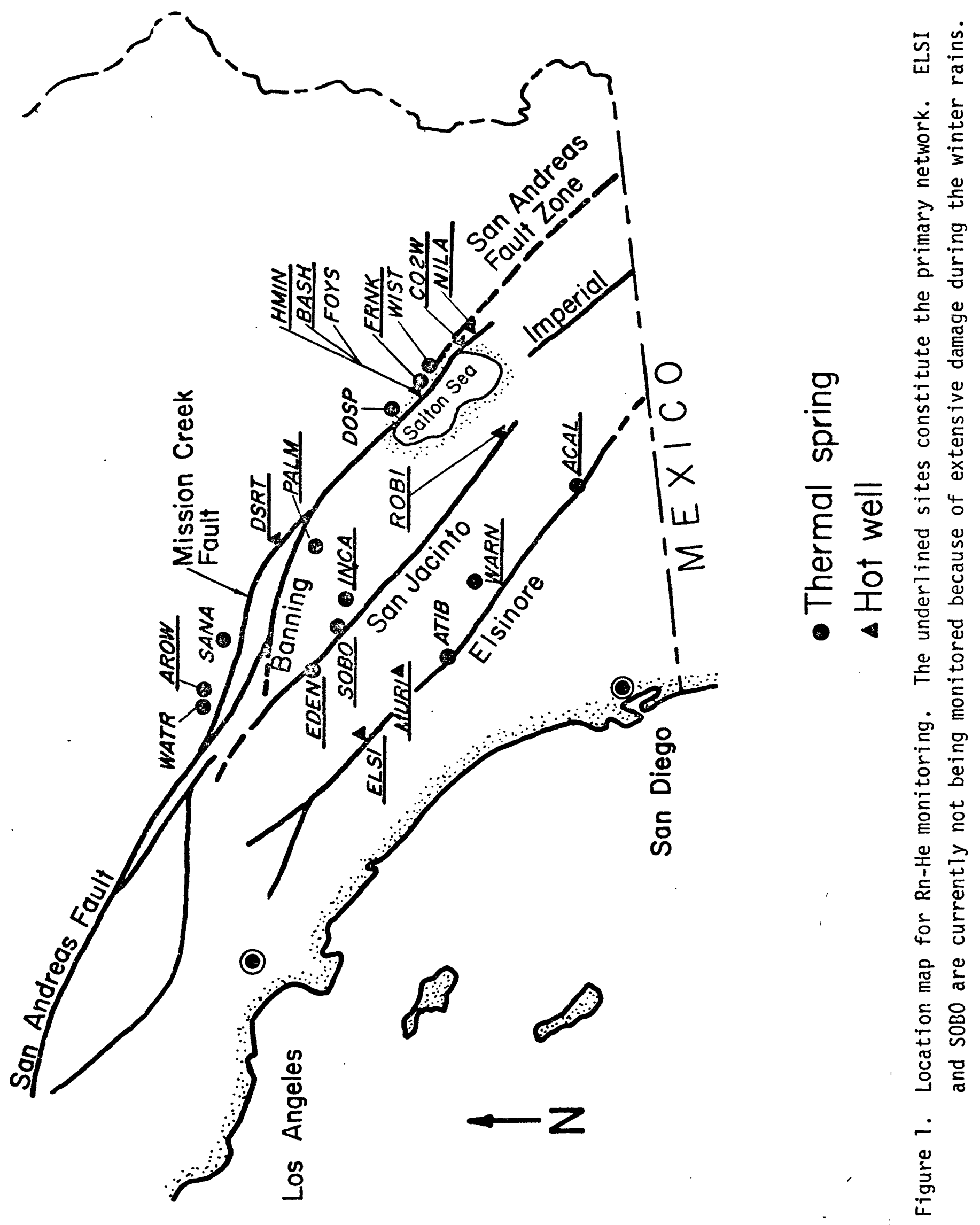
TABLE 1. PRIMARY SAMPLING NETHORK

SITE CODE LOCATION TYPE $\quad T^{\circ} \mathrm{C}$ NUMBER

\section{Elsinore Fault}

$\begin{array}{cllll}\text { * ELSI-1W } & \text { Elsinore Hot Spring } & \text { Well } & 40 & 169 \\ \text { * MURI-1W } & \text { Murrieta Hot Springs } & \text { Well } & 54 & 170 \\ + \text { MURI-2P } & \text { Murrieta Hot Springs } & \text { Pool } & 50 & 170 \\ \text { WARN-1P } & \text { Warner Hot Springs } & \text { Pool } & 56 & 179 \\ \text { ACAL-1S } & \text { Agua Caliente, Borrego Park } & \text { Spring } & 38 & 180\end{array}$

\section{$\underline{\text { San Jacinto Fault }}$}

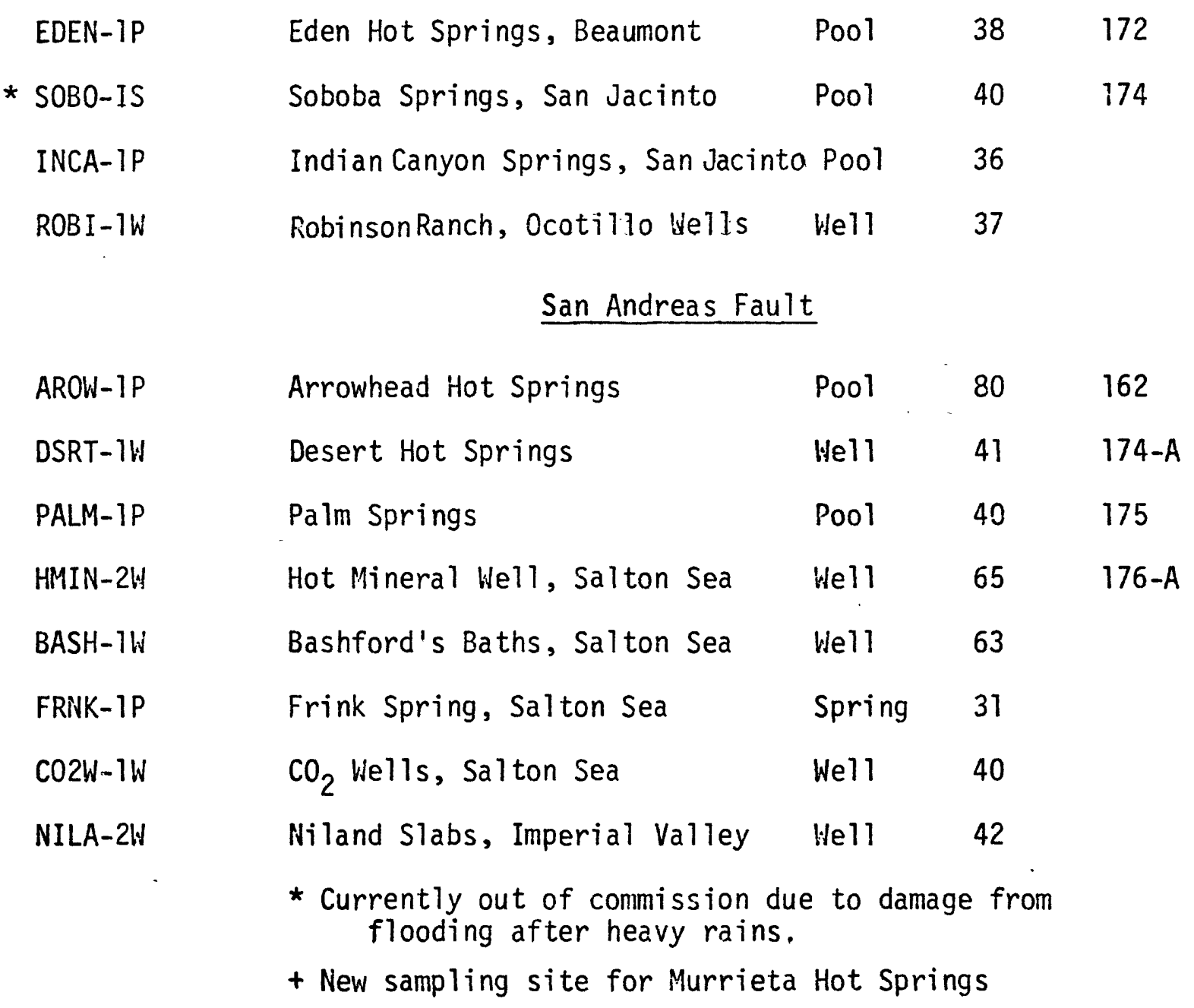


replacing the pump. SOBO-1S was damaged by an earlier flood, and was then buried by a second flood immediately after we had installed a new plumbing system for sampling in January. The Indian Canyon Springs have not been accessible for sampling since the floods. At Murrieta Hot Springs, our monitoring well (MURI-1W) was damaged two years ago. A new sampling site, MURI-2P, was initiated in February of this year. No sites in the Salton Sea area have been damaged by the winter floods although some sites have been temporarily inaccessible due to blockage of the roads. Thus we now have 14 active primary sites with INCA-1P remaining inaccessible to date.

Figure 2 shows the present sampling and analytical program. The sampling for dissolved helium and gases other than radon is now done with evacuated 1720-type glass flasks which have replaced the copper-tubing samplers previously used. The glass flasks are much less susceptible to two-phase separation effects in the sampling line for low-pressure samples. Gases are extracted on a glass vacuum line, and total helium is measured immediately on the He "sniffer", the leak detector mass spectrometer. Ar, $\mathrm{N}_{2}$, and $\mathrm{CH}_{4}$ are trapped on charcoal and saved for gas chromatographic analysis. The water, stripped of gases, can be saved in the evacuated flasks for tritium analysis by "growing-in" of new $\mathrm{He}^{3}$. A fraction of the original helium is saved for isotopic analysis. Other water samples are collected for chemistry, conductivity, stable isotope $\left(\mathrm{D} / \mathrm{H}, 0^{18 / 016}\right.$, $\mathrm{c}^{13 / \mathrm{C}^{12}}$ ) analysis, and for measurements of radon, radium 226 , and lead 210 using low-level counting systems (alpha scintillation counting for radon in original sample, and radon grown-in from radium, beta counting for lead 210 in solid-sample flow counters).

\section{ARROWHEAD HOT SPRINGS}

\subsection{Dissolved Gases}

Figures 3, 4, 5 and 6 show the present status of radon, helium, nitrogen, and methane levels at AROW-1P. As described in TR 11 and 12 , large increases, i.e., about $55 \%$ for radon, were observed prior to the Big Bear earthquake swarms in June of 1979, with an induction period of $60 \pm 15$ days. These components (and also Ar, not shown here) increased together, demonstrating that the "deep" component, which mixes with 


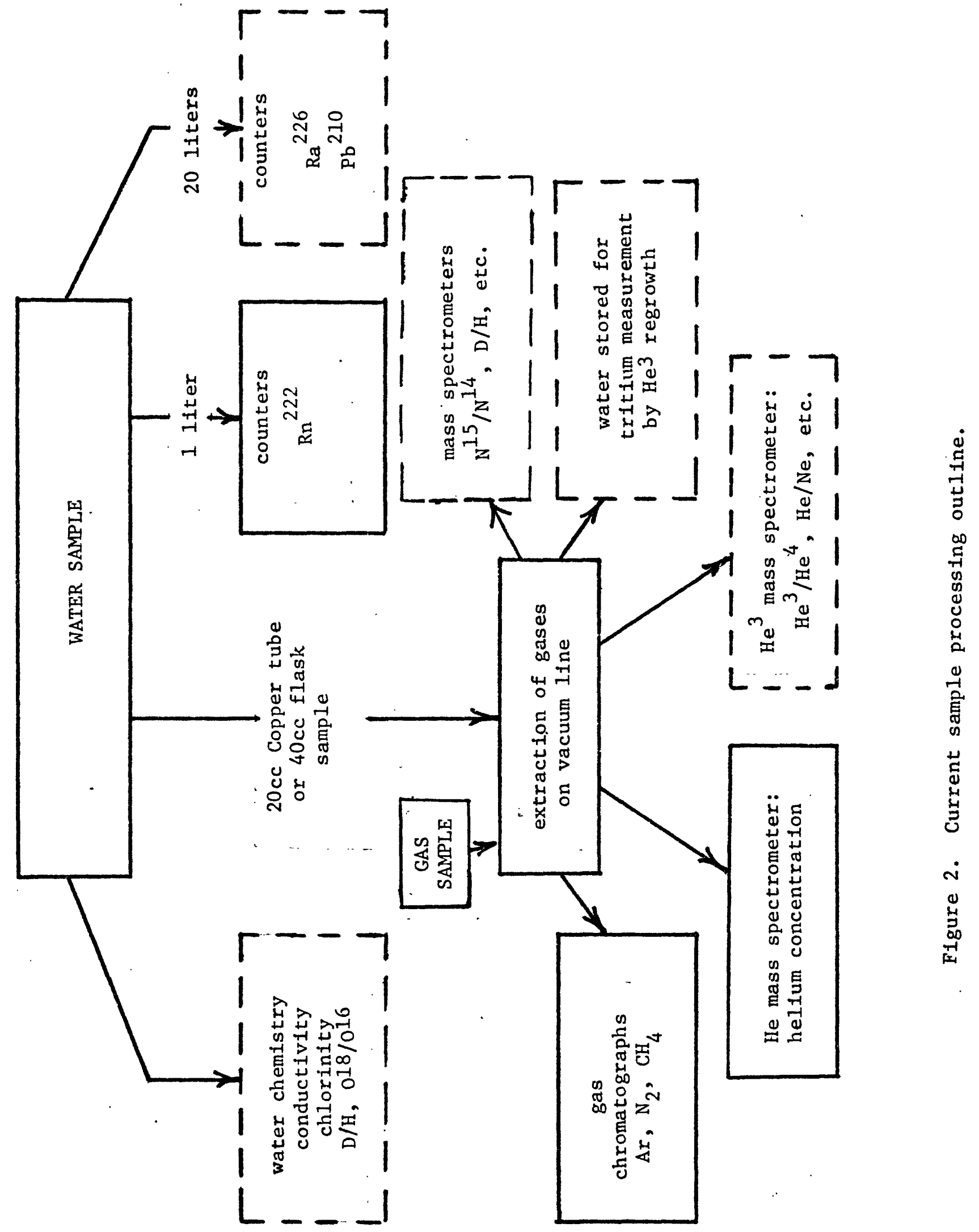




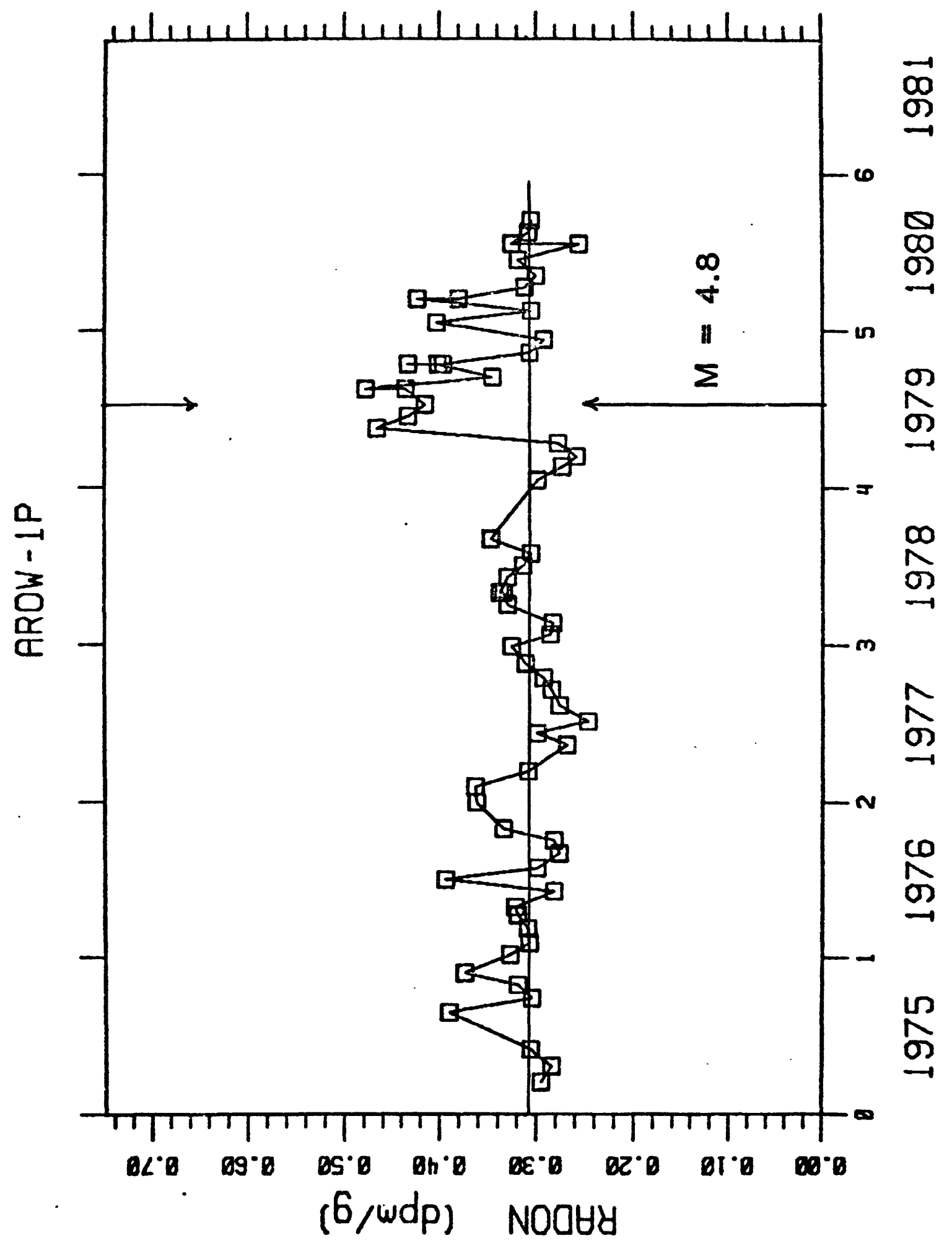

Figure 3. Radon variations at AROW-1P 


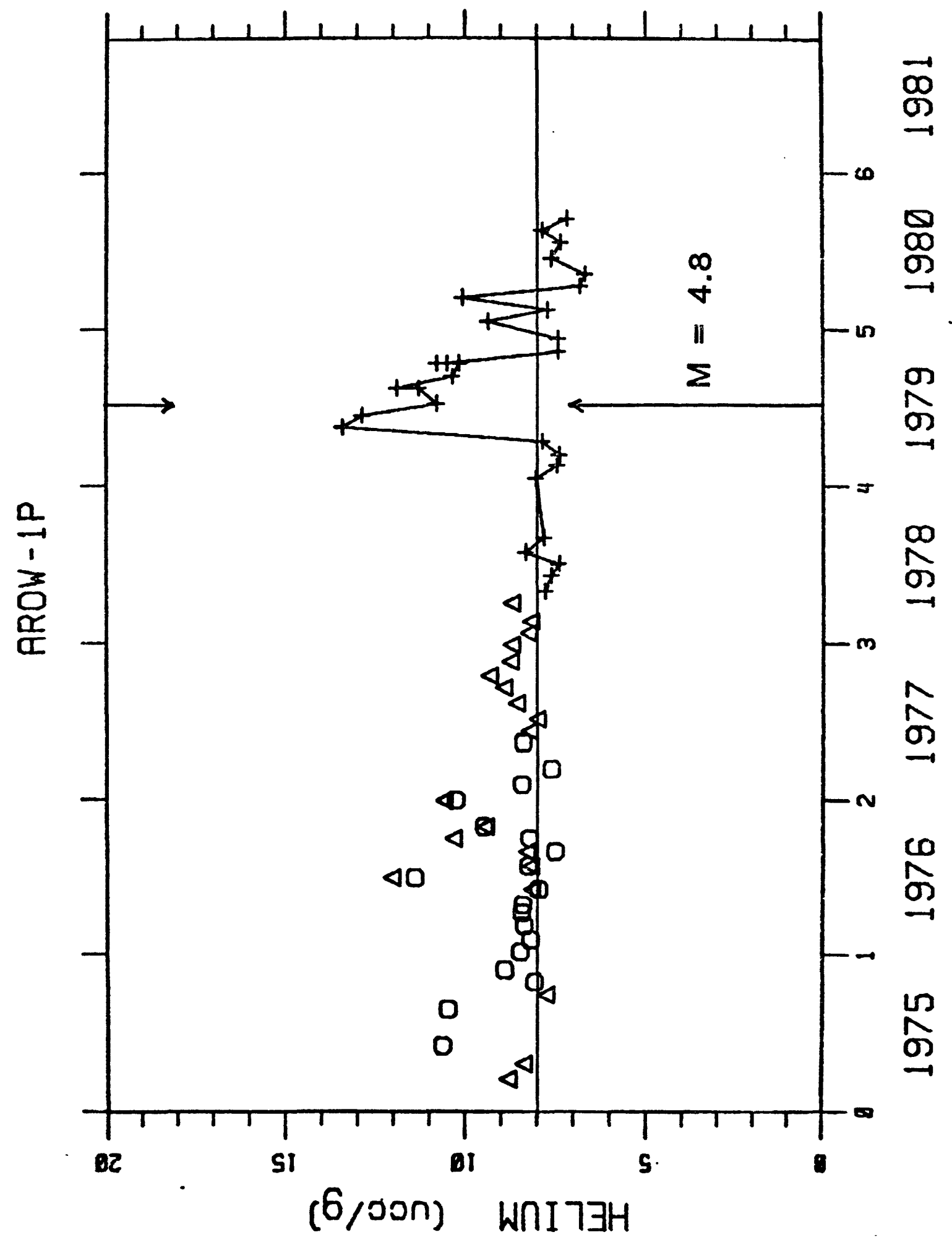

Figure 4. Helium variations at AROW-1P 


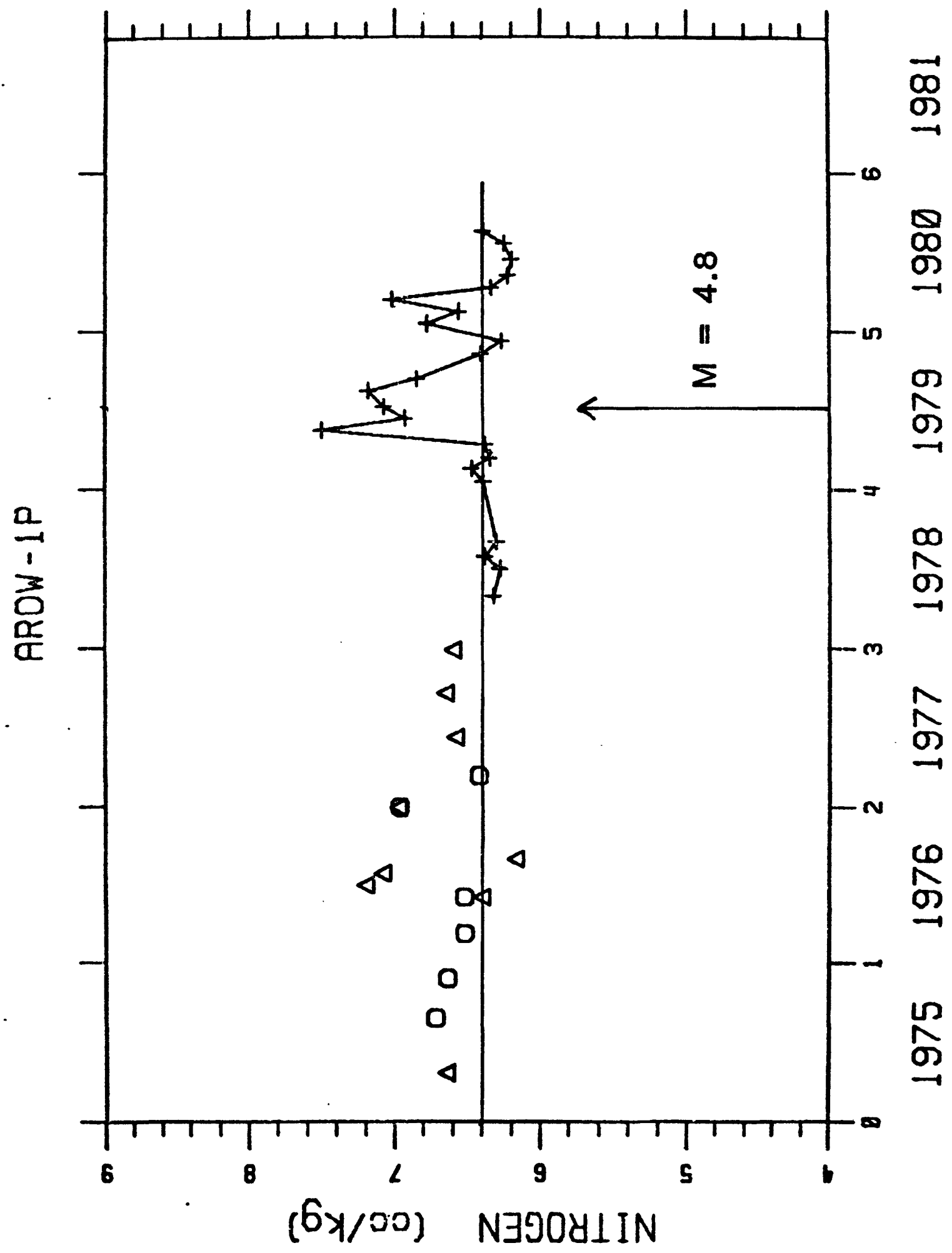

Figure 5. Nitrogen variations at AROW-1P 


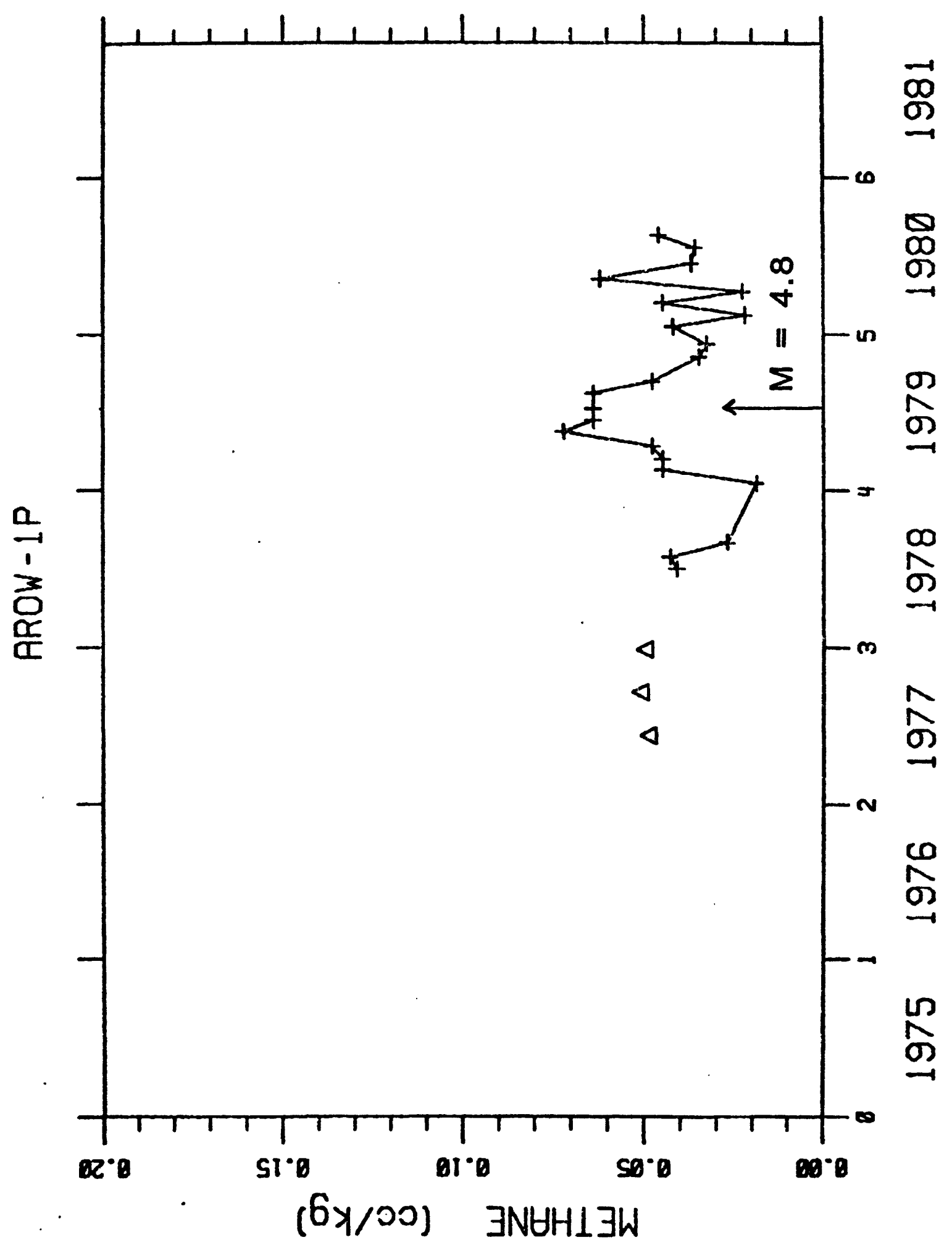

Figure 6. Methane variations at AROW-1P 
atmospheric gases dissolving into the hot spring surface water, increased in this spring prior to the earthquakes. The peaks in all concentrations continued we.11 into 1980 as shown in Figs. 3 - 6, in which the concentration peaks are seen to be double peaks with a short return to baseline just before the end of 1979. By mid-1980 all peaks had returned to the normal, pre-event, baseline levels.

Figures 7 and 8 show the $\mathrm{Rn}-\mathrm{He}$ and $\mathrm{He}-\mathrm{N}_{2}$ relationships based on samples taken since early 1978 when 1720-glass flasks replaced the previously used Cu-samplers (flask samples are indicated by crosses in all figures, while circles and triangles indicate the Cu-tubing samples). Samples taken in glass flasks have been found to be affected much less by cavitation and bubble formation during collection. As shown in Figs. 7 and 8 , the $\mathrm{Rn}-\mathrm{He}$ and $\mathrm{He}-\mathrm{N}_{2}$ relationships remained unchanged during the double peaks and return to baseline in 1980 .

Detailed discussions of these correlations have been given in previous technical reports TR 非, TR \#8, TR 非1, and TR 非12. The increase of all gaseous components represents an increase in sub-surface flow of the "deep" component previously identified in our two-component mixing model for the hot spring gases. Methane, a non-atmospheric component, is particularly important in recognizing these relationships.

\subsection{Temperature and Conductivity}

Figure 9 shows the temperature record at AROW-1P. Except for the fluctuation observed in 1977 and 1978, the temperature remained quite constant throughout the monitoring period. The variations show no correlation with radon or with the other dissolved gases. The temperature spike (2* $\mathrm{C}$ above the baseline of $80^{\circ} \mathrm{C}$ ) observed in March, 1980 is, however, associated with a higher discharge rate and a higher concentration of radon and other dissolved gases. The general lack of correlation of temperature with the dissolved gases indicates that convective mixing with the surface hot water does not significantly affect the temperature balance.

Figure 10 shows the conductivity variation with time at AROW. The rapid drops in conductivity in early 1978 and early 1980 are not correlated with temperature or with any dissolved gas variation. At present, we do not understand what process produces such dramatic conductivity variations which show no correlations with other parameters. 


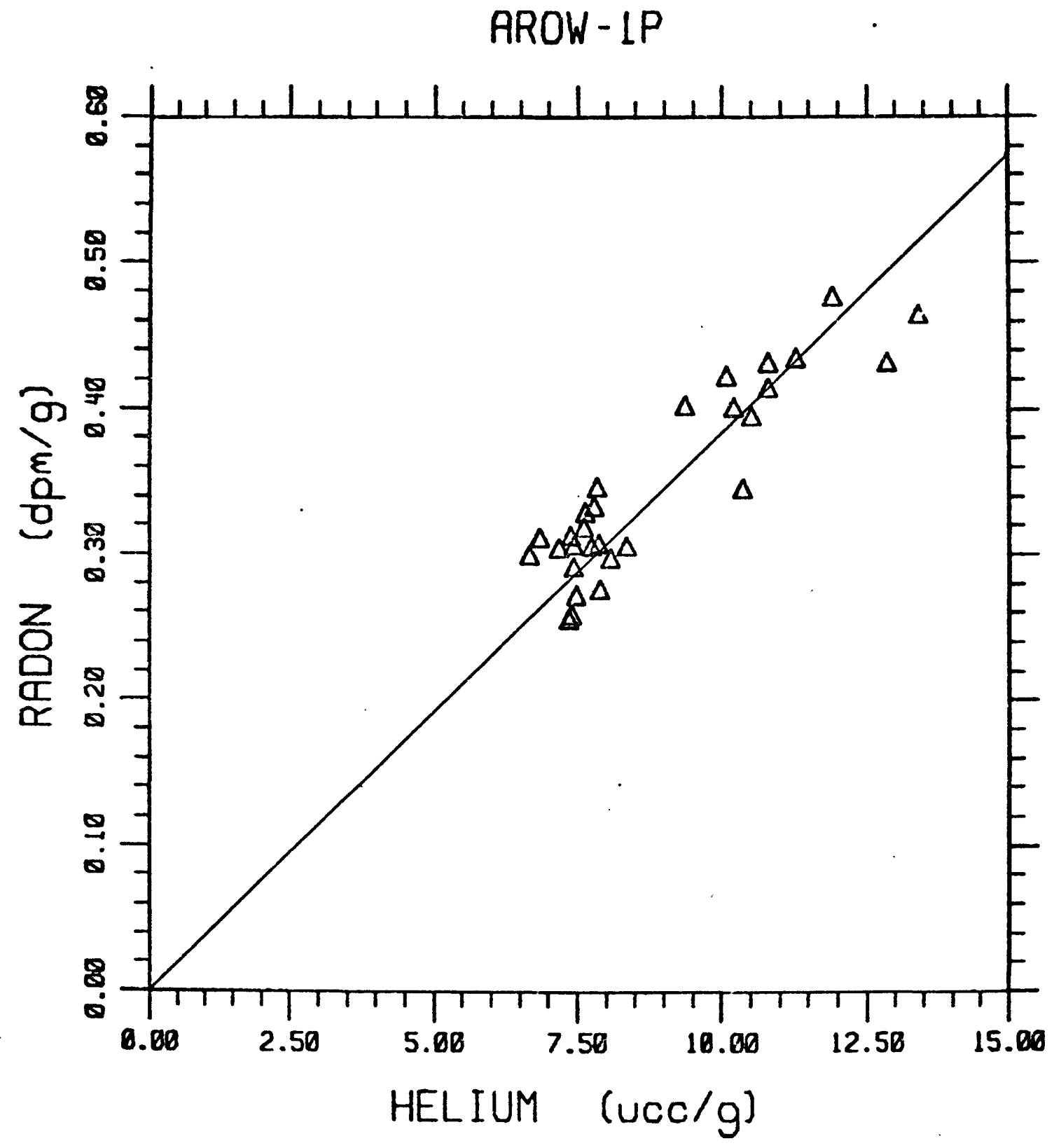

Figure 7. Radon vs. helium variations at AROW-1P, for helium sampled in 1720-glass flasks 


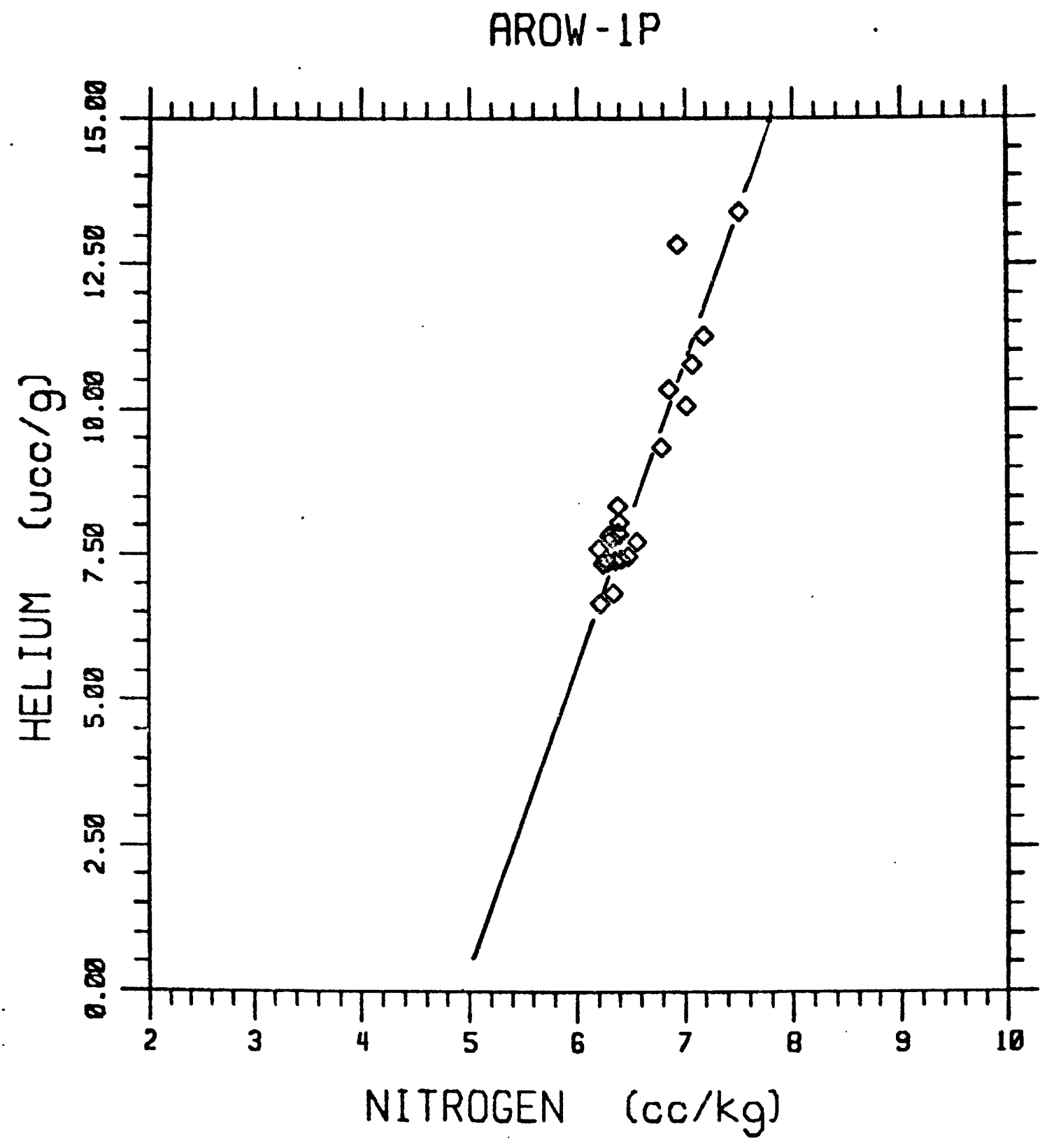

Figure 8. Helium vs. nitrogen variations at AROW-1P 


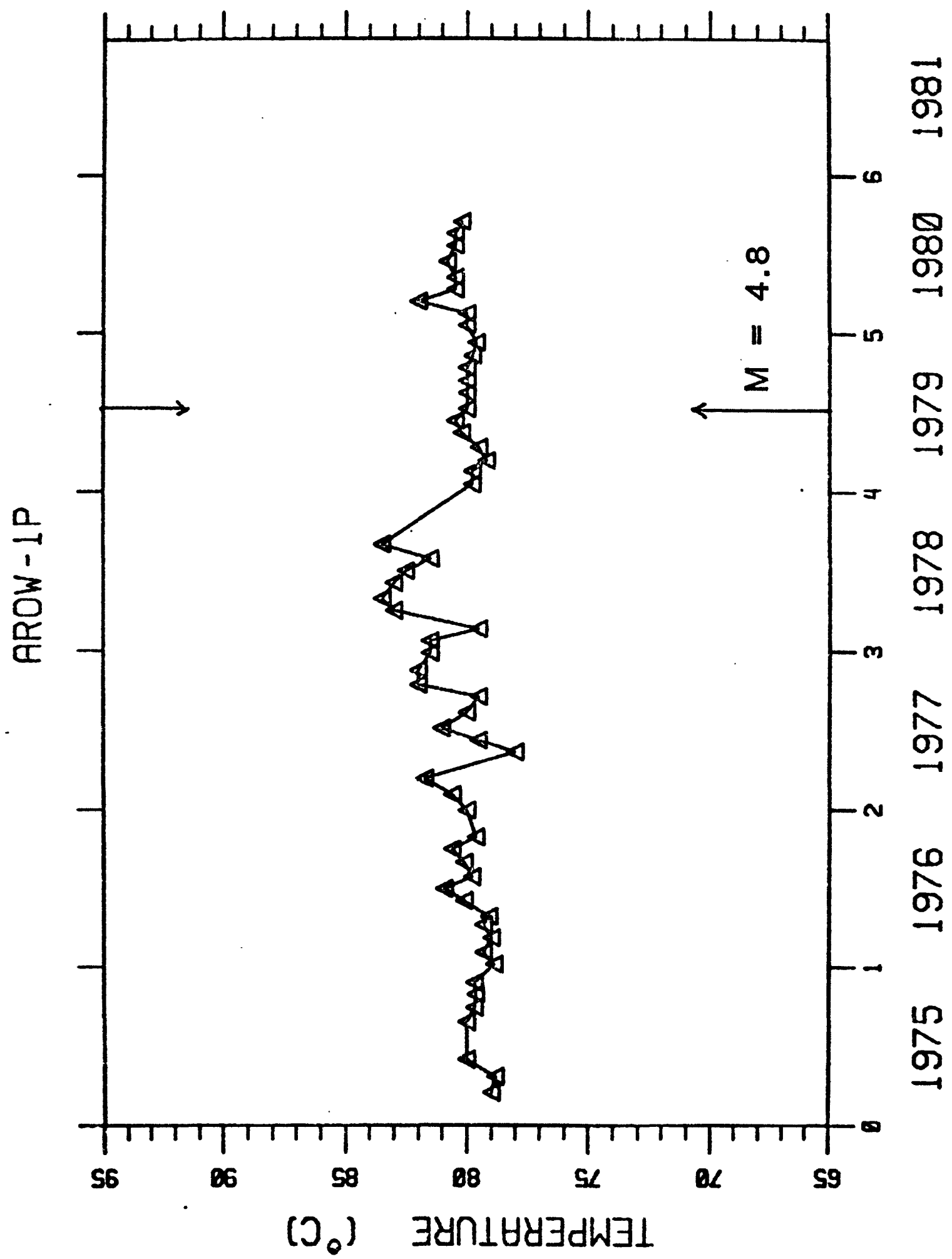

Figure 9. Temperature variations at AROW-1P 


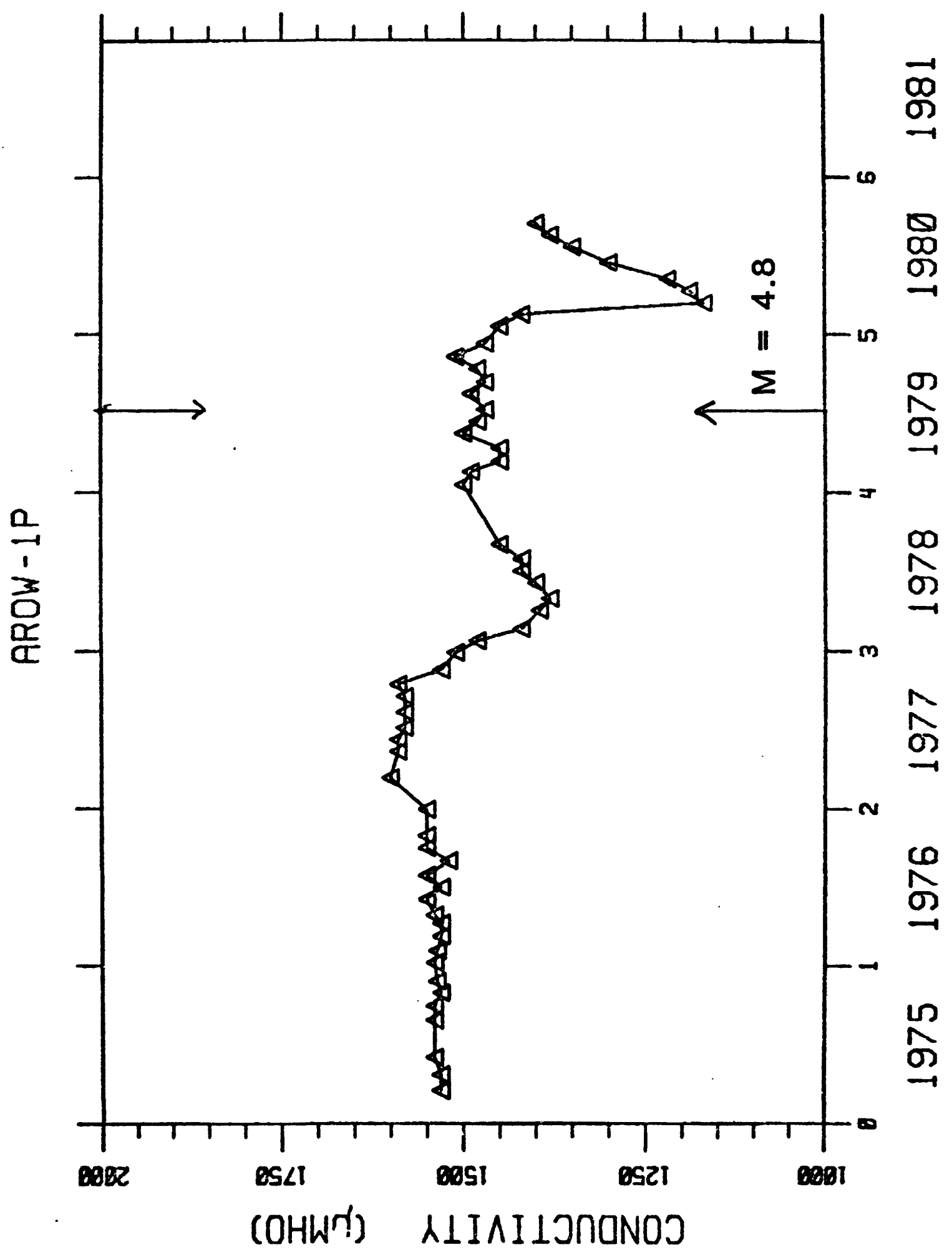

Figure 10. Conductivity variations at AROW-1P 
4. RADON VARIATIONS AT HOT MINERAL WELL AND BASHFORD'S BATH WELL

Two hot wells $\left(T=60^{\circ} \mathrm{C}\right)$ in the Salton Sea geothermal area on the San Andreas fault have shown small radon increases, approximately $37 \%$, prior to a nearby earthquake this year. Figures 11 and 12 show these radon variations in HMIN $-2 W$ and $B A S H-I W$ in relation to those small earthquakes $(M=3.3,3.0$, and 3.3) which occurred at the southeast edge of the Salton Sea on April 6 and 7 of this year. The distance from these wells to the epicenter is $\sim 25 \mathrm{~km}$ (see Figure 1 ). No similar variations in $\mathrm{He}, \mathrm{N}_{2}$, or $\mathrm{Ar}$ were observed. Further, no radon variations in $\mathrm{CO} 2 \mathrm{~W}$ and NILA wells, both located very close to the epicenter, were observed (see data plots in appendices 1, 2, and 3). However, these wells are much lower in temperature (both $\sim 40^{\circ} \mathrm{C}$ ) than the two high-temperature wells. The time interval between radon increase and the earthquakes is $\sim 66$ days, considerably longer than expected from correlations based on dilatancy theory. The radon increase in $\mathrm{BASH}-1 \mathrm{~W}$ is particularly unimpressive compared with the large variations due to random cavitation and two-phase effects, so that this is not yet a very convincing precursory phenomenon.

\section{HELIUM AT FRINK SPRINGS}

FRNK-IP is also close to the April 6-7 earthquake epicenter by the Salton Sea. This is a low-temperature spring $\left(31^{\circ} \mathrm{C}\right)$, and no radon or $\mathrm{N}_{2}$ variations were observed. However, as shown in Figure 13, the helium concentration has been rising steadily at the rate of $5 \%$ per year since 1975. The reason for this increase is unknown. The radon and nitrogen records are shown in Figures 14 and 15, and they are entirely constant over the entire monitoring period. Thus this phenomenon is completely different from the increases observed at Arrowhead, as only helium is affected.

In Figure 16 we show the $\mathrm{He}^{3} / \mathrm{He}^{4}$ ratios measured on samples kept as aliquots for isotopic measurement, and analyzed recently. The mean $\mathrm{He}^{3} / \mathrm{He}^{4}$ ratio is 2.05 times the atmospheric ratio $\left(\mathrm{R}=1.40 \times 10^{-6}\right)$ and it is seen that the ratio is constant, over the entire helium concentration range, to better than $2 \%$. Thus the influx of helium is not due to high $\mathrm{He}^{3}$ mantle helium ( $R=6.5$ times atmospheric, in $\mathrm{CO} 2 \mathrm{~W}$ and in nearby Wister 


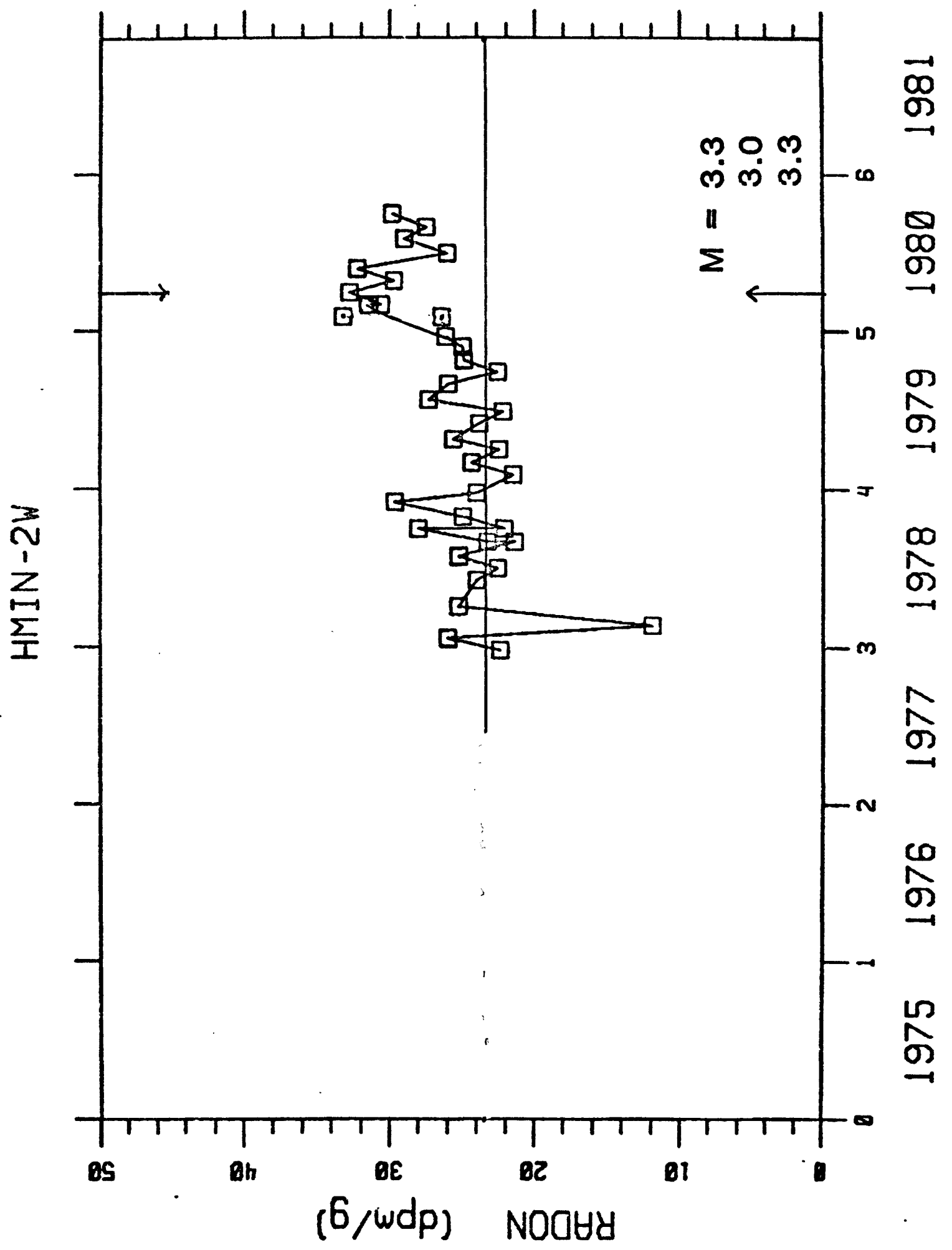

Figure 11. Radon variations at HMIN-2W 


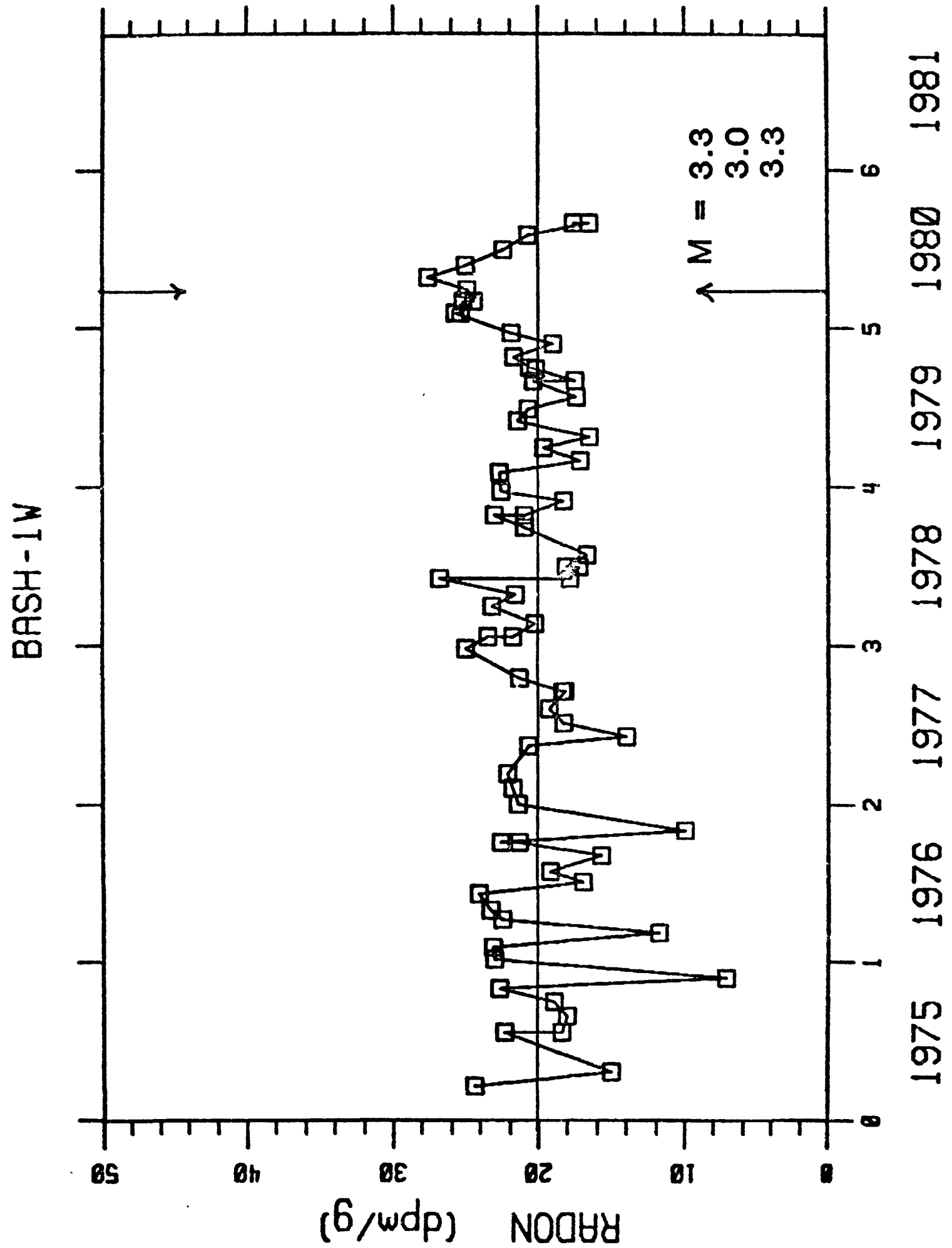

Figure 12. Radon variations at BASH-1W 


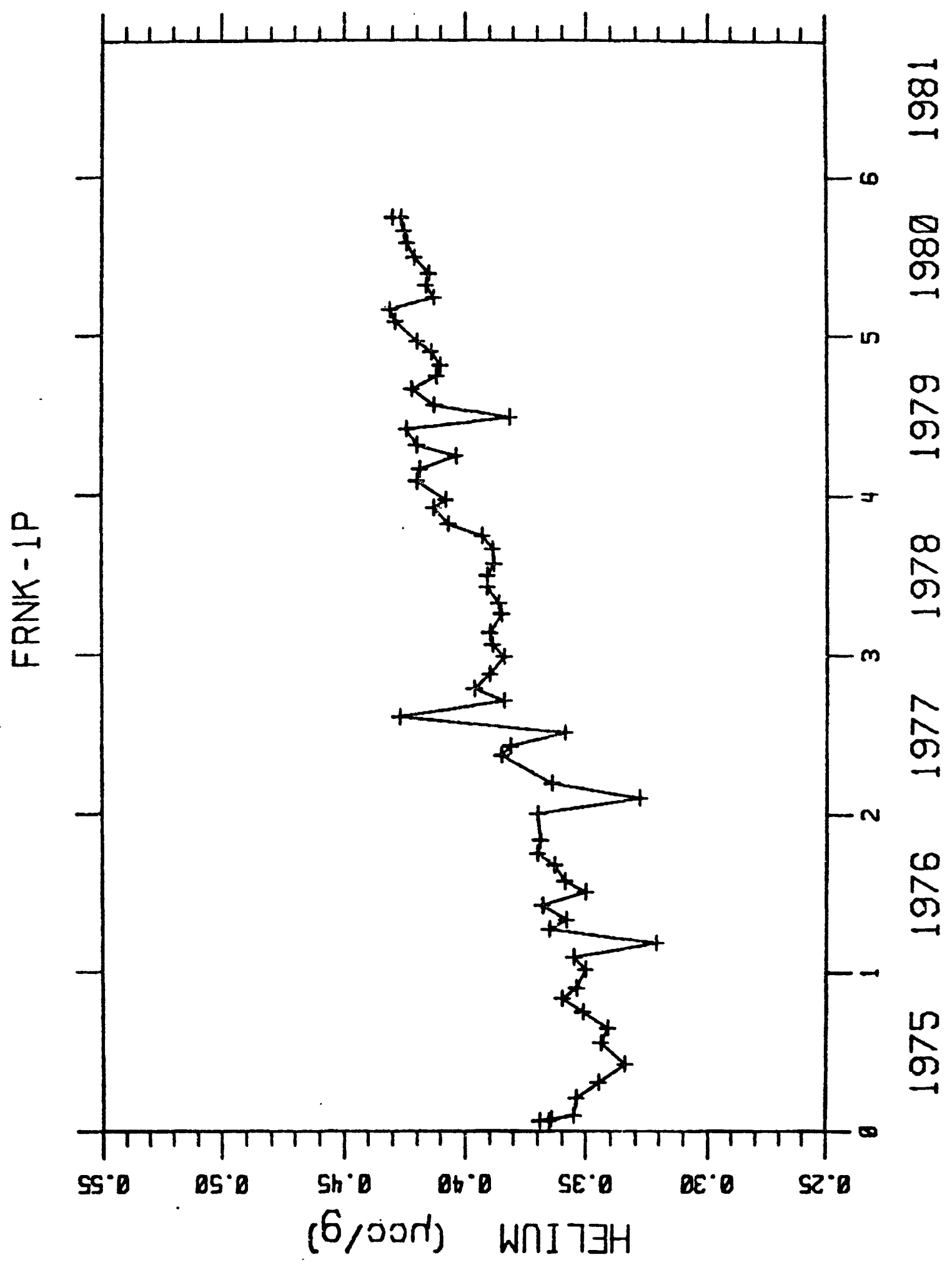

Figure 13. Helium increases at FRNK-1P 


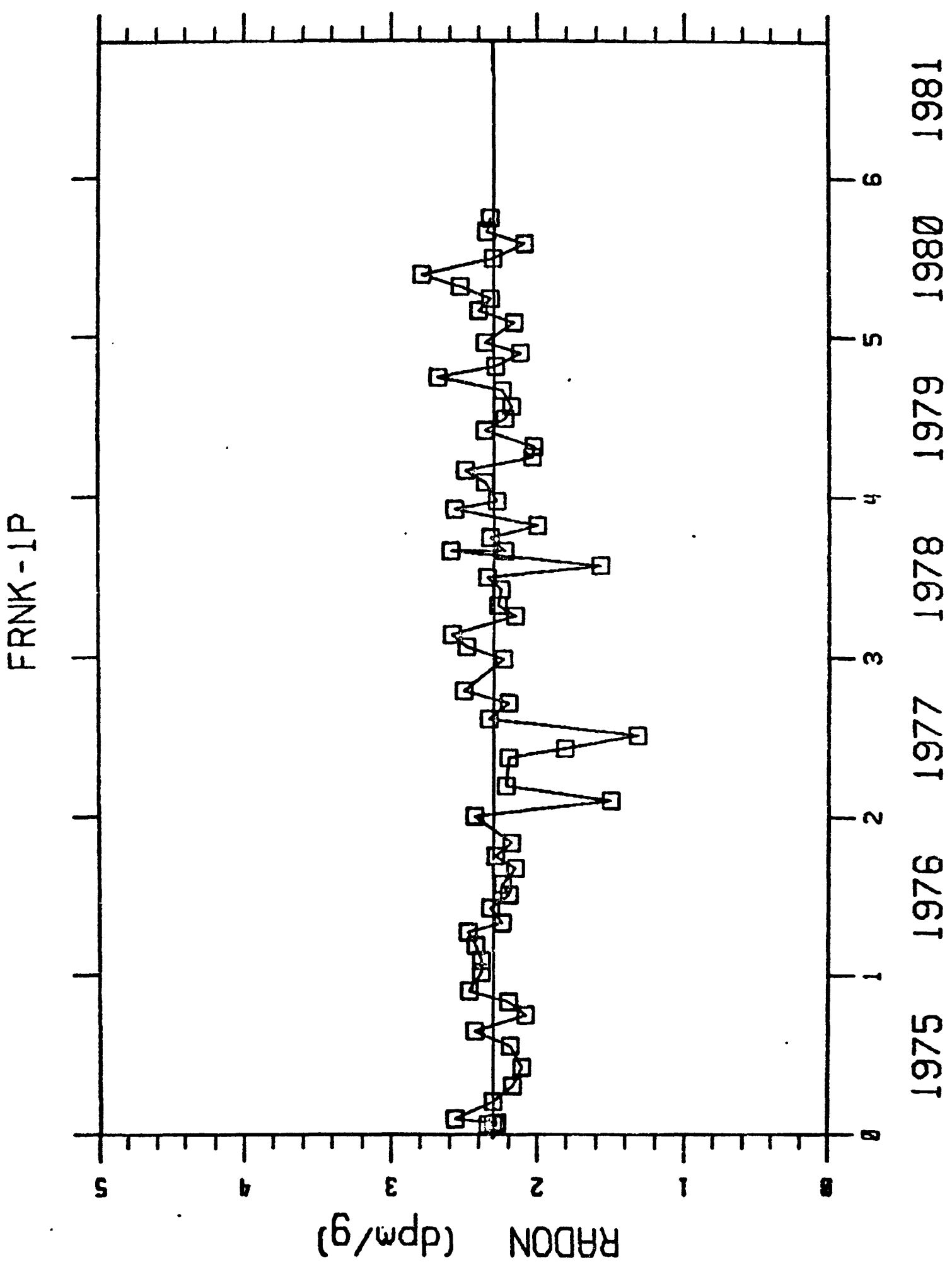

Figure 14. Radon variations at FRNK-1P 


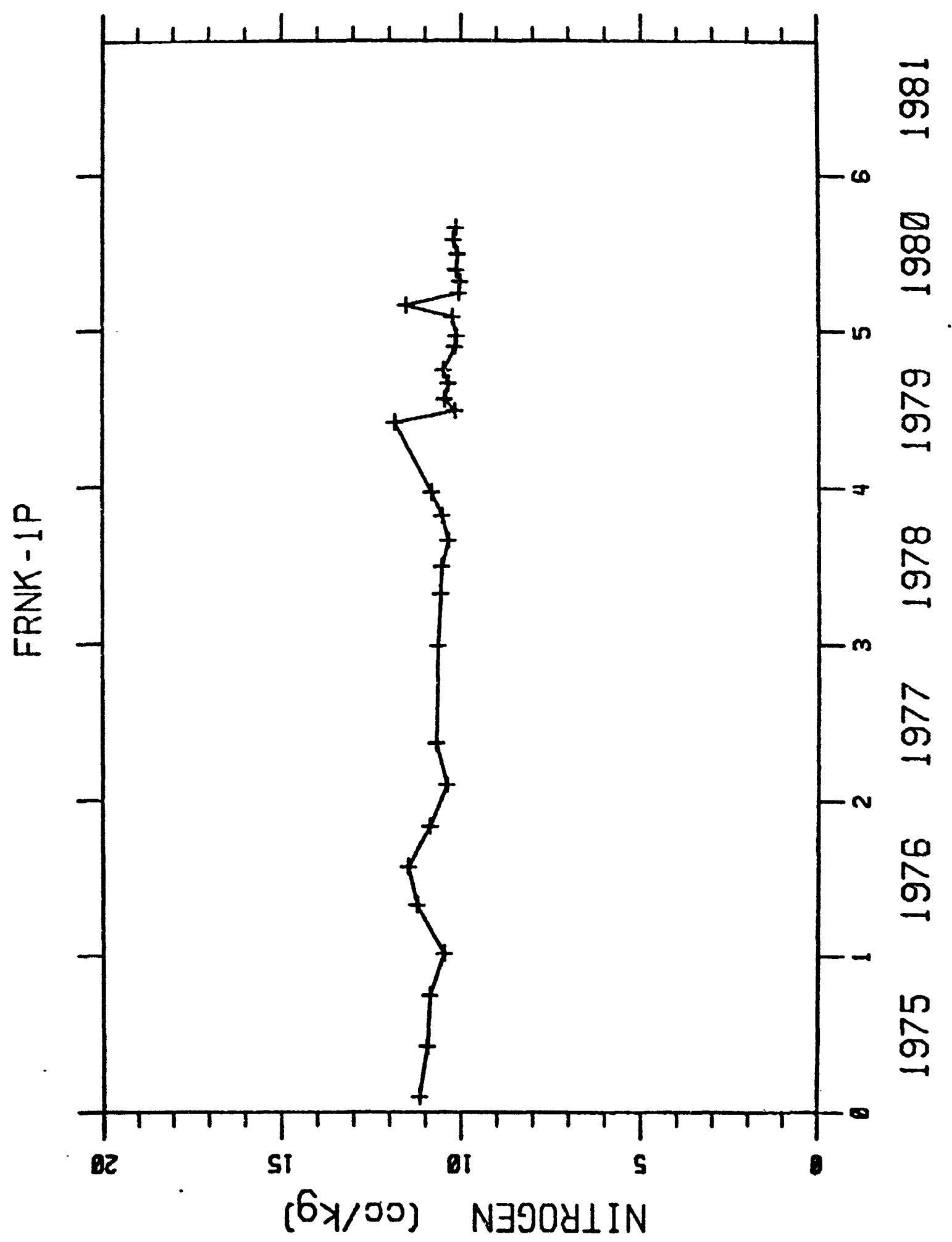

Figure 15. Nitrogen variations at FRNK-IP 


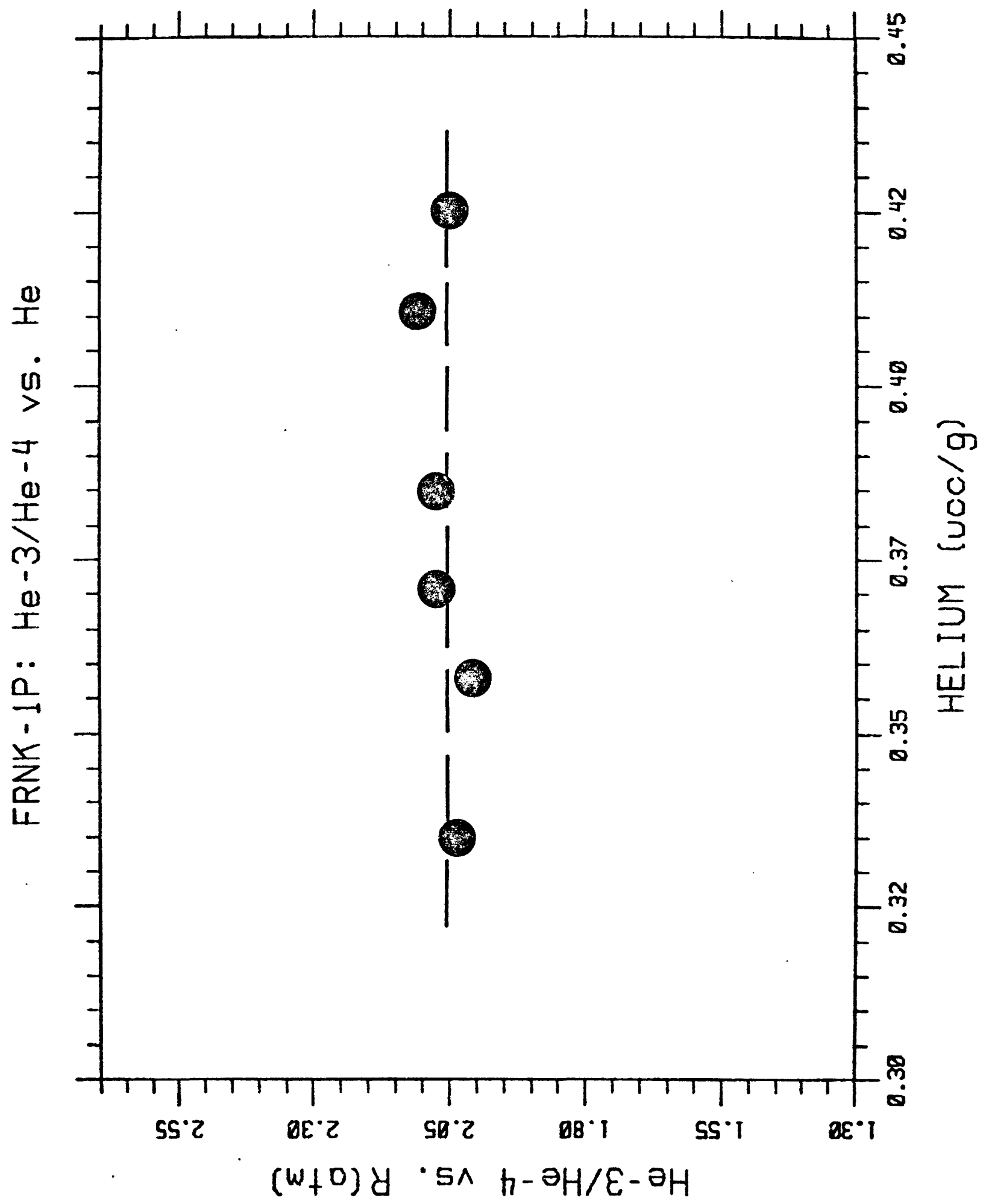

Figure 16. $\mathrm{He}^{3} / \mathrm{He}^{4}$ vs. He at FRNK-1P 
Mud Pots and geothermal wells). That is, a reservoir of helium with $R=2 \times$ atmospheric must exist in this area and is leaking into Frink Spring increasing the concentration without changing the isotopic ratio.

Frink Spring also has increased $\mathrm{N}_{2}$ and $\mathrm{Ar}$ concentrations, quite different from other hot springs in our network. In general, these components resemble those in the wells (such as BASH-1W and HMIN-2W), rather than the hot springs. This spring is quite large and the inflow (where we sample) is from vertical submerged iron pipe. Is Frink an old we11? We are attempting to determine this. The helium increase is obviously an important phenomenon, and one which is at present not at al1 understood.

\section{GENERAL DATA SUMMARY}

Our last annual report, TR 非11, presented the 5-year data record (1975-1979) in graphical format, without the extensive tables of data. Since then, some corrections and revisions have been made to some of the data, and a revised and up-to-date table of all data, to 30 September 1980, is attached to this report as Appendix 7. In these tables the liquidphase radon, helium, and dissolved gas measurements are listed. (Previous reports also include tables of isotope ratios, gas-phase measurements, radium and lead-210 data, etc.)

Specific revisions to the data set include the following. At Eden Hot Springs, we have been observing real and significant changes in radium 226 concentration, which we believe are random effects due to the sampling bottle lowered into the pool striking the bottom on occasion and stirring up high radium water from the sediments. This random Ra variation has nothing to do with the radon concentration. Hence we now calculate all Eden radon data as total, rather than excess radon, and all data have been recalculated in this way, using the original counting results.

The C02W-1W radon values 1isted in TR 非 after April, 1978 were incorrect due to errors in the calendar subroutine used for data reduction. These data have been corrected in Appendix 7.

Radon, helium, nitrogen, methane, temperature, and conductivity variations vs. time are presented in Appendixes 1 - 6 for the entire monitoring period. Temperature and conductivity records are shown for the 
first time, following the development of computer tabulation and plotting of all data with the Prime 350 laboratory computer. The total data set for the S. California Network and the Palmdale network (monitored for two years) now amounts to more than 10,000 measurements. The addition of computer handling of the data has thus been essential to continuation of the network with rapid access to the data.

Radon, helium, nitrogen, and methane graphs (concentration vs. time) have now been scaled in a consistent format, so that (in general), $1 \mathrm{~cm}$ on the ordinate represents approximately a $20 \%( \pm 3 \%$ ) variation in concentration. This modification allows a direct comparison of changes in different parameters and at different sites, in terms of percentage effects. However, some exceptions are made. At $\mathrm{CO} 2 \mathrm{~W}-1 \mathrm{~W}$, we set $1 \mathrm{~cm}$ on the nitrogen graph equal to $60 \%$ variation because of the very $10 \mathrm{w} \mathrm{N}_{2}$ concentration and large fluctuations (this is a degassed fluid emerging from a broken casing underground). The methane graph is treated similarly.

The general nature of the long-term trends in the various components has been discussed in detail in TR 非11, and only a few comments will be added here. The most significant long-term variation, the helium increase in Frink Spring, is discussed in Section 5 above. Helium is decreasing in DSRT-1W and PALM-1P (Desert Hot Springs and Palm Springs) on the San Andreas. At DSRT- $1 W$, the decrease amounts to $43 \%$, essentially all during 1980 . This has been accompanied by a $12 \%$ decrease in $\mathrm{N}_{2}$, and thus this appears to be a gas loss pattern from this hot well. However, radon has not been affected, and is essentially constant. This effect may be a sampling artifact for $\mathrm{He}$ and $\mathrm{N}_{2}$, which are sampled separately from $R n$, and in a smaller container. The effect is being studied. The Palm Springs records are strongly affected by a change in the pumping system in 1977, as discussed in TR 非1 (p.12).

Methane continues to decrease at the "new" Niland Slabs we11, NILA-2W, at a rate of $20 \%$ year for the past 4 years. Methane has now almost dropped to zero, presumably having been flushed out of a small reservoir tapped by the new well.

MURI-2P, our new sampling site at Murrieta Hot Springs on the Elsinore 
Fault (TR \#12, p.3): helium and radon continue to decrease after an initial increase; this site was apparently affected by the heavy rains which destroyed our previous sampling site (a well) at this location. At Warner Hot Springs, also on the Elsinore, the methane increase from 1977-1979 (described in TR 非11, p.10) has leveled off, and the concentration now appears to have been essentially constant since 1978 .

\section{TEMPERATURE AND CONDUCTIVITY VARIATIONS}

Temperature data accumulated over the total monitoring interval are shown as graphs vs. time in Appendix 5 (except for AROW-1P, given in section 3.2). Along the Elsinore Fault, temperature ranges from about $38^{\circ} \mathrm{C}$ at ACAL and ATIB to about $57^{\circ} \mathrm{C}$ at WARN. Except for MURI-1W, which shows a large temperature drop in 1977, all the other sites show quite constant temperatures with fluctuations less than $\pm 22^{\circ} \mathrm{C}$.

On the San Jacinto Fault, the temperature variations at EDEN and SOBO reflect water usage and seasonal effects. At INCA and ROBI, the temperature values are quite constant with fluctuations of about $\pm 0.5^{\circ} \mathrm{C}$. On the Mission Creek and Banning Faults, DSRT and PALM show some correlation in their temperature fluctuation.

In the Imperial Valley, the hottest water comes from the Hot Mineral Wells (HMIN-1W and $2 \mathrm{~W}$ ). The temperature at $2 \mathrm{~W}$ has been increasing steadily since the beginning of our monitoring activity at this well. The overall increase is $7^{\circ} \mathrm{C}$ in three years, a change (in absolute temperature) of only $2 \%$. At NILA, the initial low values were due to a lack of flushing before sampling. There is a temperature correlation between NILA and $\mathrm{CO} 2 \mathrm{~W}$, showing similar seasonal fluctuations.

Conductivity data on the network sites are presented in groups in Appendix 6, and a brief summary follows.

On the E1sinore Fault, ELSI shows a change in conductivity associated with a large fluctuation in 1977, with no change in temperature (Appendix 5). ACAL-1S, ATIB-1W, and WARN-1P, all on the E1sinore Fault, have very similar, and low, conductivities, essentially constant except for the large usage effects at ATIB, a we11. On the San Jacinto, rather low conductivites are found at EDEN, SOBO, and INCA (500 or lower), with 
a much higher conductivity at ROBI, a well at the south end of the fault trace, which has now leveled off at 1750, after an initial decrease.

Both DSRT and PALM on the Mission Creek and Banning Faults show fairly constant conductivity, but the DSRT values ( 1500$)$ are almost 5 times greater than the PALM values ( 320). In the Salton Sea area, where geothermal brines occur, the waters from all the sites are highly conductive, with the highest values at $\mathrm{CO} 2 \mathrm{~W}$ (between 30,000 and 35,000 ). There appears to be a correlation in variations between FRNK, BASH and CO2W (from 1976 to 1978). However, recent remeasurements of some stored samples from FRNK, HMIN and BASH did not reproduce some variations. It was also found that samples stored in glass bottles tend to give higher values than those stored in plastic bottles. Since storage effects are not clear at present, we are not certain whether those variations are real. These features are not correlated with radon or other dissolved gases, and we are continuing to study them.

\section{OTHER ACTIVITIES}

Soil radon installations at 10 network sites (6 on the Imperial Fault) continued to be monitored until July, 1980. During the July field trip to the Imperial Valley, five new holes were selected and bored after the new fault trace had become apparent due to the October 15 , 1979 Imperial Valley earthquake. One of these 5 new holes was not usable (HOLT-new), another was lost together with the old hole (ROSS) due to ditching, and so only 3 new holes are currently in use (HEBR, S-31 and KEYS: No new site names were assigned because the corresponding old holes will be abandoned after controlled experiments are completed). Only the new improved type of films has been used in these 3 new holes. For the old holes, the older type films were used until September, 1980. The film strips are installed and collected monthly, and sent to $C$. $Y$. King at Menlo Park for track measurements.

9. COLLABORATIVE WORK WITH THE CHINESE STATE SEISMOLOGICAL BUREAU, PEKING Development of a joint research program with scientists of the State Seismological Bureau (SSB) in Peking was begun when $\mathrm{H}$. Craig went. to China 
in May to participate in the Symposium on the Qinghai-Xizang (Tibet) Plateau, organized by the Chinese Academia Sinica with a field excursion in Tibet after the meeting. A paper on the significance of helium isotope studies for work in Tibetan geothermal areas was given (this is interesting for two reasons: the thick continental crust of $73 \mathrm{~km}$, and the lack of associated volcanics). Continuing lectures and discussions begun during a previous visit in 1976, several lectures on the $\mathrm{S}$. California monitoring studies and on helium isotope research were given at the SSB before the meeting and plans were developed for outlining a joint research program on geochemical monitoring.

\subsection{Research on Tibetan and Chinese Geothermal Areas}

After the field excursion in Tibet, H. and V. Craig returned to Lhasa and carried out a sampling program in the Yangbajin geothermal area to the north, where a geothermal power station is being developed based on steam in a number of steam wells which have been drilled in the region. Six hot springs and 4 geothermal steam wells were sampled for gas studies. The samples were returned to Scripps for analysis and the first results are given in Table 2.

The table gives the absolute amounts of $\mathrm{He}$ and $\mathrm{CO}_{2}$ in the samples (non-condensible gases are very low and $\mathrm{CO}_{2}$ is the primary constituent except in sample YS $\|_{111}$, an acid hot spring), the $\mathrm{He} / \mathrm{CO}_{2}$ ratios, and the helium isotope ratios $\mathrm{He}^{3} / \mathrm{He}^{4}$ relative to atmospheric helium. The very interesting result is that the $\mathrm{He}^{3} / \mathrm{He}^{4}$ ratio is only $12 \%$ of atmospheric, showing that this is purely "crustal" or radiogenic helium. This is in strong contrast to the isotope ratio in the Salton Sea geothermal area (up to 6.5 times atmospheric; cf. map, Fig. 6, p.29 in TR 非10), and in Yellowstone Park, where the ratio is up to 16.5 times atmospheric, because of primordial helium from the mantle in the geothermal fluids.

Further work was done on samples from Liaoning (following a study on one such sample obtained in the 1976 visit), and on samples from Peking and Shantong. These data, all on liquid samples in areas where earthquake studies are being developed emphasizing geochemical monitoring, are given in Table 3. Here the ratios are significantly higher than in Tibet, but 
TABLE 2: TIBET GAS SAMPLES

\begin{tabular}{|c|c|c|c|c|}
\hline SAMPLE & $\mathrm{He}(\mu c \mathrm{c})$ & $\mathrm{CO}_{2}(\mathrm{ccSTP})$ & $\begin{array}{l}\mathrm{He} / \mathrm{CO}_{2} \\
(\mathrm{ppm})\end{array}$ & ${\underline{\mathrm{R} / \mathrm{R}_{\mathrm{ATM}}}}^{+}$ \\
\hline $\begin{array}{l}\text { YS \# } 1^{*} \\
\text { YS } \# 12^{*}\end{array}$ & $\begin{array}{l}667 \\
596\end{array}$ & $\begin{array}{l}25.6 \\
22.8\end{array}$ & $\begin{array}{l}26.0 \\
26.2\end{array}$ & $\begin{array}{l}0.12 \\
0.12\end{array}$ \\
\hline YS \# 2 & 2750 & 25.0 & 110 & 0.12 \\
\hline YS \# 3 & 511 & 24.9 & 20.5 & 0.12 \\
\hline YS \# 4 & 2410 & 24.3 & 99 & 0.12 \\
\hline YS \#10 & $5] 8$ & 24.6 & 21.0 & 0.13 \\
\hline YS \#11 & 1470 & 20.1 & 73 & 0.13 \\
\hline$\cdots \cdots$ & $\cdots$ & $\ldots-\cdots$ & $\cdots$ & $-\cdots$ \\
\hline$Y W \# 5(W-9)$ & 2810 & 25.3 & 111 & 0.12 \\
\hline$Y W \# 6(W-6)$ & 2190 & 21.0 & 104 & 0.12 \\
\hline YW \#7 $(W-8)^{* *}$ & $(9.3)$ & $(0.74)$ & $(12.7)$ & 0.13 \\
\hline$Y W \# 9(W-4)$ & 5450 & 54.9 & 99 & 0.12 \\
\hline
\end{tabular}

$Y S=$ Hot Spring. $Y W=$ Well. $(W-X)=$ Well Number.

* Duplicate samples of same spring.

* 53.7 grams of condensed steam in flask.

$+\mathrm{R}=\mathrm{He}^{3} / \mathrm{He}^{4}$ ratio; $\mathrm{R}_{\mathrm{ATM}}=1.40 \times 10^{-6}$ 
$-31-$

TABLE 3

CHINA SAMPLES IN 1720-FLASKS

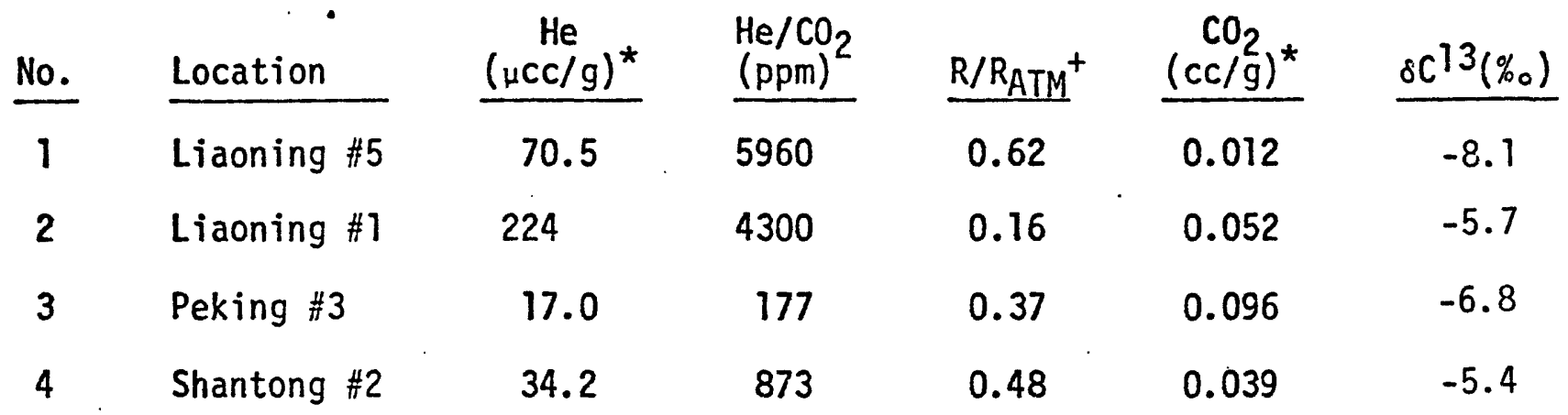

* Gas concentrations, per gram of water in flask.

$t \mathrm{R}=\mathrm{He}^{3} / \mathrm{He}^{4}$ ration; $\mathrm{R}_{\mathrm{ATM}}=1.40 \times 10^{-6}$. 
still less than atmospheric, indicating the helium is dominantly radiogenic and not volcanic.

Work on chemical and stable isotope analyses on these samples will continue when the Chinese visitors from the SSB arrive. The locations of all the above samples are shown in Figure 17.

\subsection{Proposal for a Joint Research Program}

The Tibetan and Chinese study described above was carried out with Drs. Cai Zuhuang and Shi Huixin of the Peking State Seismological Bureau, who have transmitted to us a formal proposal for joint research on geochemical research on earthquake prediction to be carried out in both countries. The text of this proposal follows at the end of this section. Dr. Shi Huixin and another Chinese scientist will arrive December 20 for a one-month stay in our laboratory, during which they will participate in two sample collecting field trips on the network and become familiar with our analytical techniques which will later be used in China. Following that visit, two of our groups will go to China for 4-6 weeks for field work and sample collection in Yunnan (in the Tengchong volcanic area) and in the Peking area. Funds for supfort of the Chinese in the U.S. and for our travel to China were obtained from the USGS Earthquake Hazards program as a supplement to our present contract. The two Chinese will also visit Menlo Park on the return trip to China.

During their visit, a detailed proposal for a systematic, longterm study of geochemical monitoring for earthquake prediction, carried out jointly by our group and the SSB in the U.S. and throughout all of China, will be written for submission to USGS and appropriate authorities in China. We expect this to be an extremely important development for this type of research, allowing the application of all our facilities for modern geochemical analytical studies to areas of high seismicity with completely available access for sampling throughout China. 


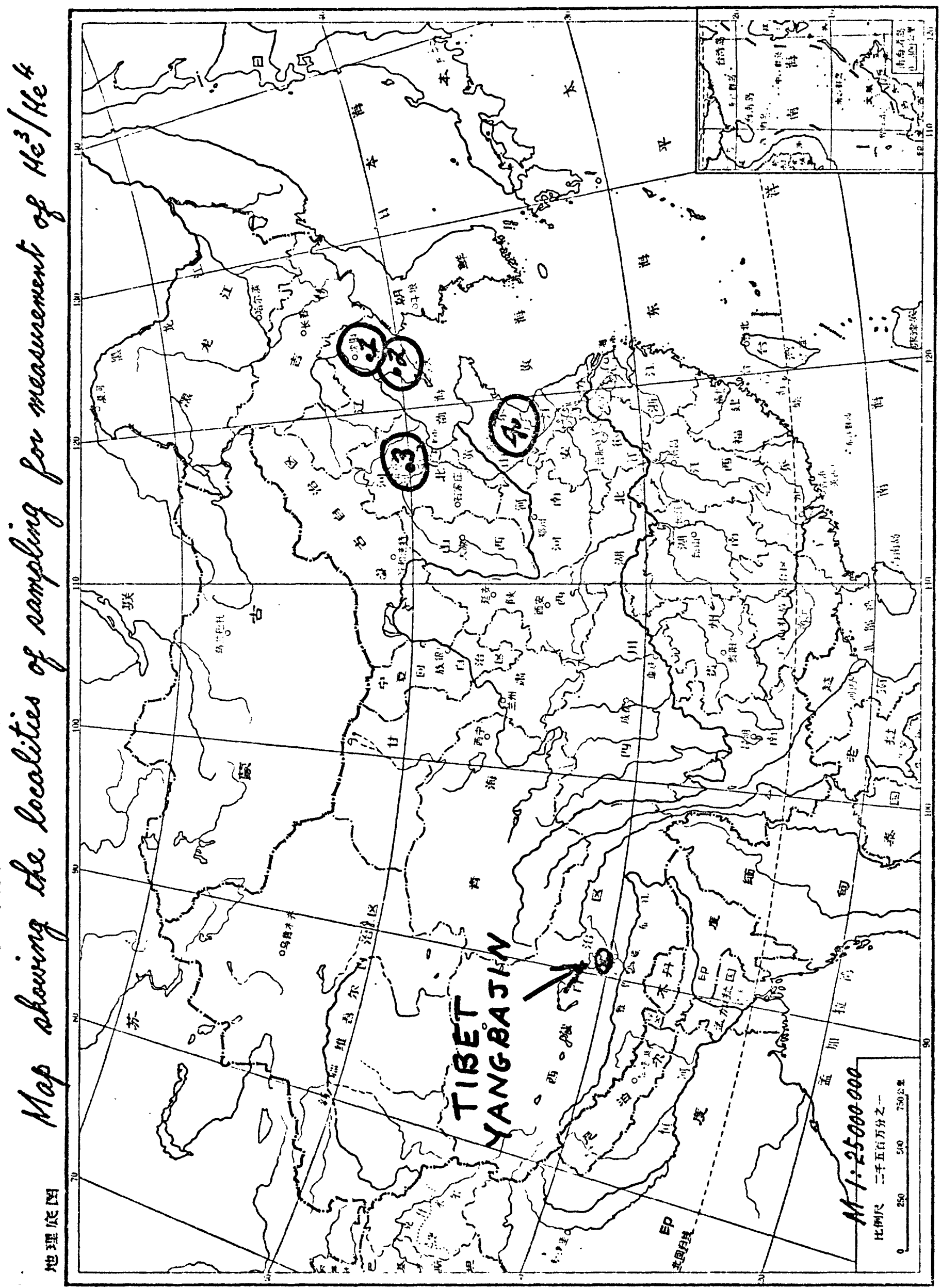


Scripps Institution of Oceanography University of California

China and the United. States of America have signed Cooperation Agreement in the field of earthquake investigation. There is a Department of Subsurface Fluids constituted by 27 persons in our Center. This Department carries out investigation of earthquake prediction and regional seismic activity by means of groundwater and subsurface gases. This Department has received Prof. Craig and Mrs. Craig from 21st to 24th of May, 1980, and has done sampling at Yangbajain in Tibet jointly from 15th to 17th of June, 1980. The samples will be measured by your Institution. We will carry out joint discussion with you, based on obtained data and connected with data of our investigation. The research report will be written jointly and will be published in the form agreed by both sides.

Our Center hopes to carry out long-term collaboration with your Institution in the below-listed fields:

(1) Joint investigation of earthquake prediction by means of groundwater and subsurface gases in laboratory and in situ, in Beijing and surrounding region and the region of West Yunnan.

(2) Study of the activity of main Chinese zones of seismic activity at the borders of plates (Tibet-Yunnan suture zone) and in plates (Guangdong, Shandong) by geochemical methods of groundwater and subsurface gases.

(3) Geodynamic investigation of some main zones at the borders of plates in the world (zone of continental collision in Tibet, San Andreas transform fault, zones of modern subduction---West-Pacific islands arc-trench, oceanic ridge, rift valleys and others) by geochemical methods of groundwater and subsurface gases.

We suggest to adopt below-listed steps to realize above-mentioned plan of collaboration:

(1) Our Center would like to send two persons to United States in this year or at the beginning of the next year for 6 weeks, as a return visit of Prof. Craig and Mrs. Craig. They will investigate the geological-hydrogeological conditions of the areas in America, where seismological fluid-geochemical work has been carried out. They will also recognize the techniques of measurement of chemical components, and the results obtained. They will study and make the plan of collaboration in future. During their stay in America they will see hydrochemical observation network along San Andreas Fault. If you will be carrying out work at oceanic ridge or in rift valley, they will prepare for seeing the investigation of deep hot water.

(2) Our Center would like to receive two scientists of your Institution in the next year for 6 weeks. They will investigate the geological-hydrogeological conditions of the areas in China, where seismological fluid-geochemical work has been carried out. They will also recognize the techniques of measurement of chemical components, and the results obtained. They will study and make plan of collaboration in future. During their stay in China they will visit the zones of seismic and geothermal activity in area Beijing-- 
Datong and Western Yunnan. They will collect samples of water and gases. Some chemical components will be measured by your Institution.

(3) Our Center would like to send other two persons to United States in the next year for 4 weeks. They will learn technique of measurement of isotopes and gases in your laboratories.

(4) We will ask your Institution to perfect the technique and equipment on two testing grounds of observation and earthquake prediction by fluidgeochemical methods---Beijing and surrounding region and the region of the Western Yunnan.

(5) Our Center would like to receive two scientists of your Institution in 1982 for 4 weeks. They will visit the zones of seismic and geothermal activity in Guangdong and Shandong in the East China. They will collect samples of water and gases.

(6) To sum up, exchange of 2--3 scientists per year. Each group pays airfare for itself. Living expenses will be paid by host group.

(7) Our Center would like to cooperate with your Institution to carry out geochemical investigation of sub surface water and gases in zones of deep faults with high seismic activity in China for evaluation of their base-level activity and for selection of components for observation as possible eartnquake precursors. Some of the samples will be measured by your. Institution. Our Center would also like to participate in the U.S. Program for earthquake studies being carried out at your Institution.

(8) Our Center would like to carry out long-term cooperation with your Institution in geodynamic investigation of some main types of plate boundary zones all over the world with geochemical methods of subsurface water and gases, and in investigation of relation between heat flow of the mantle and seismic activity. The cooperation may take the form of exchange visit of scientists and joint work in other countries.

Please consider if above-listed plan is feasible.

Analysis and Prediction Center

State Seismological Bureau, Beijing

(Transmitted by Drs. Cai Zuhuang. and Shi Huixin). 
LIST OF TECHNICAL REPORTS PREVIOUSLY

SUBMTTTED

Investigation of Radon and Helium as Possible Fluid-Phase Precursors to Earthquakes, H. Craig, J. E. Lupton, Y. Chung, and others:

No. 1 SIO Reference Number 75-15 Mar. 1975

No. 2 SIO Reference Number 75-23 Aug. 1975

No. 3 SIO Reference Number 75-35 Dec. 1975

No. 4 SIO Reference Number 76-9 May 1976

No. 5 SIO Reference Number 75-15 Oct. 1976

No. 6 SIO Reference Number 77-6 Apr. 1977

(Includes: Radon, Helium, and Geochemical Monitoring on the Palmdale Uplift: No. 1 SIO Reference Number 77-6 Apr. 1977)

No. 7 SIO Reference Number 77-21 Oct. 1977

(Includes: Radon, Helium, and Geochemical Monitoring on the Palmdale Uplift: No. 2 SIO Reference Number 77-21 Oct. 1977)

No. 8 SIO Reference Number 78-11 Apr. 1978

No. 9 SIO Reference Number 78-29 Oct. 1978

No. 10 SIO Reference Number 79-10 Apr. 1979

No. 11 SIO Reference Number 79-31 Dec. 1979

No. 12 SIO Reference Number 80-8 May 1980 
APPENDIX 1

RADON VARIATIONS VS. TIME 


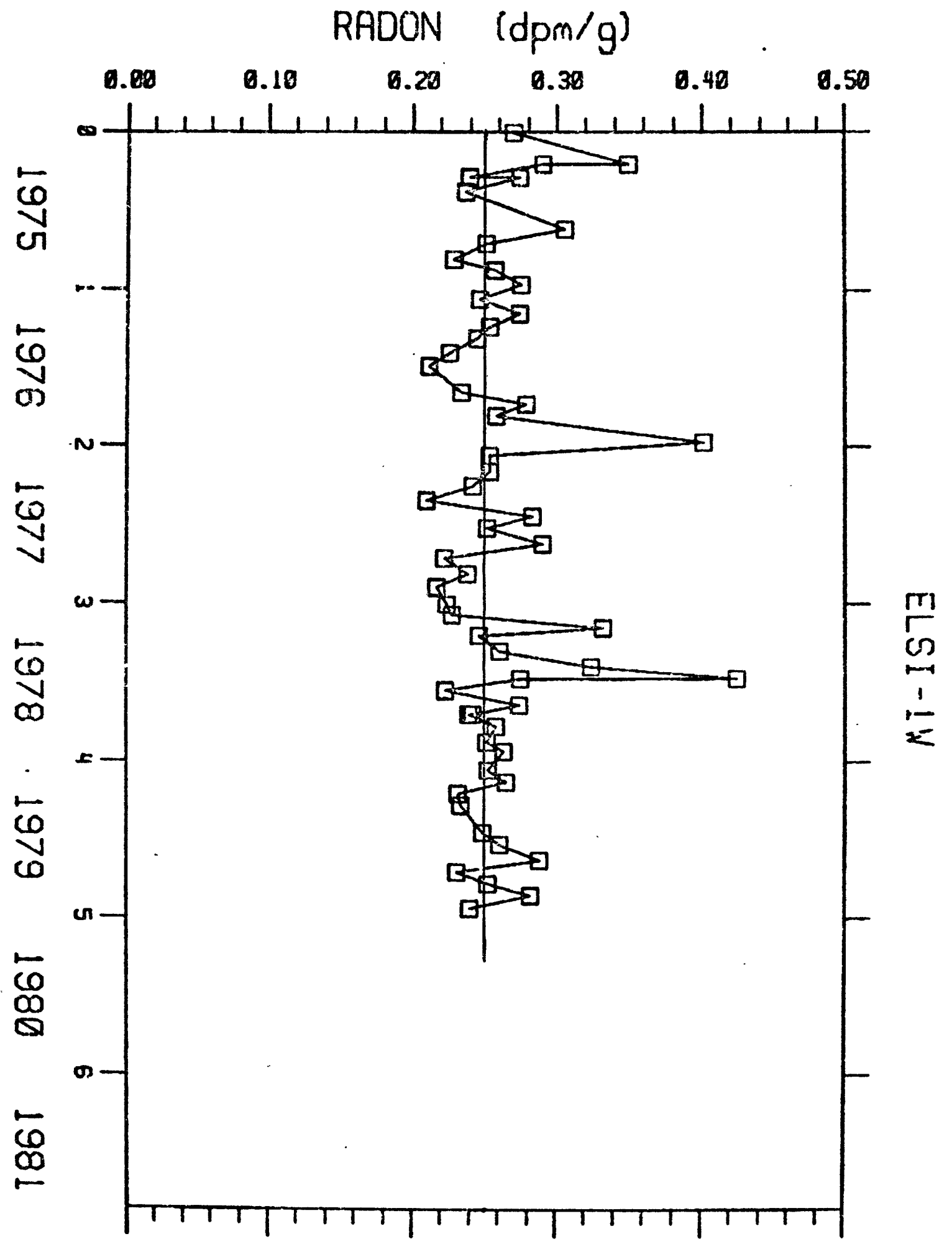




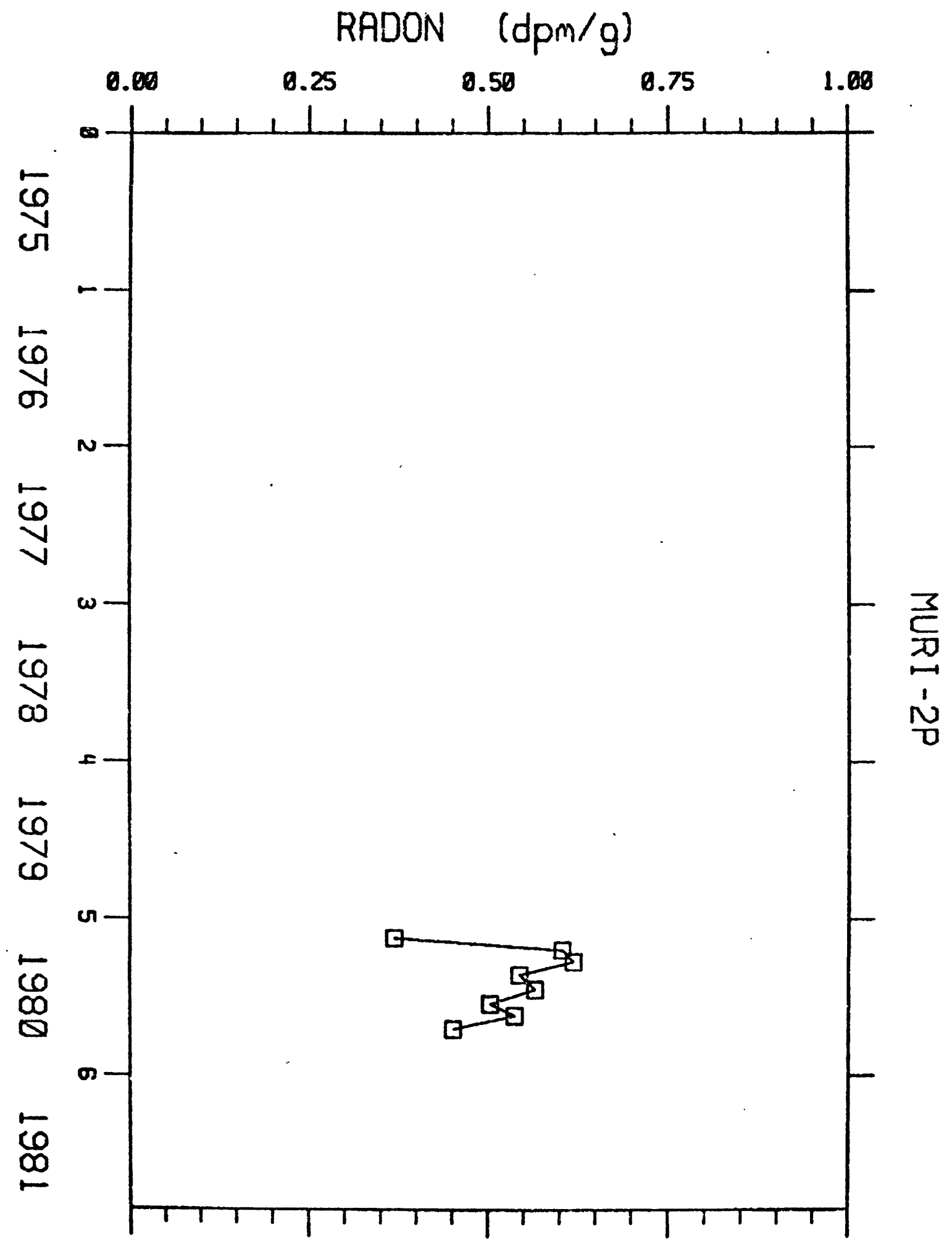




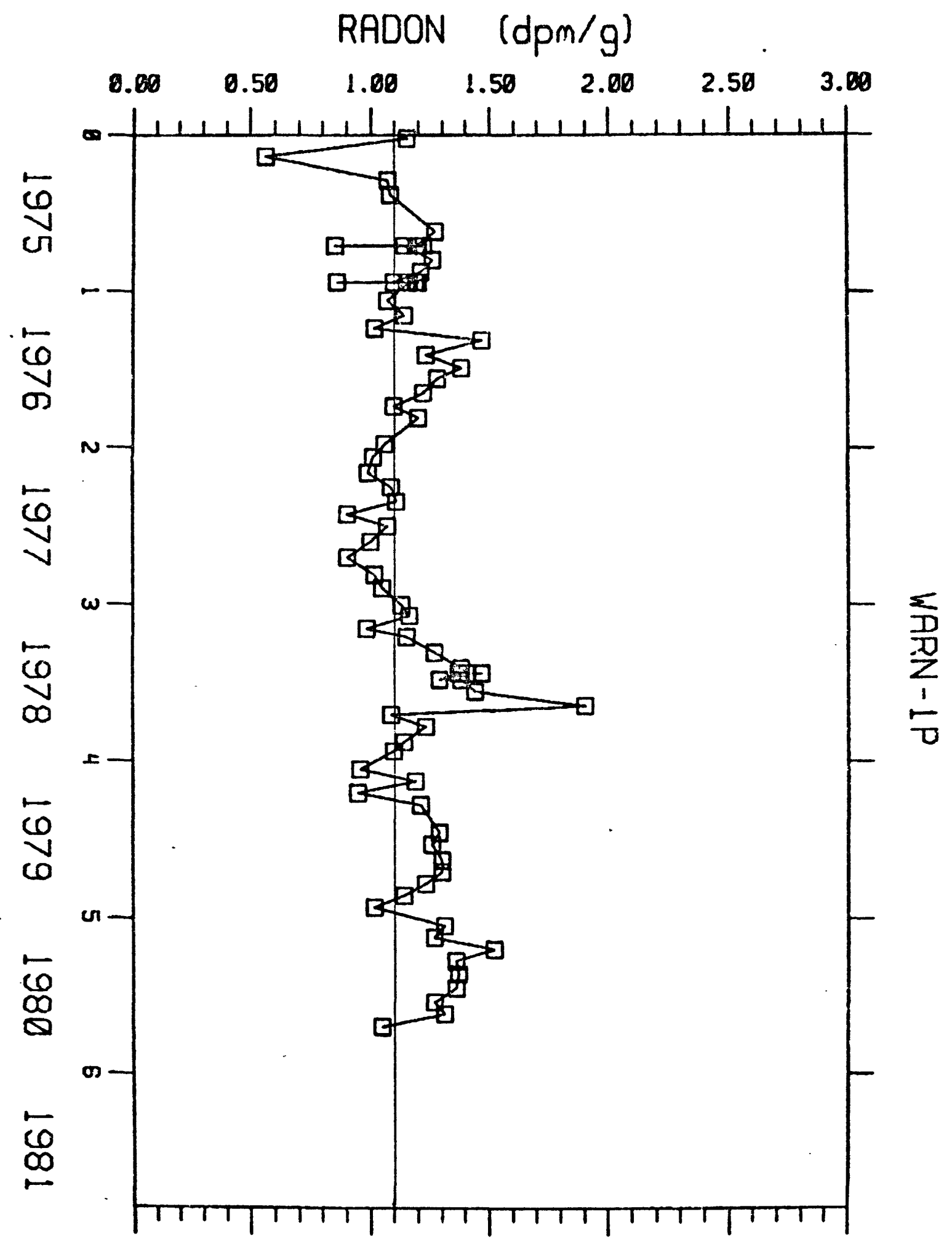




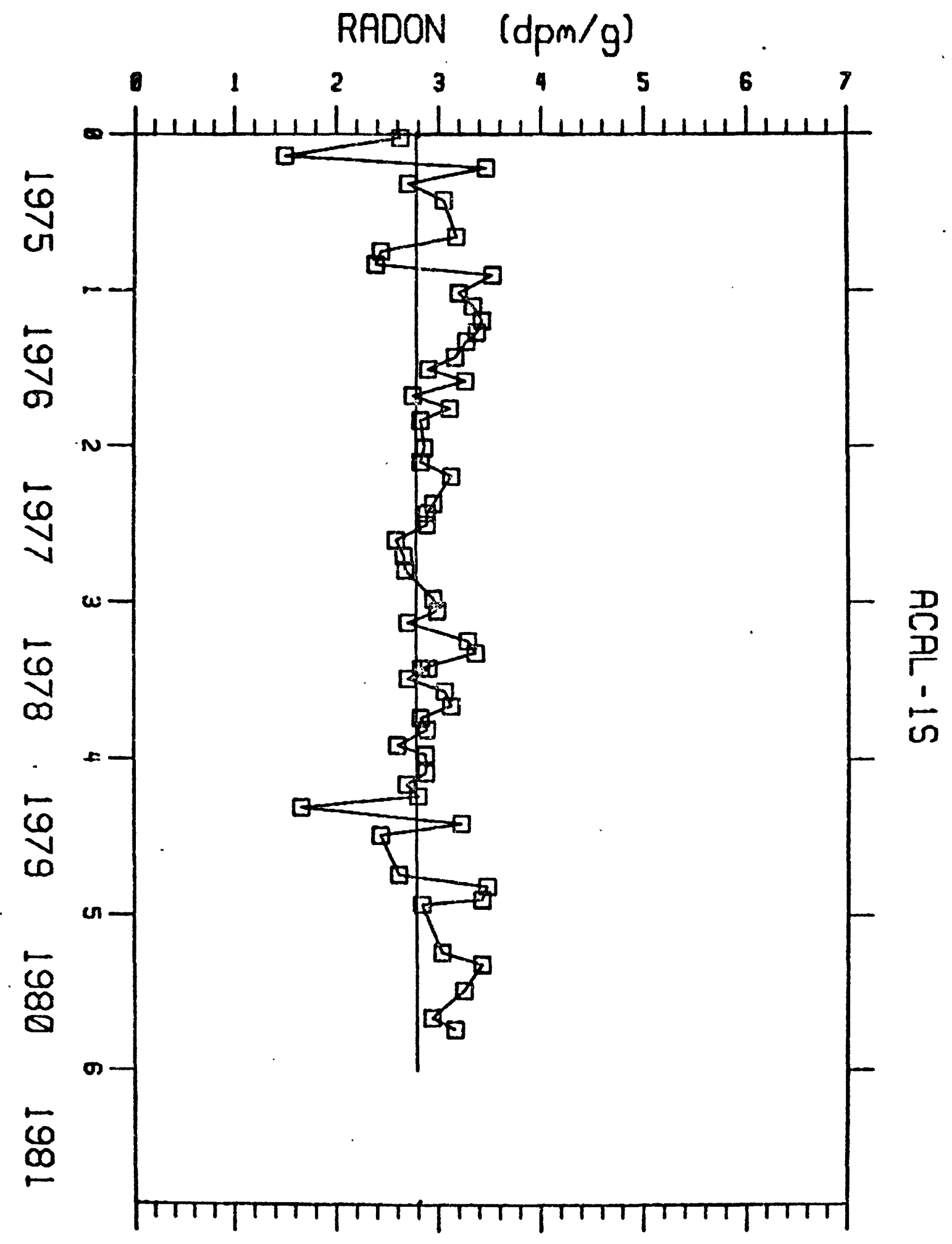




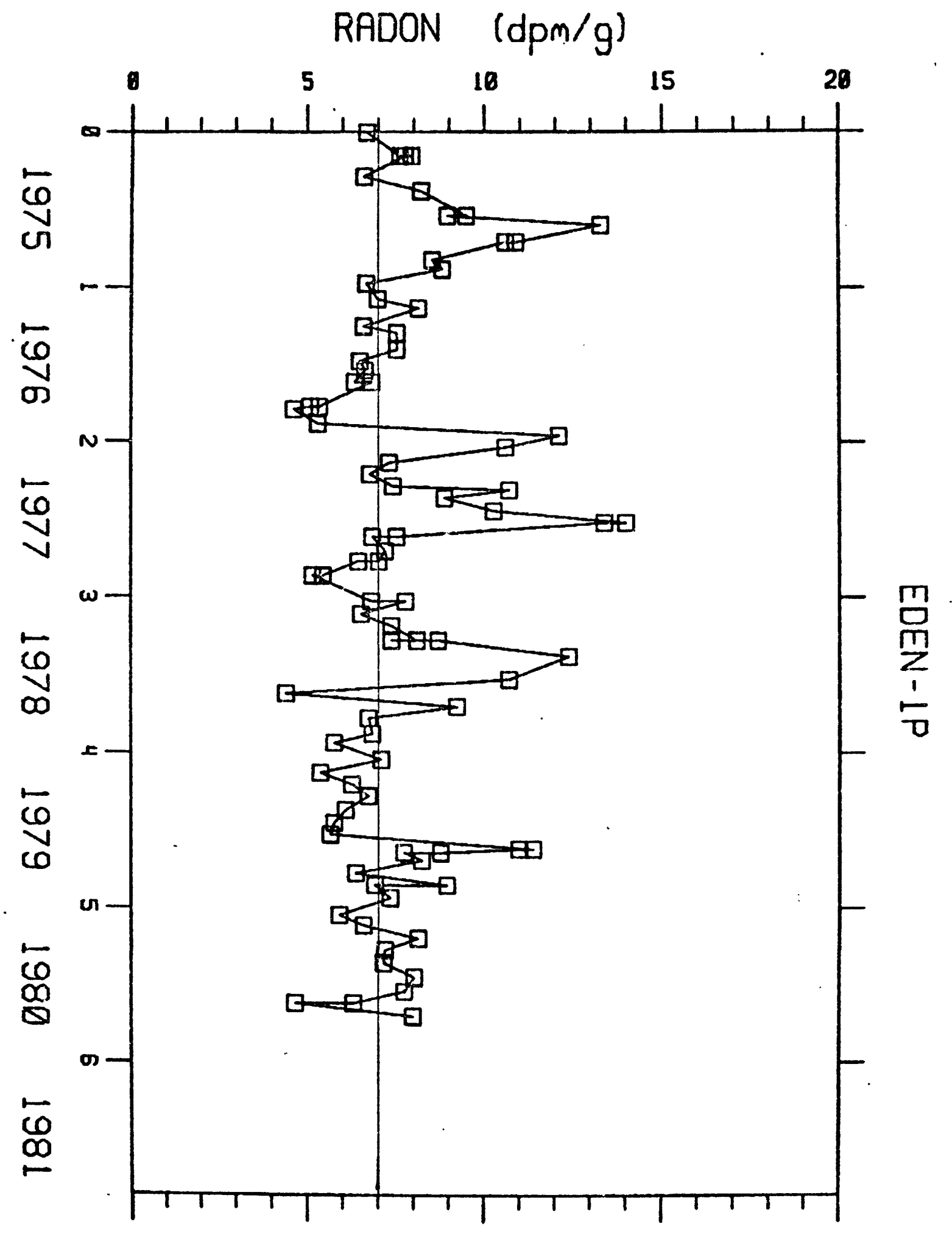




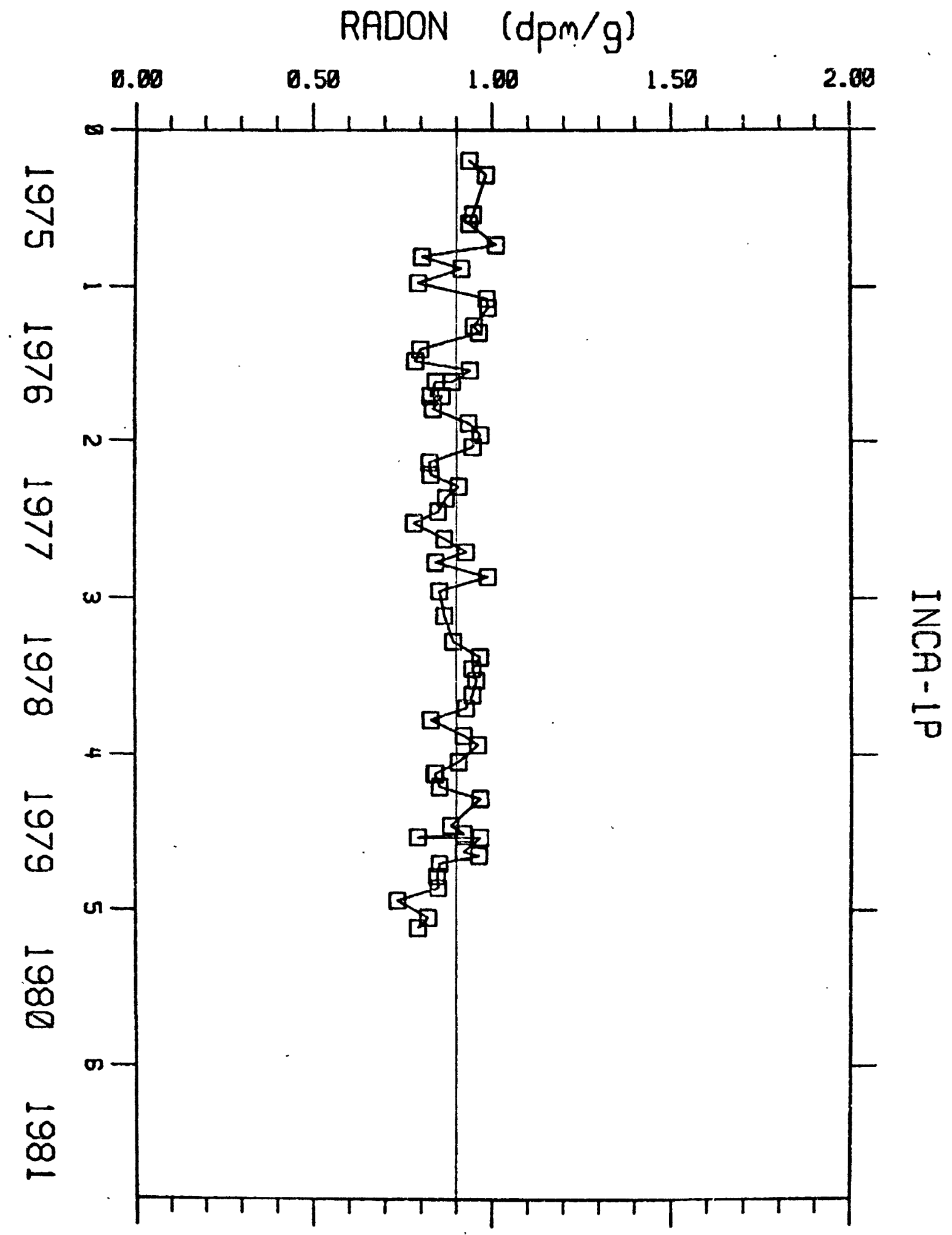




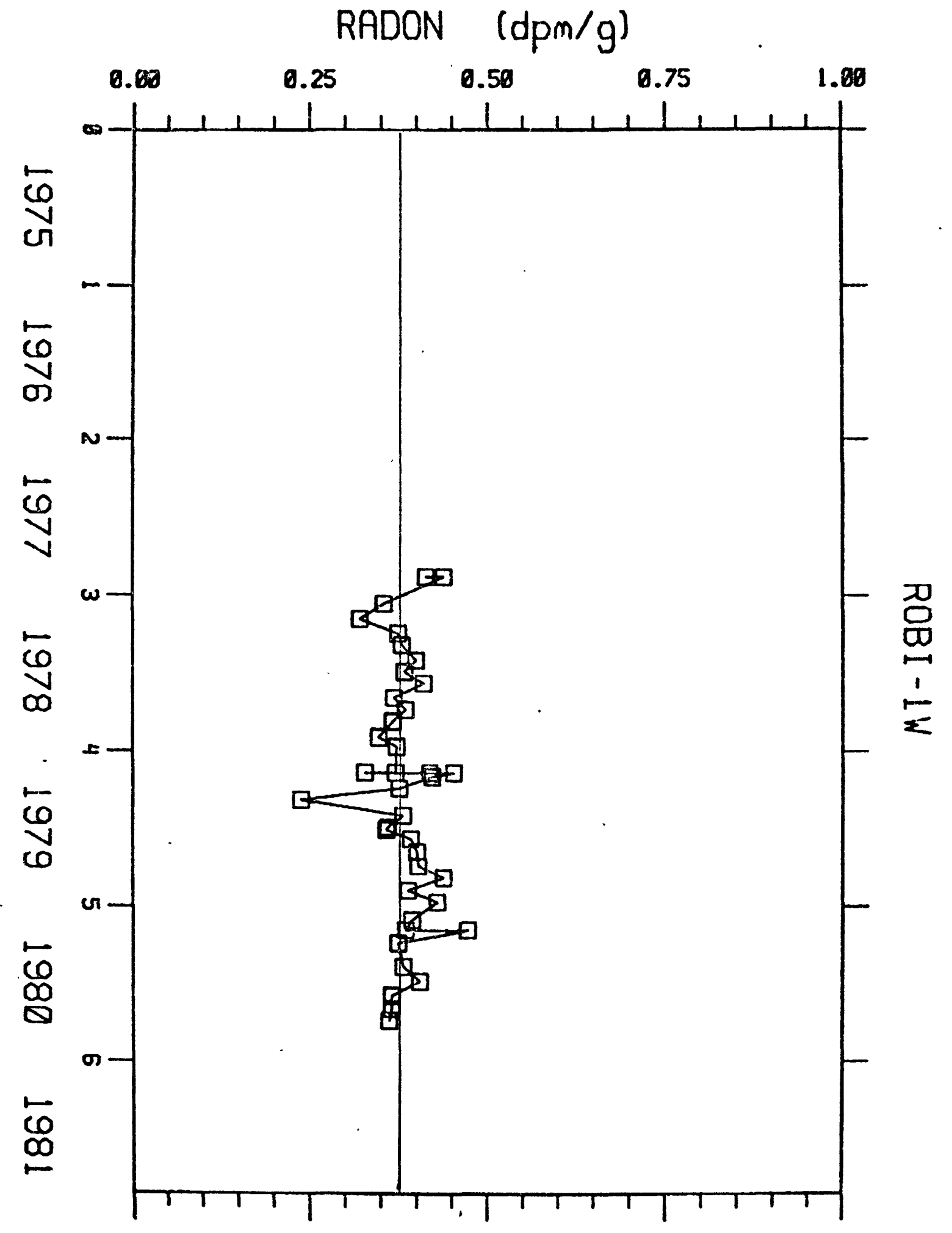




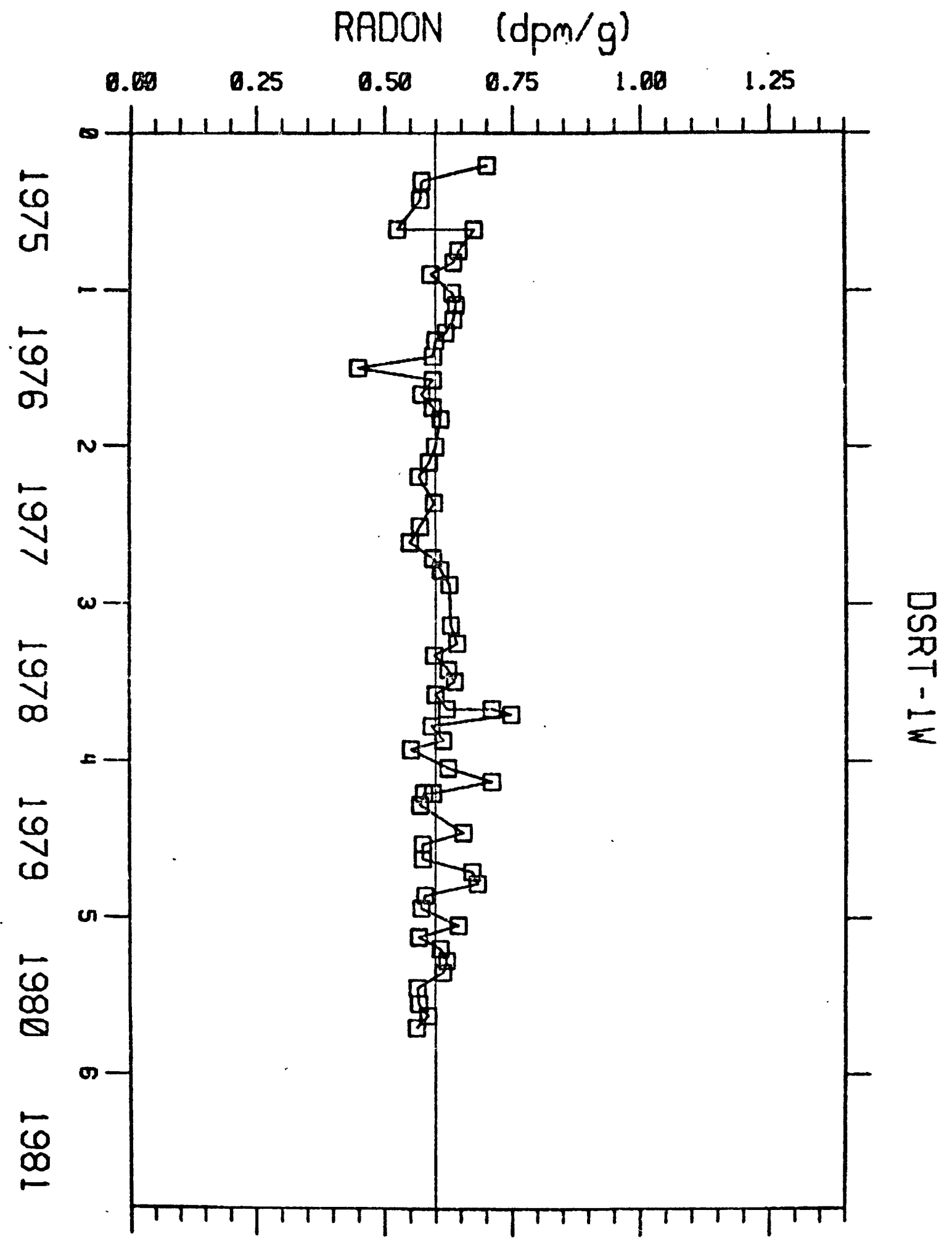


RADON (dpm/g)

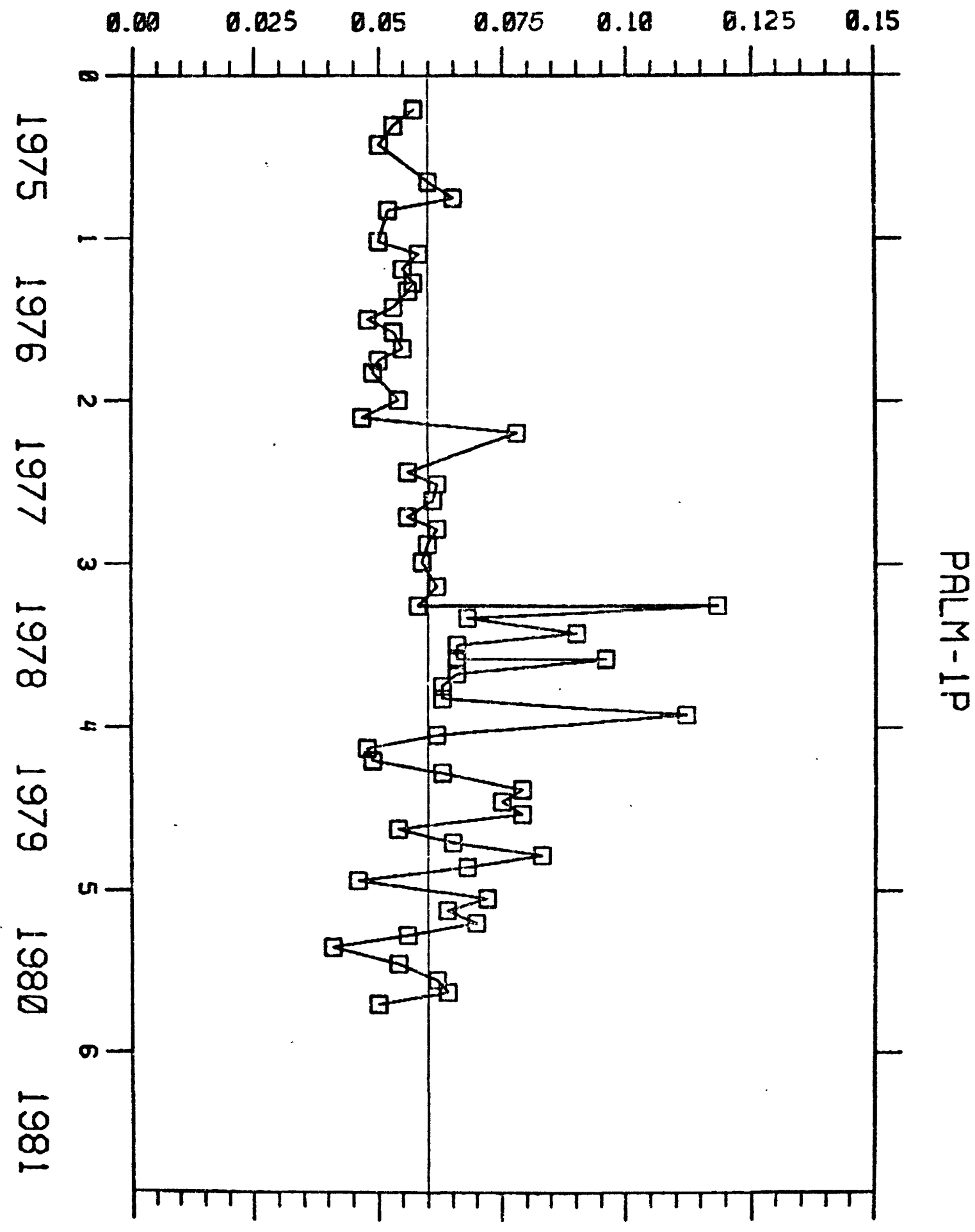




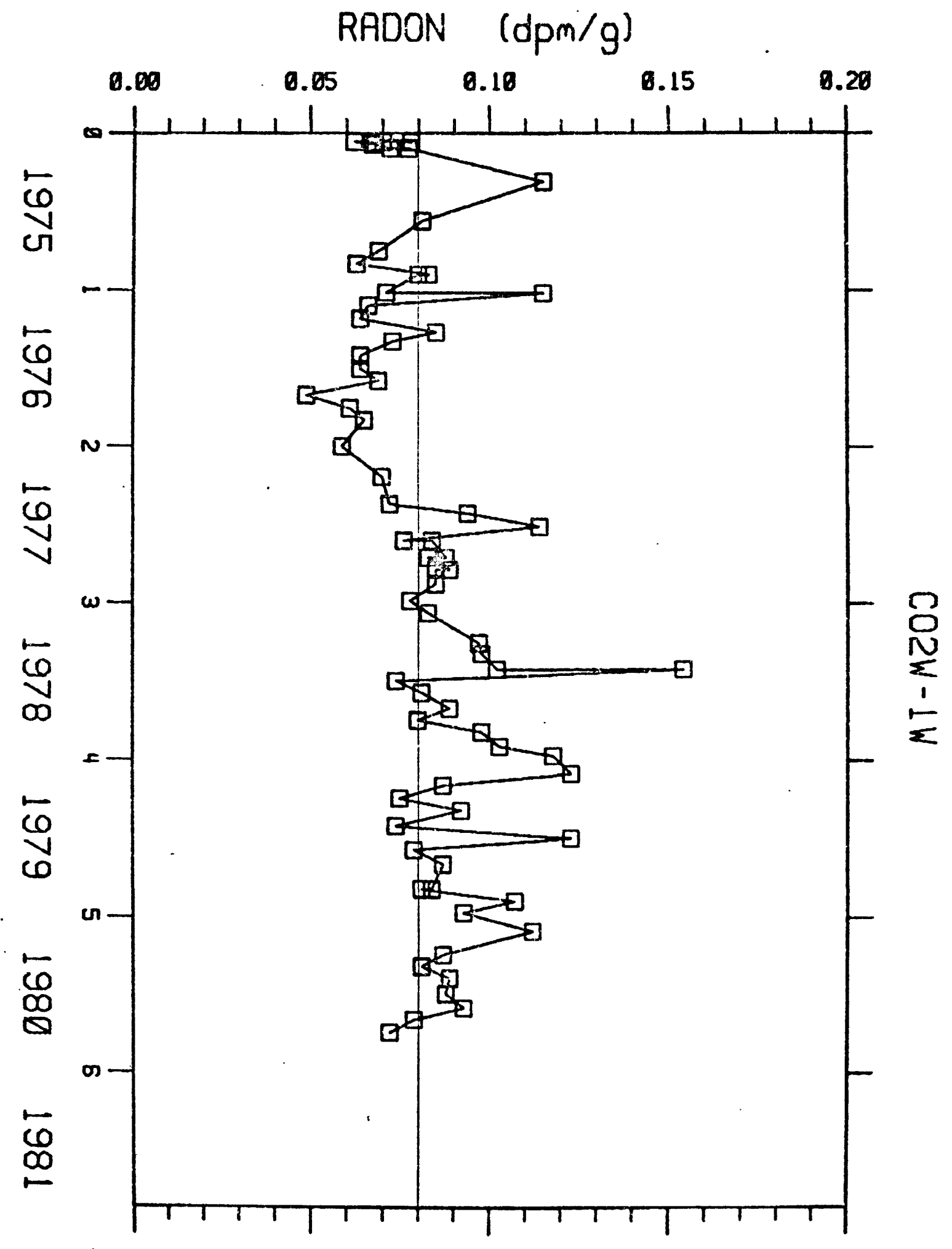




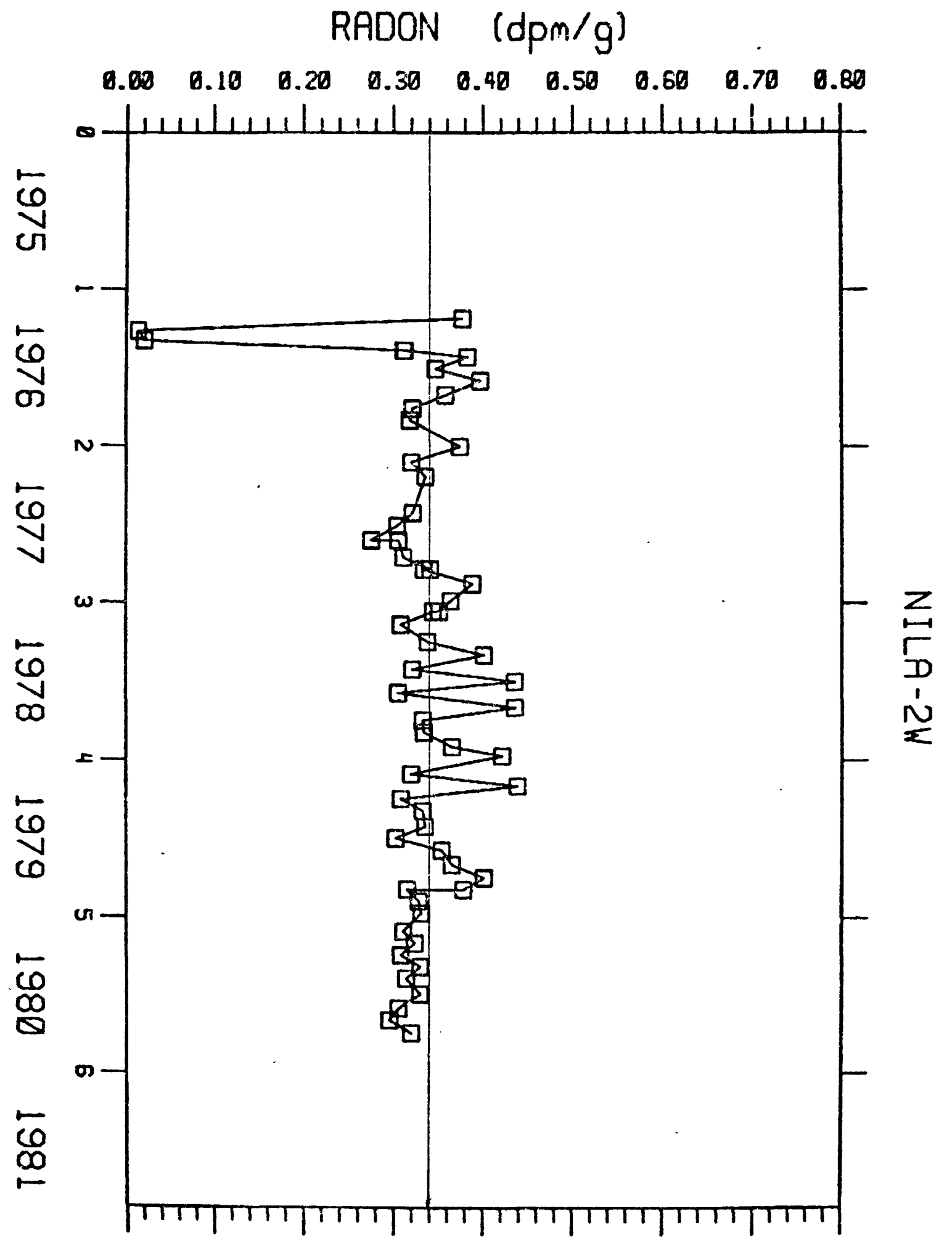


IKII 'SA SNOIIVIYUA WNITAH

乙 XIGNGddV 


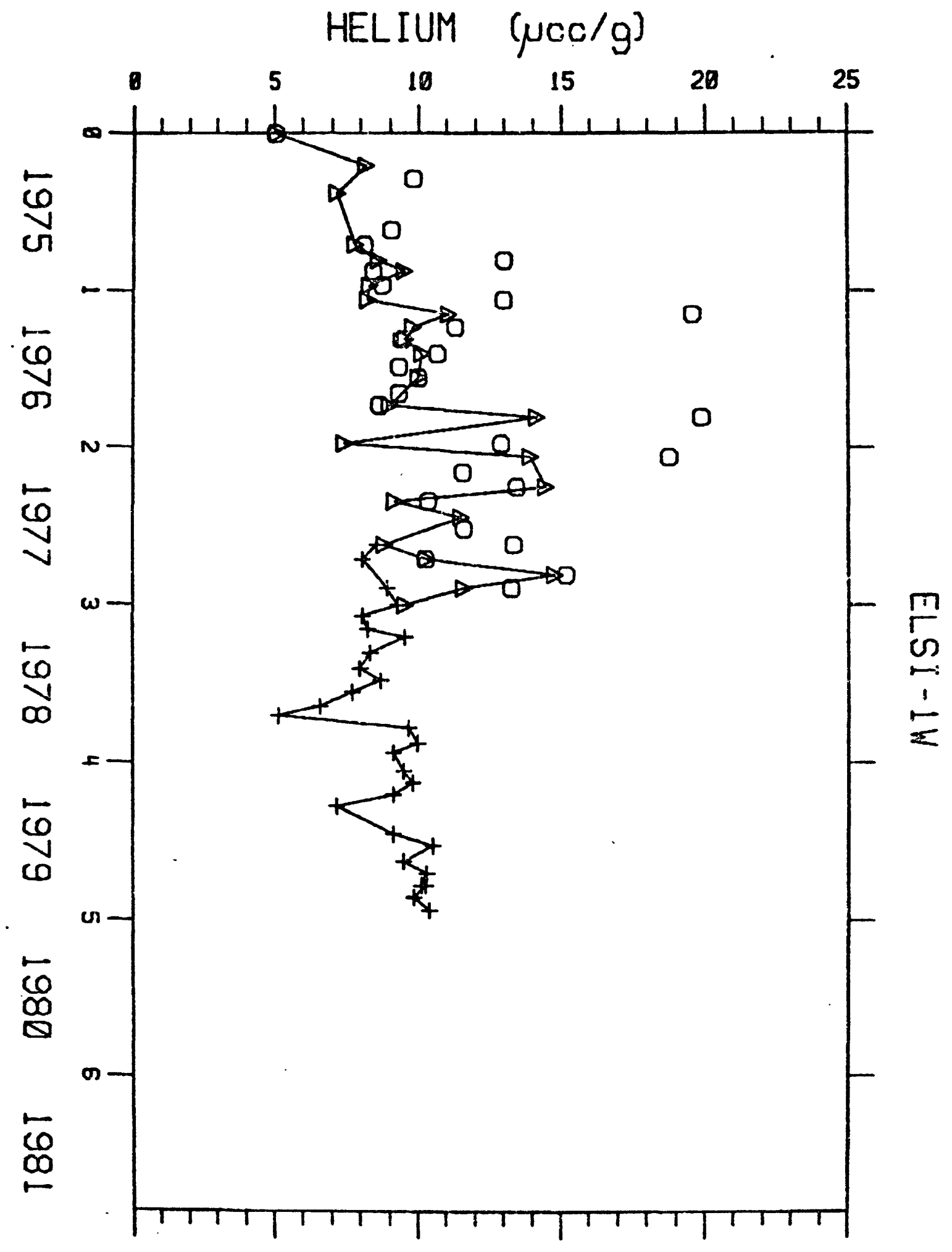




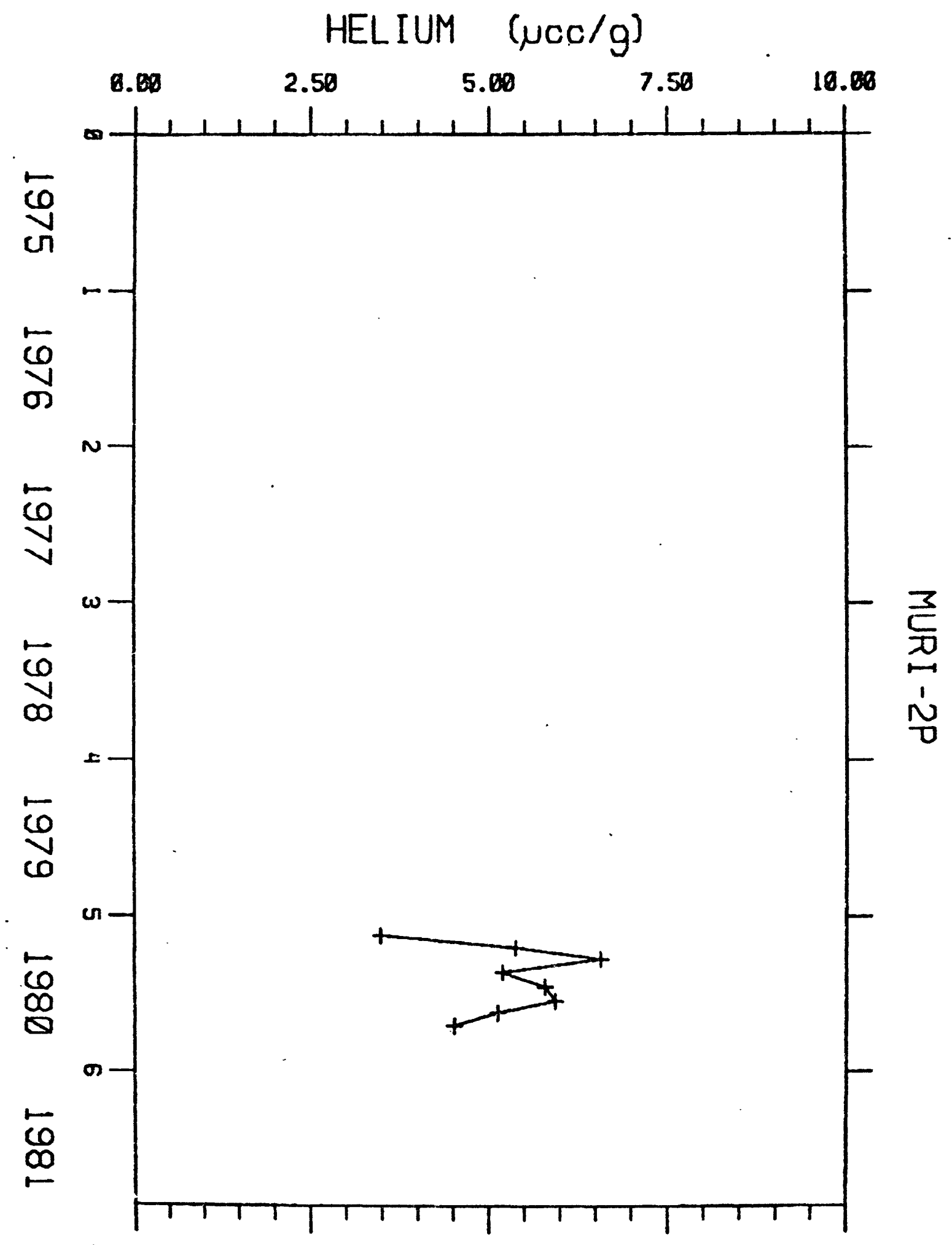




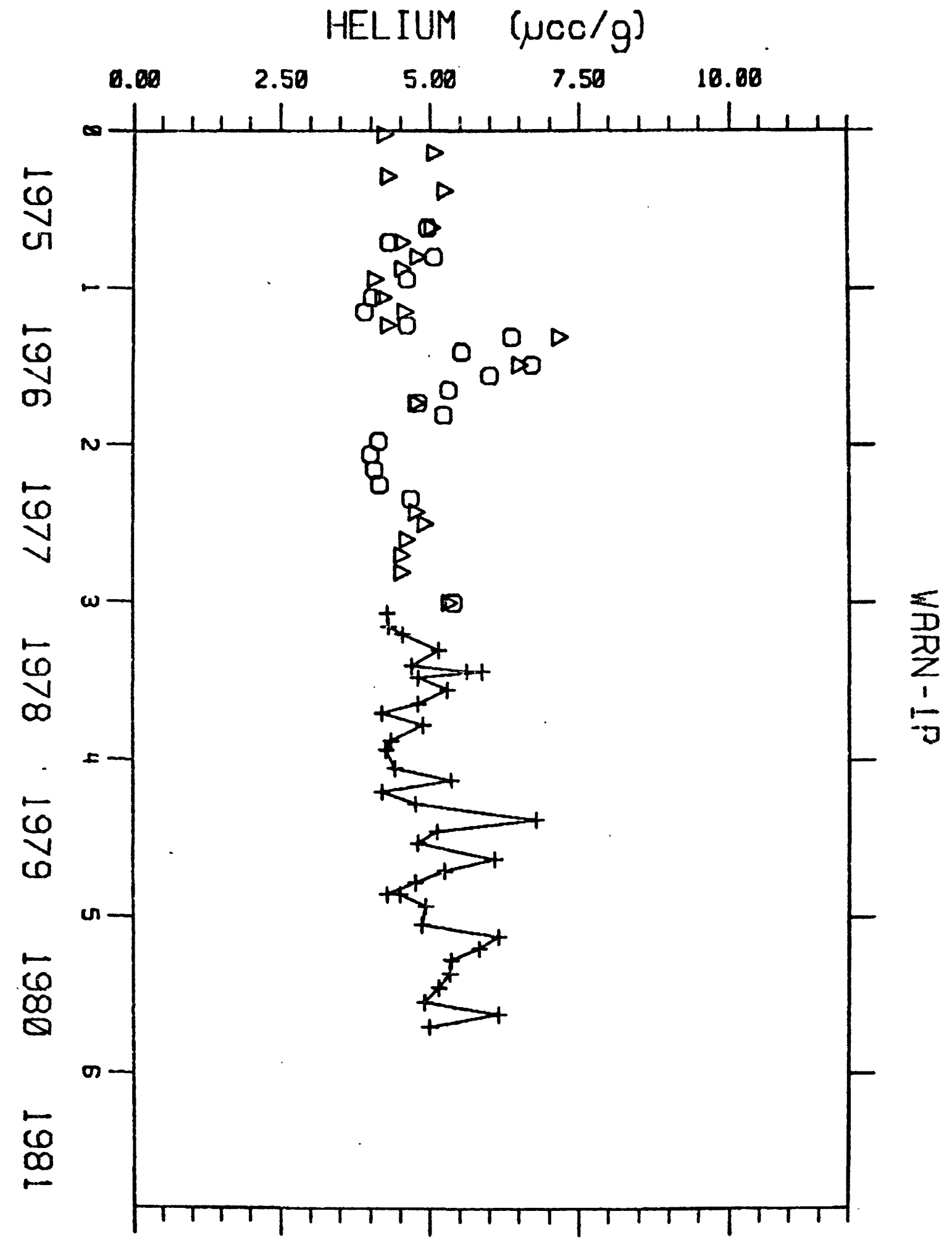




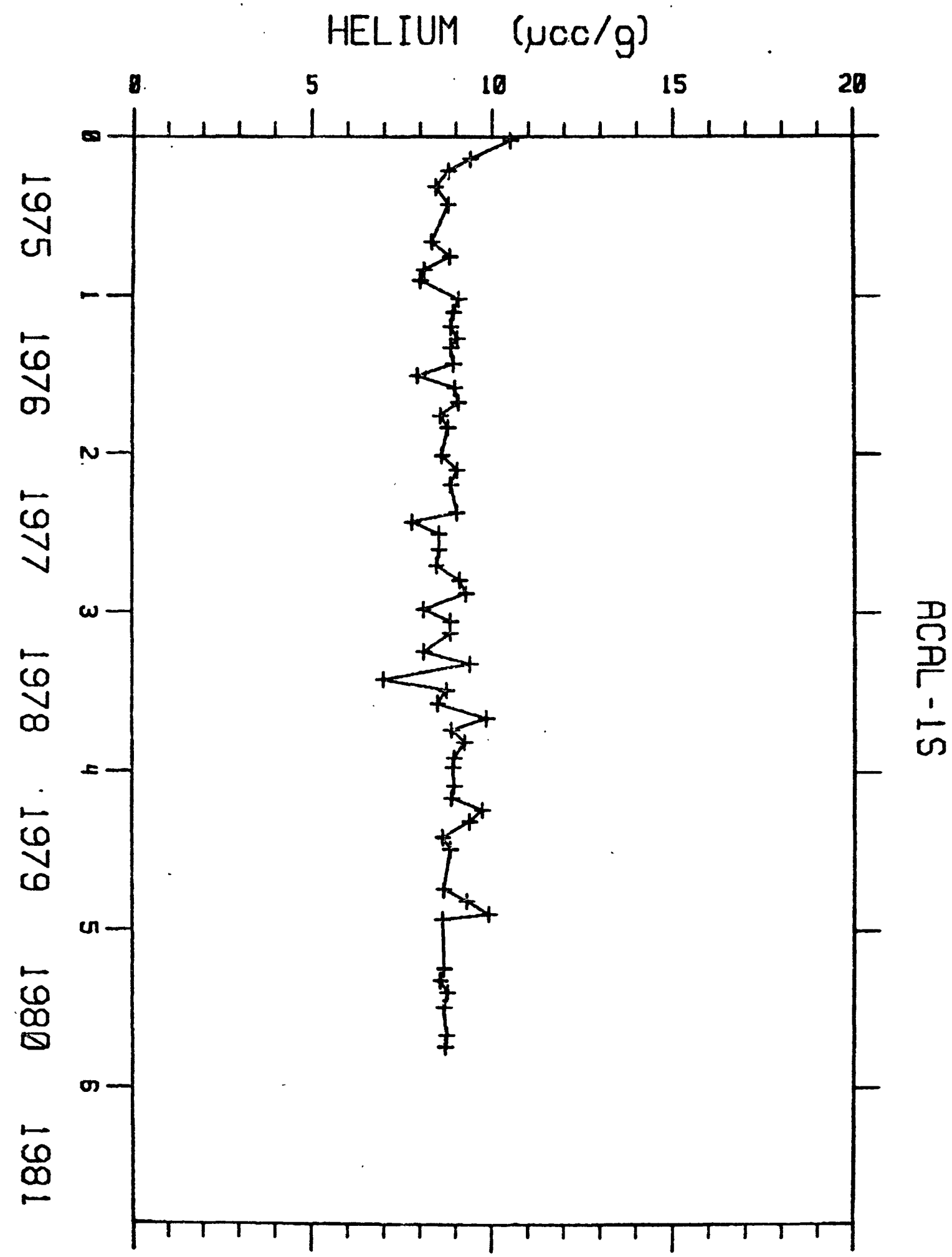




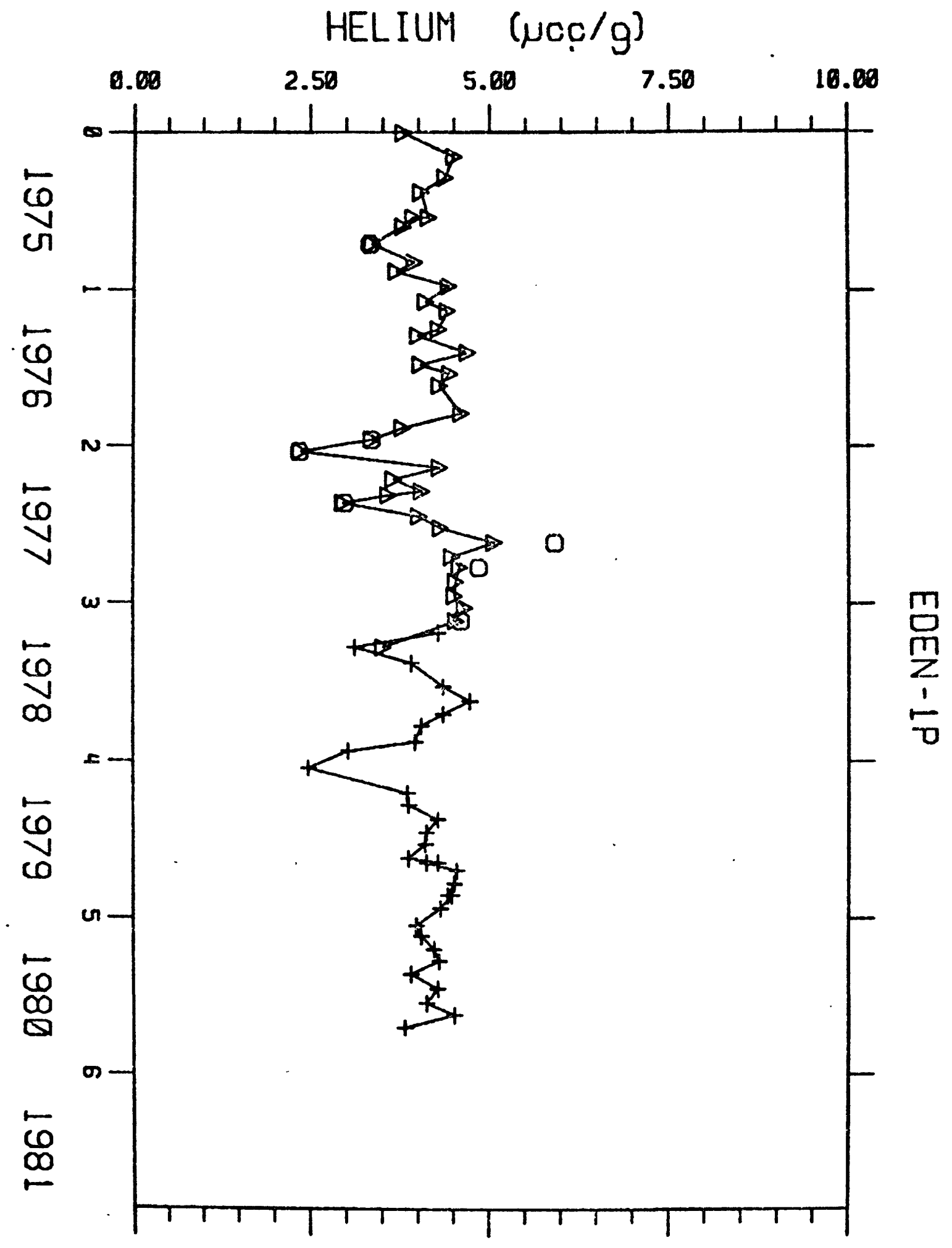




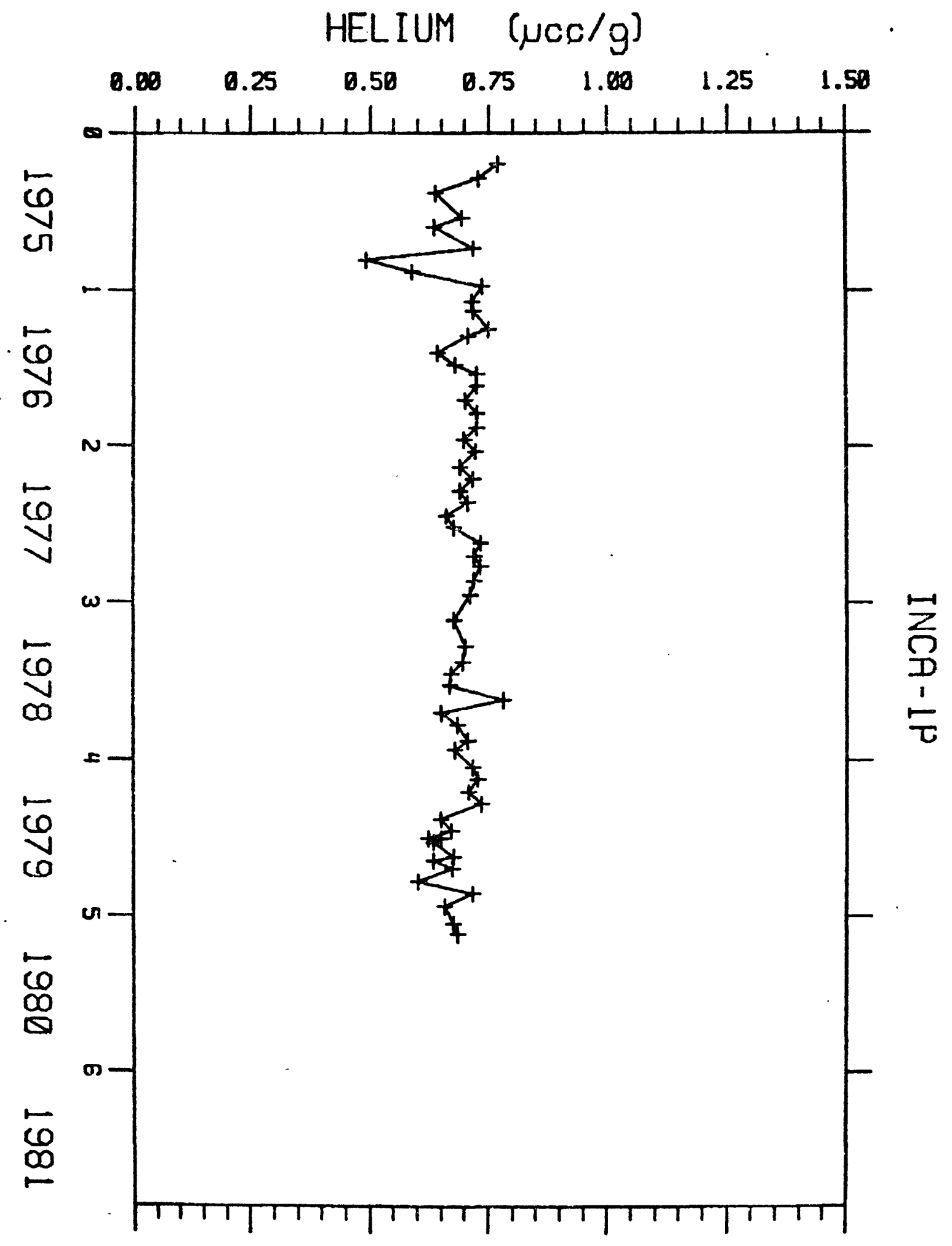




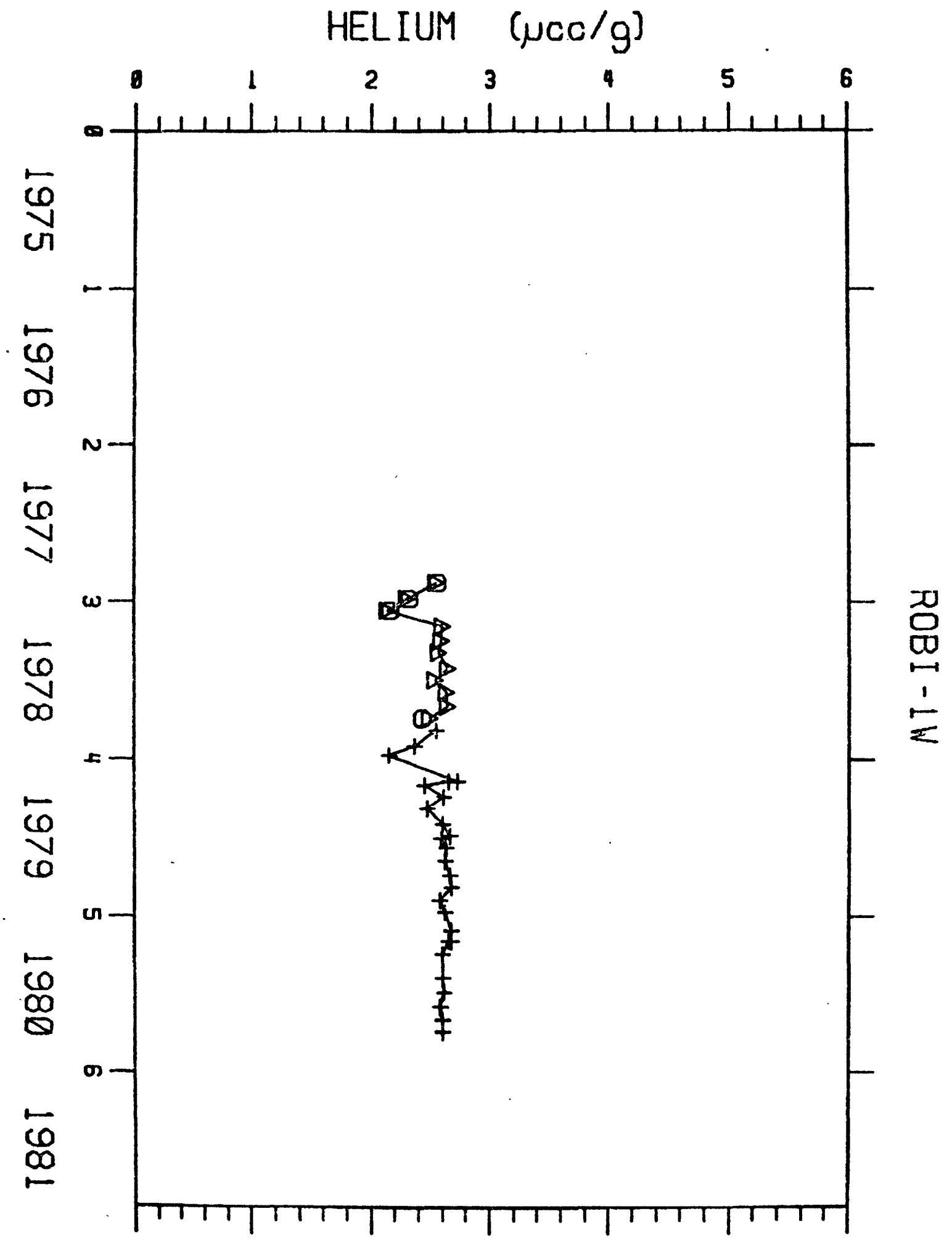




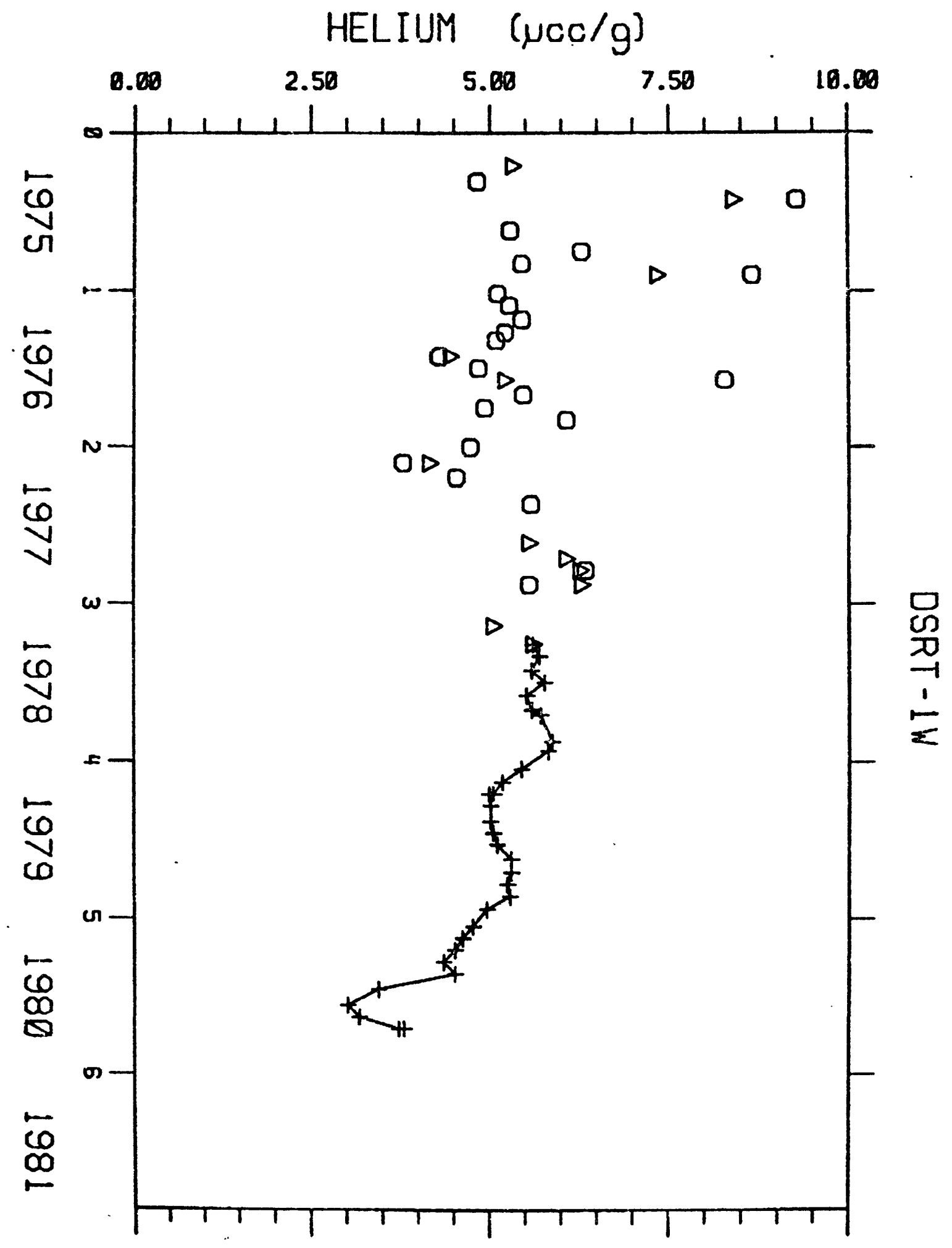




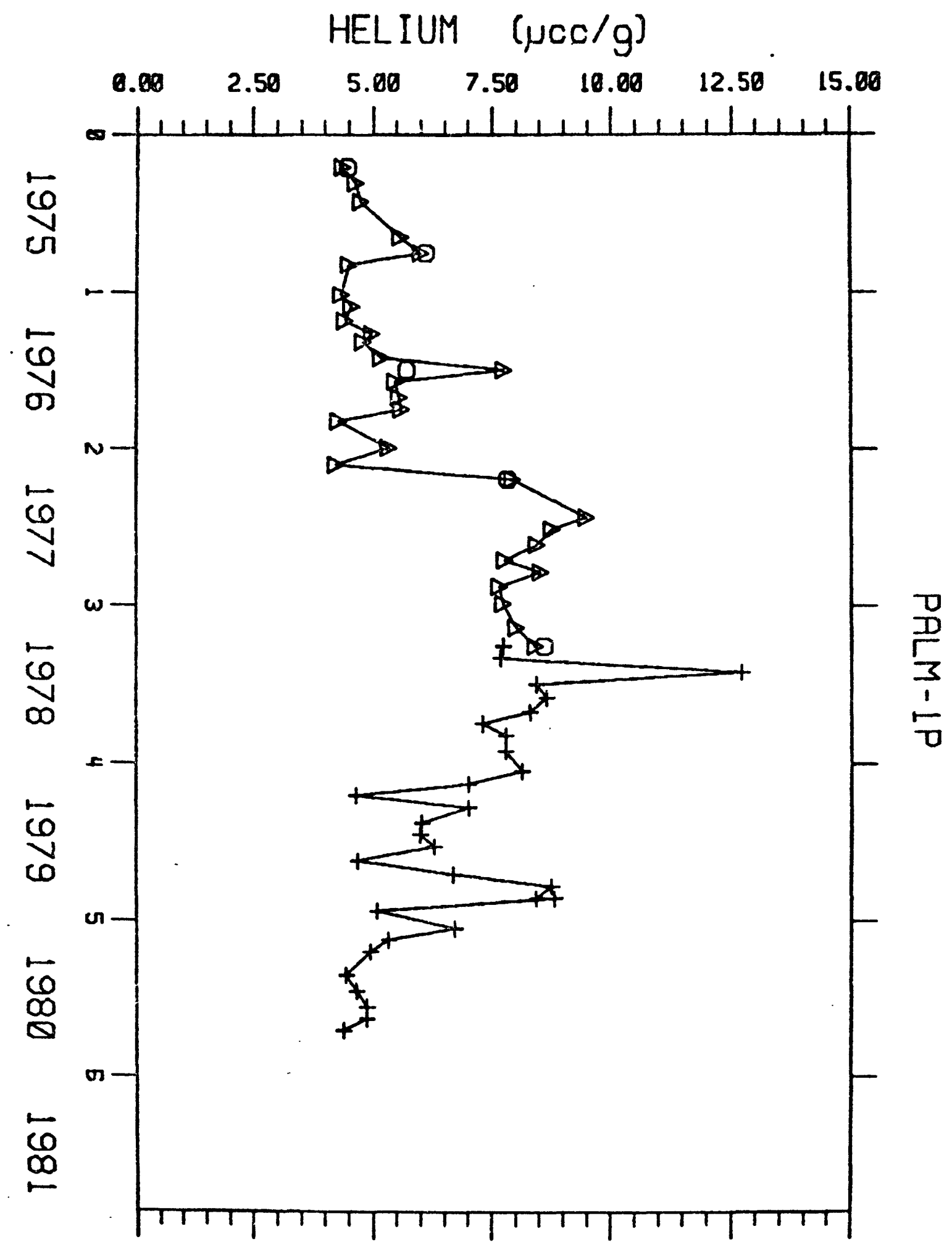




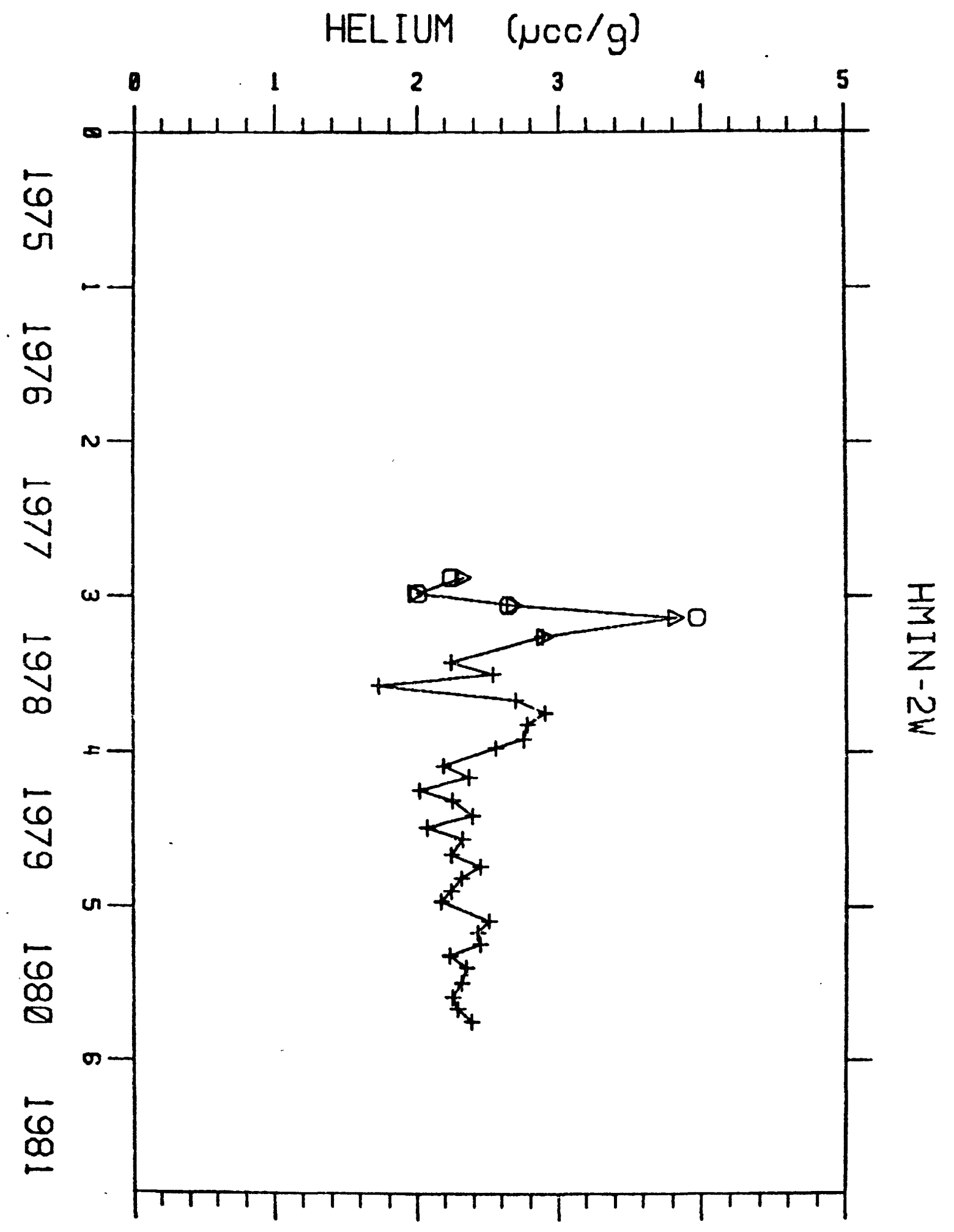




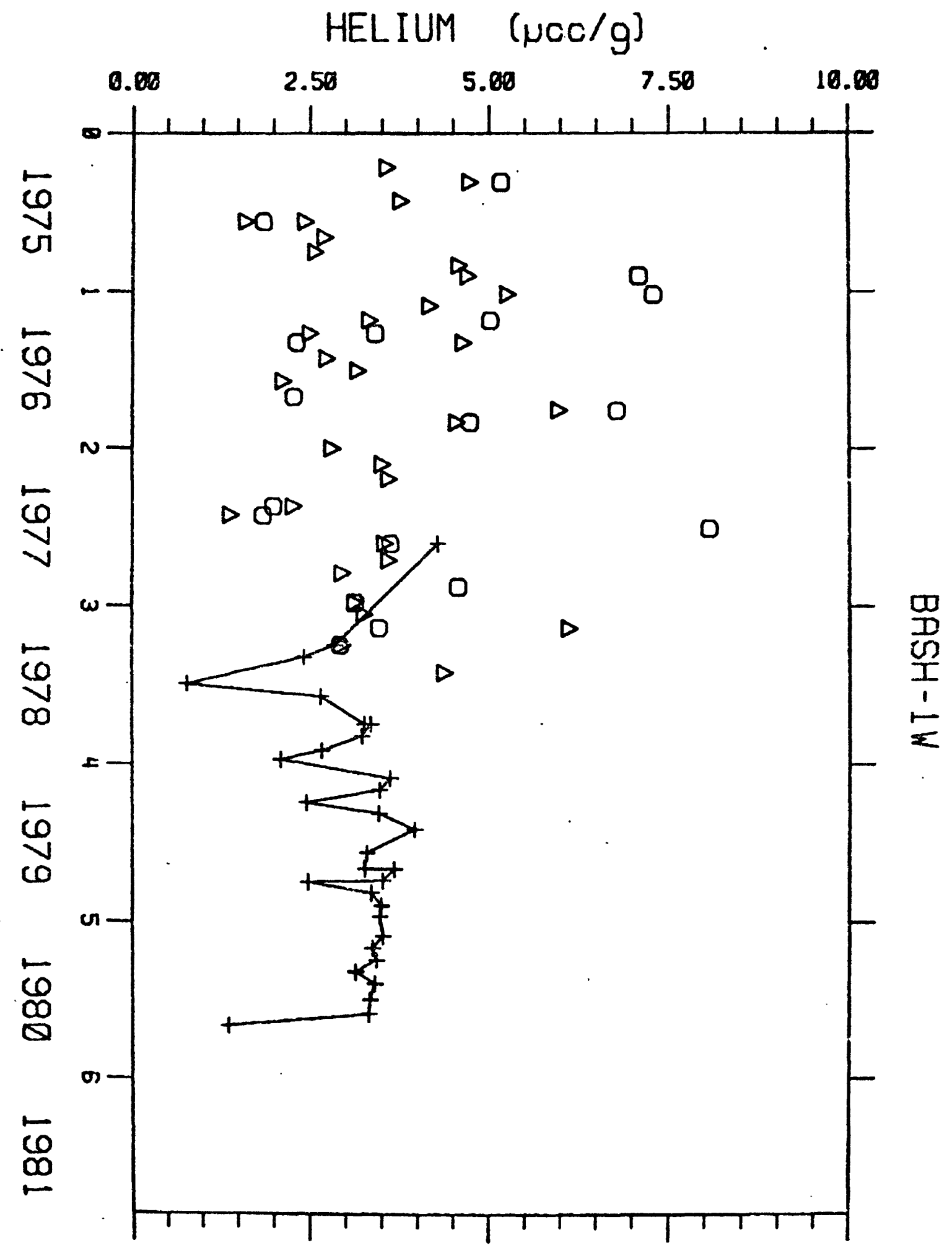




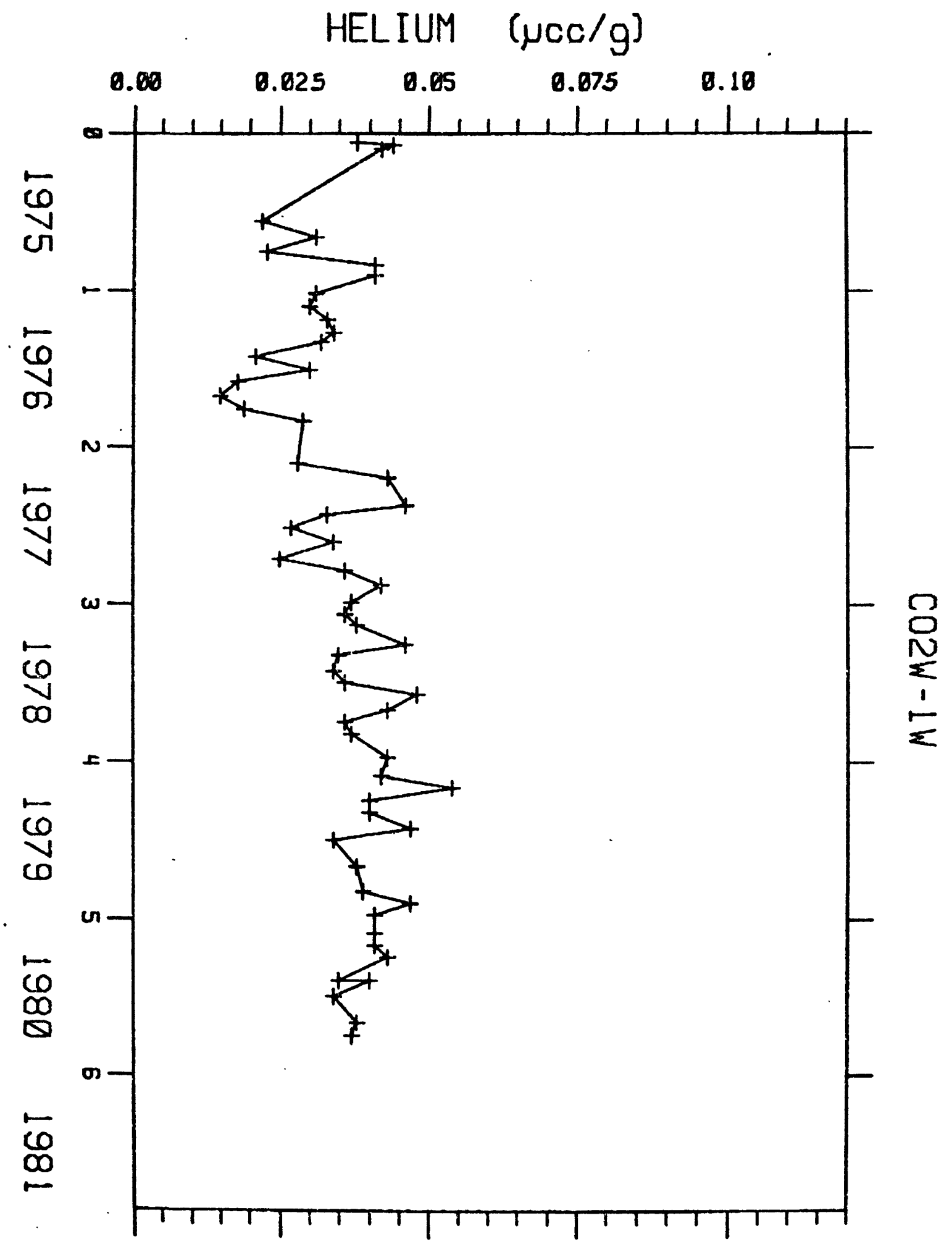




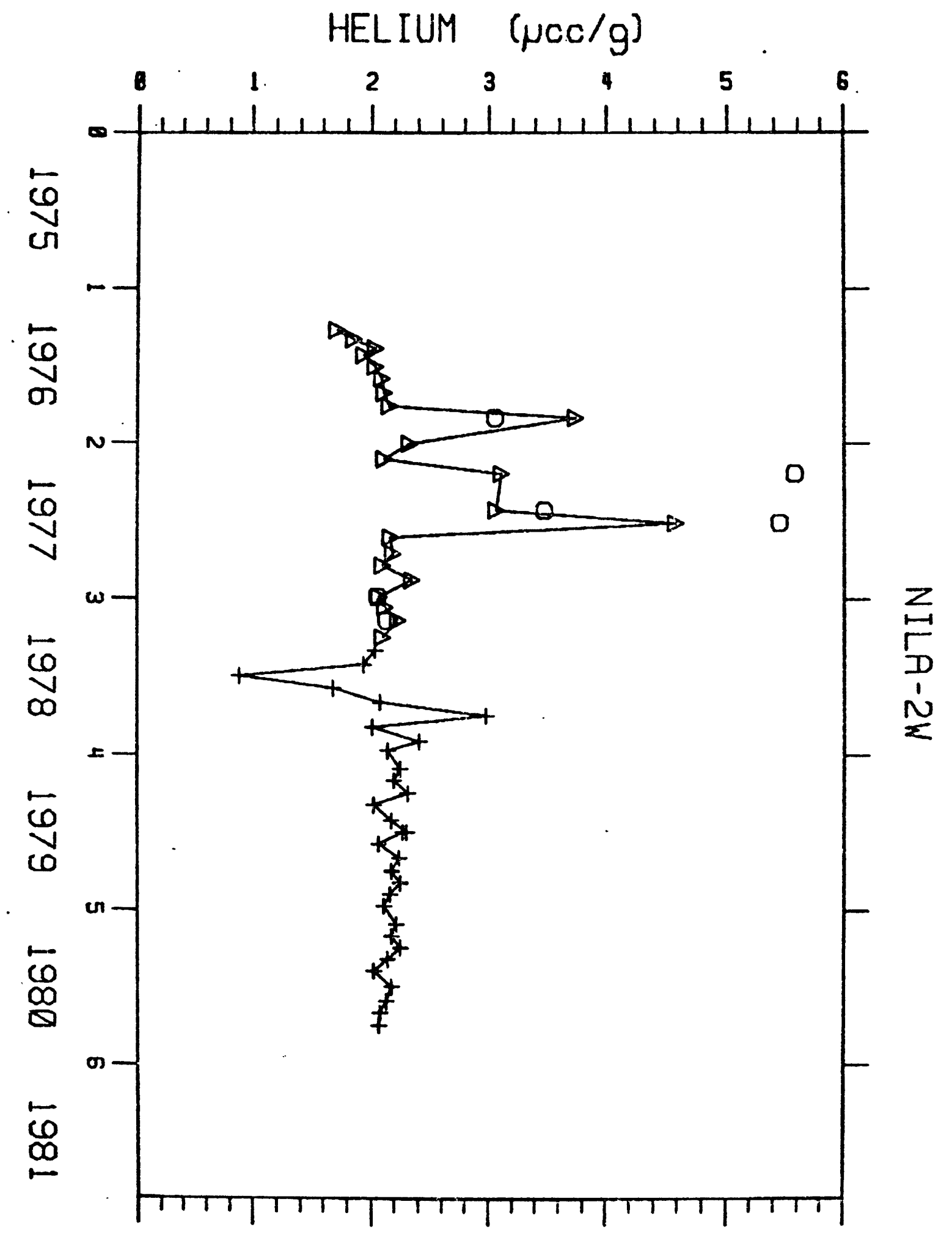


APPENDIX 3

NITROGEN VARIATIONS VS. TIME 


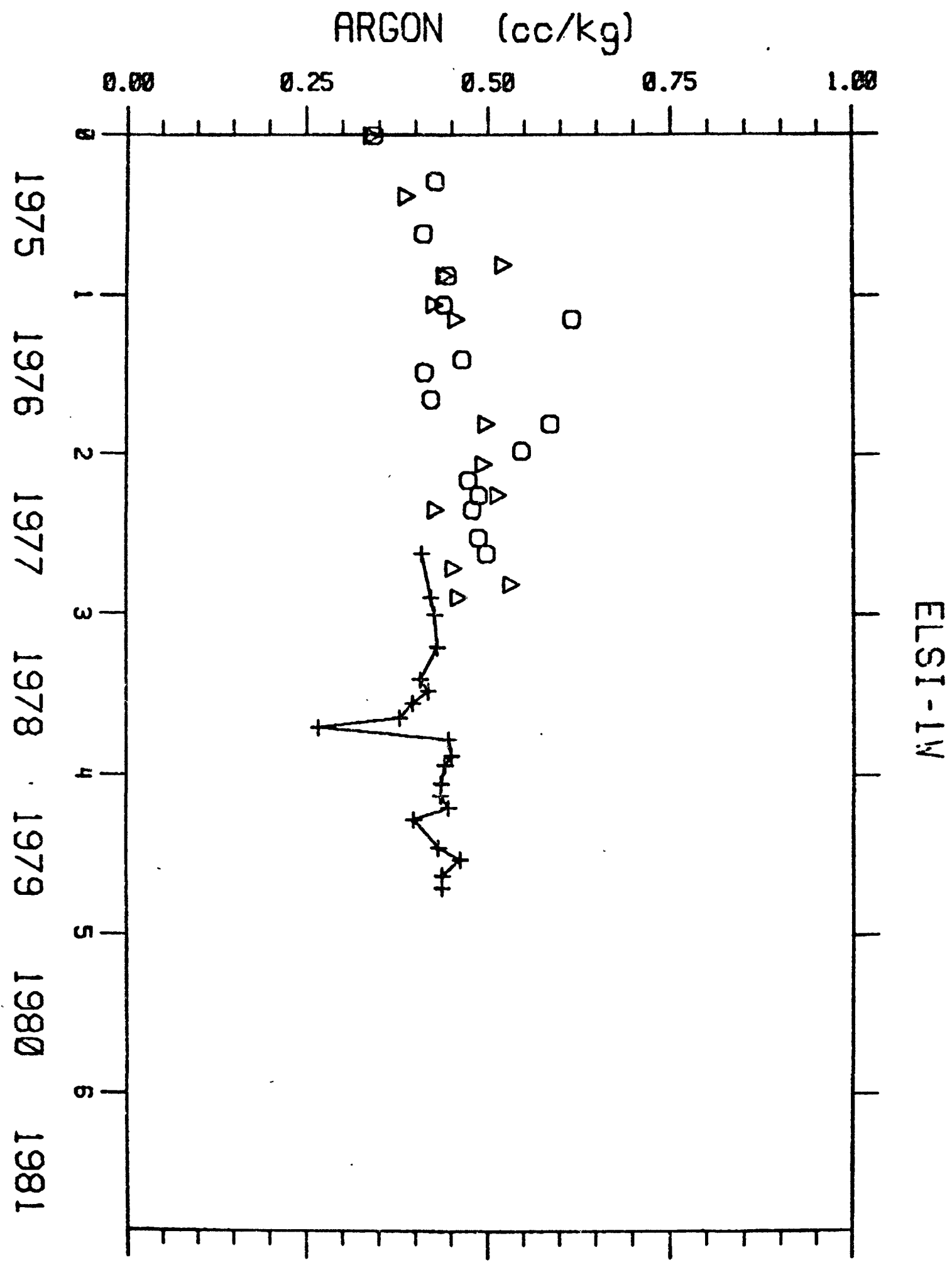




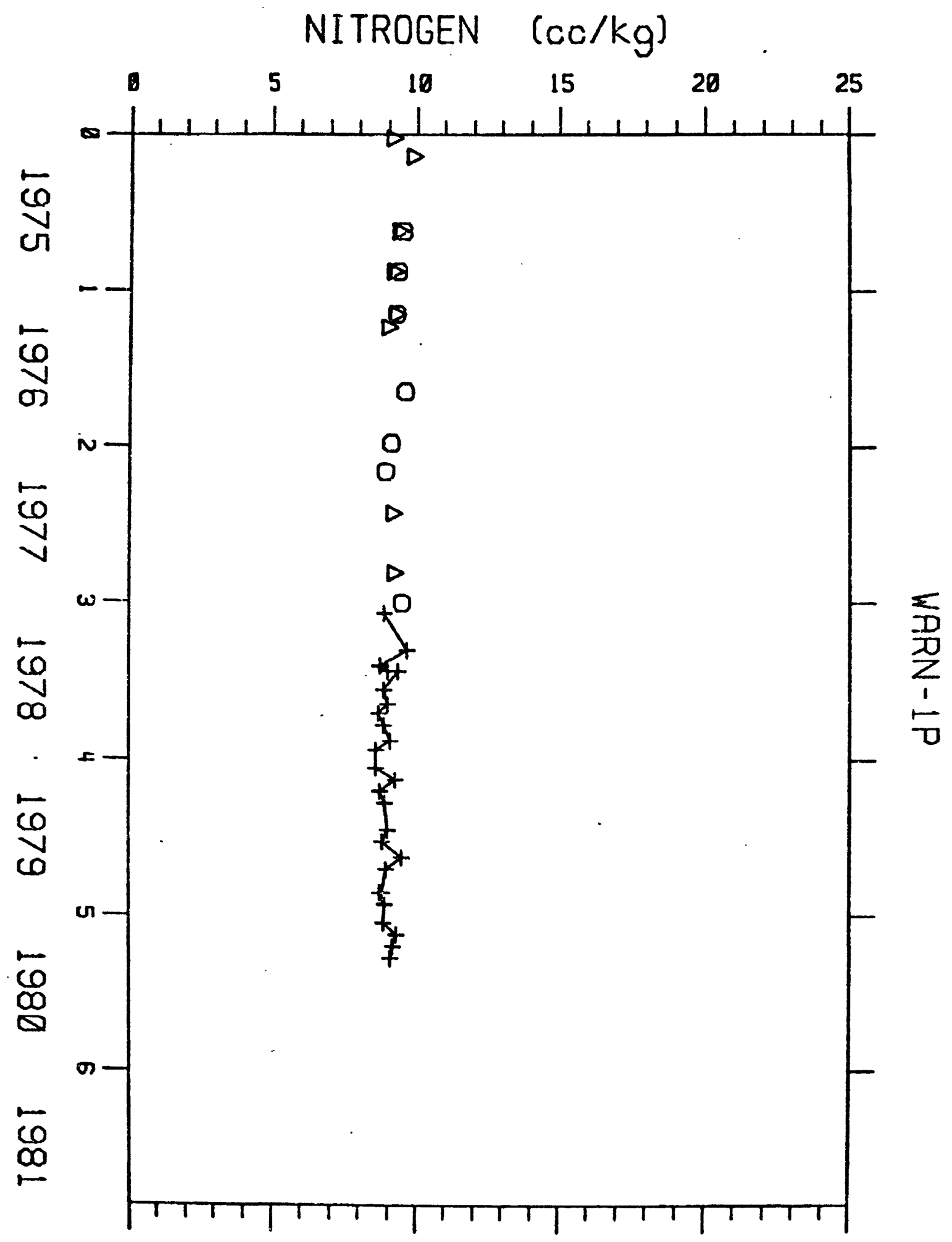




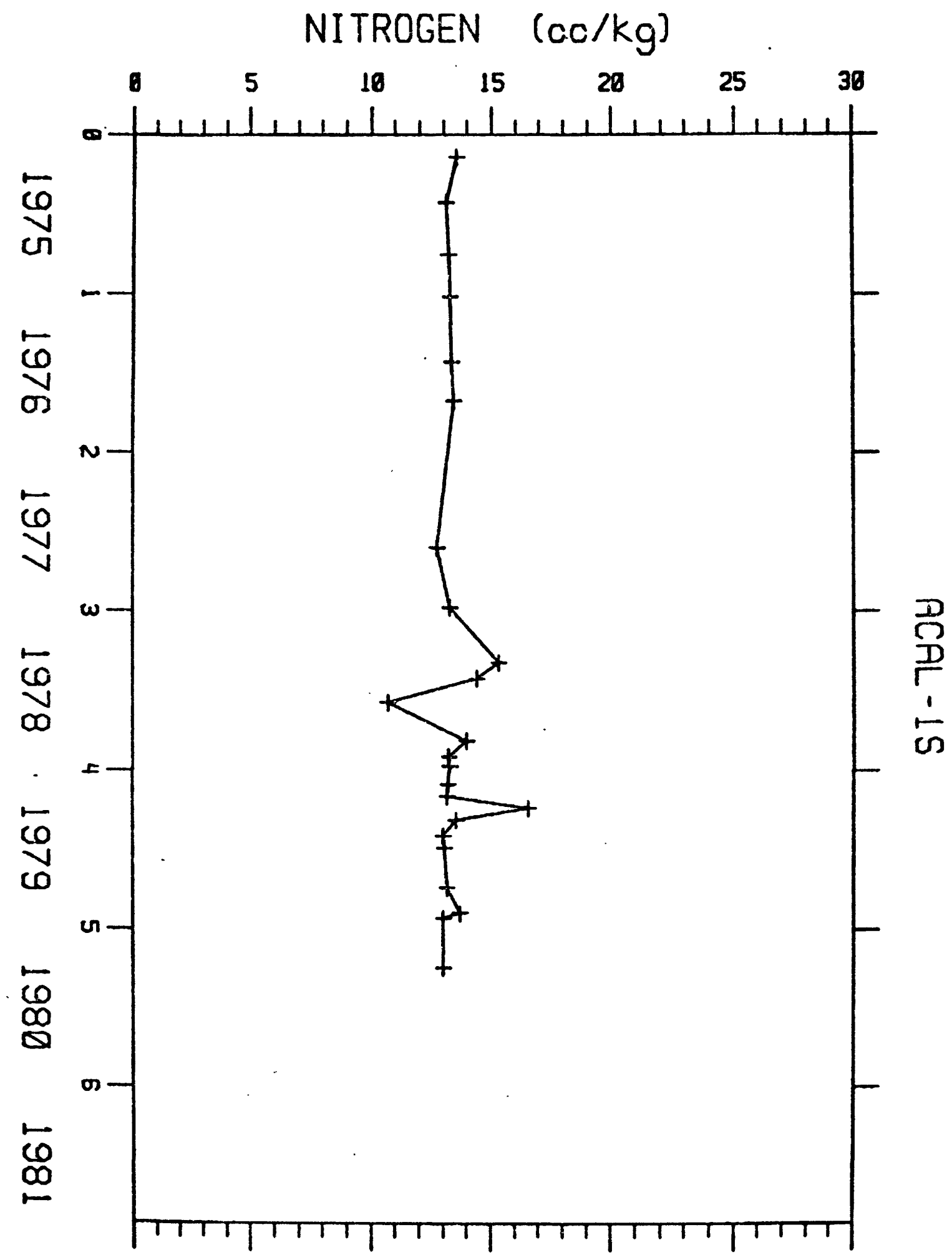




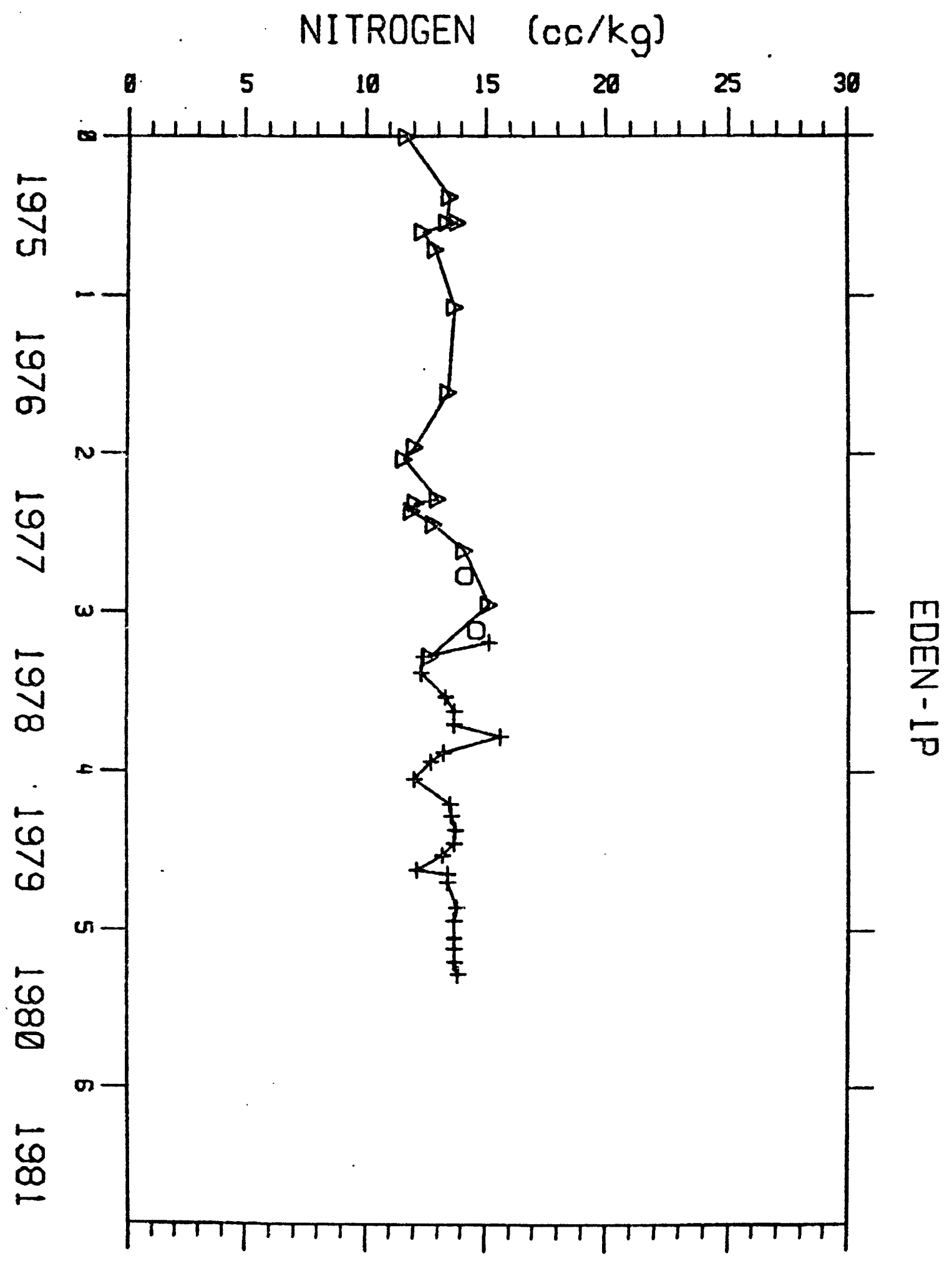




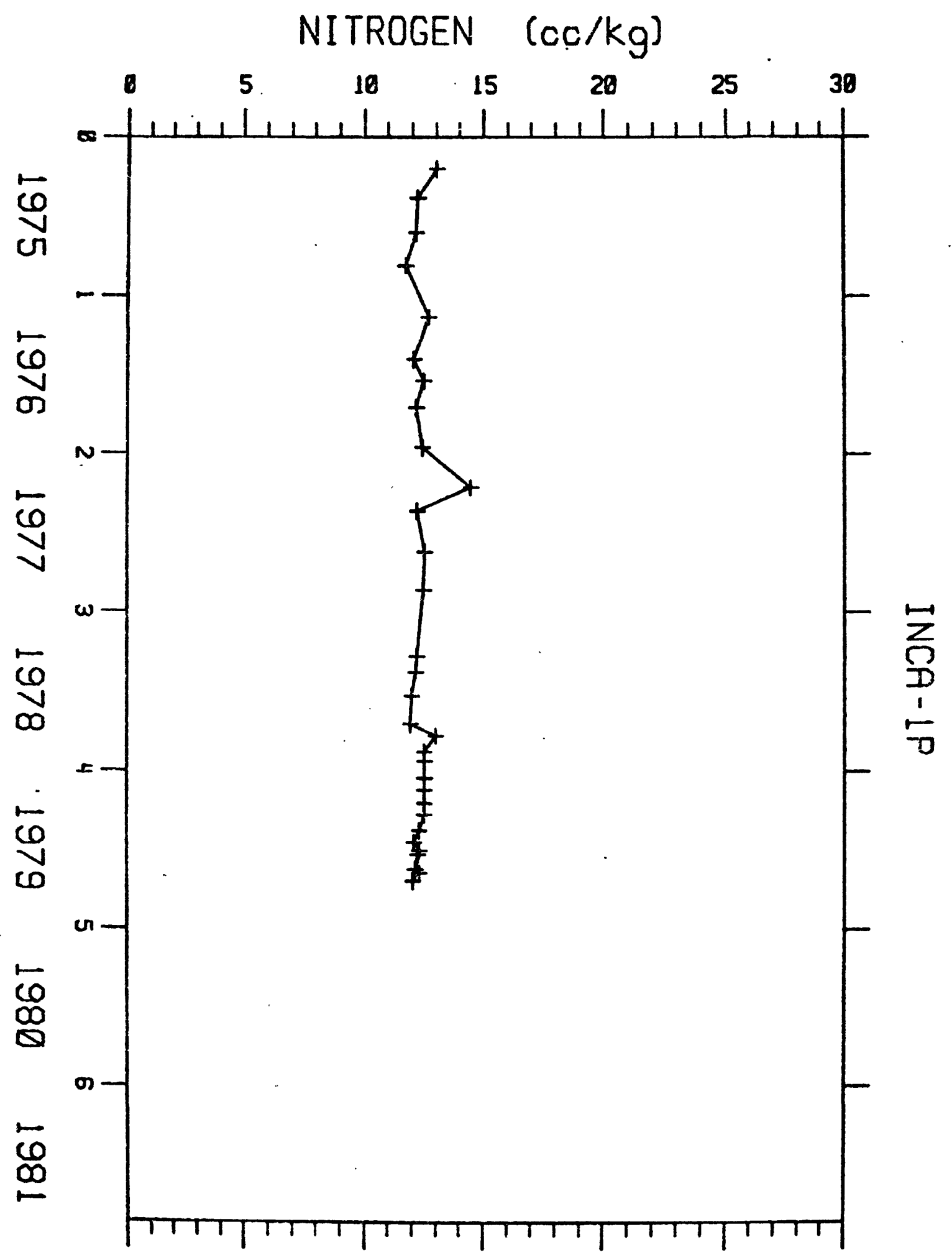




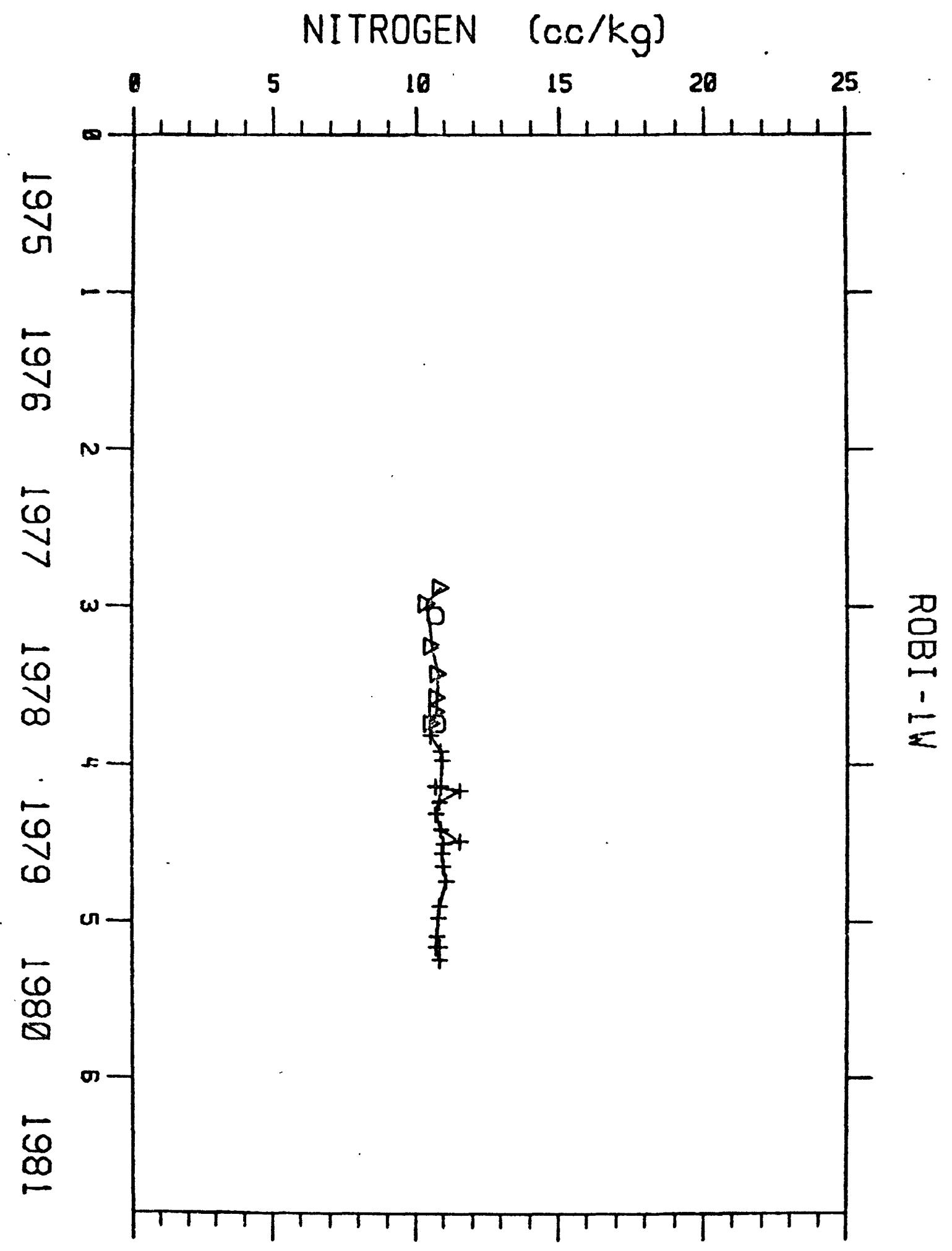




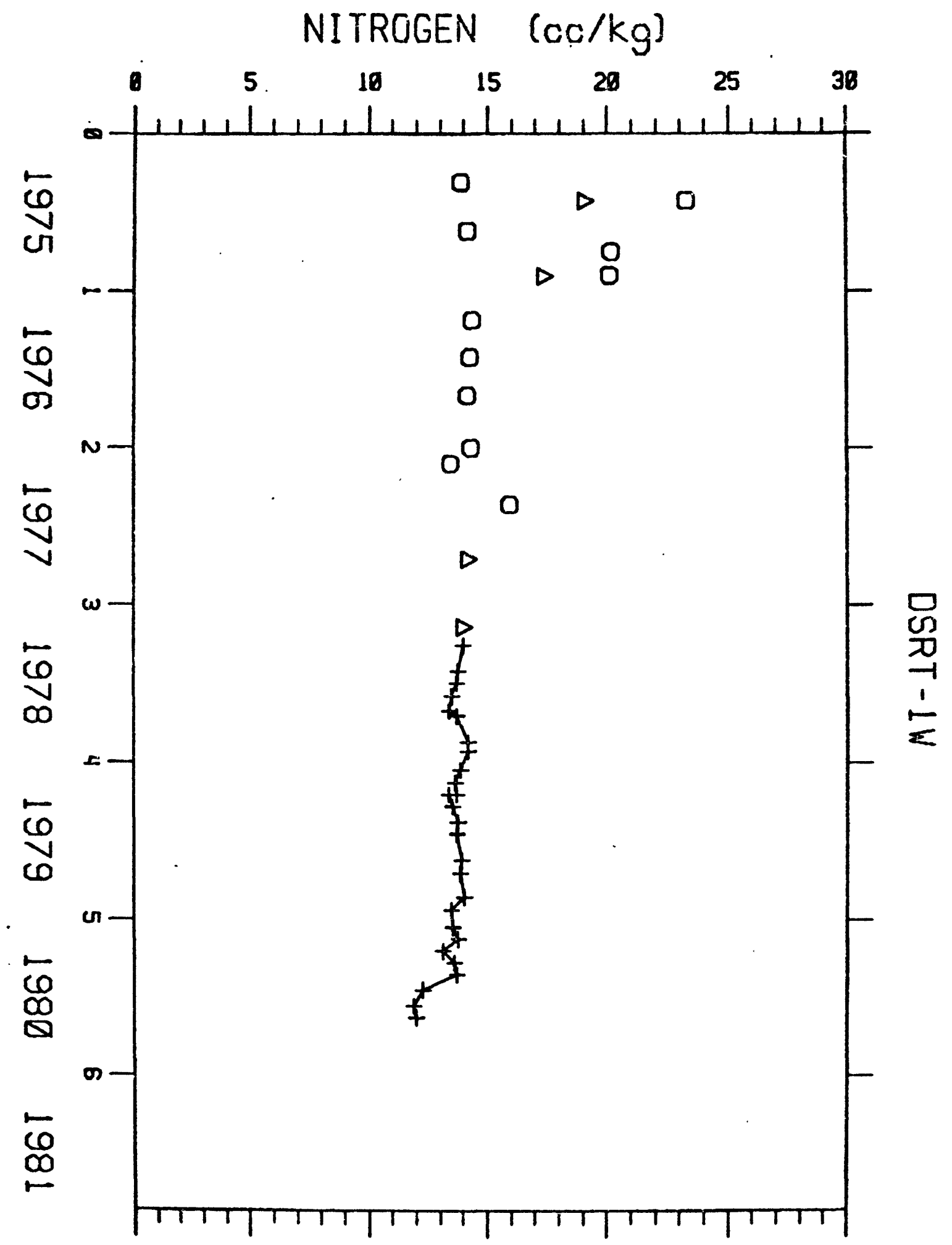




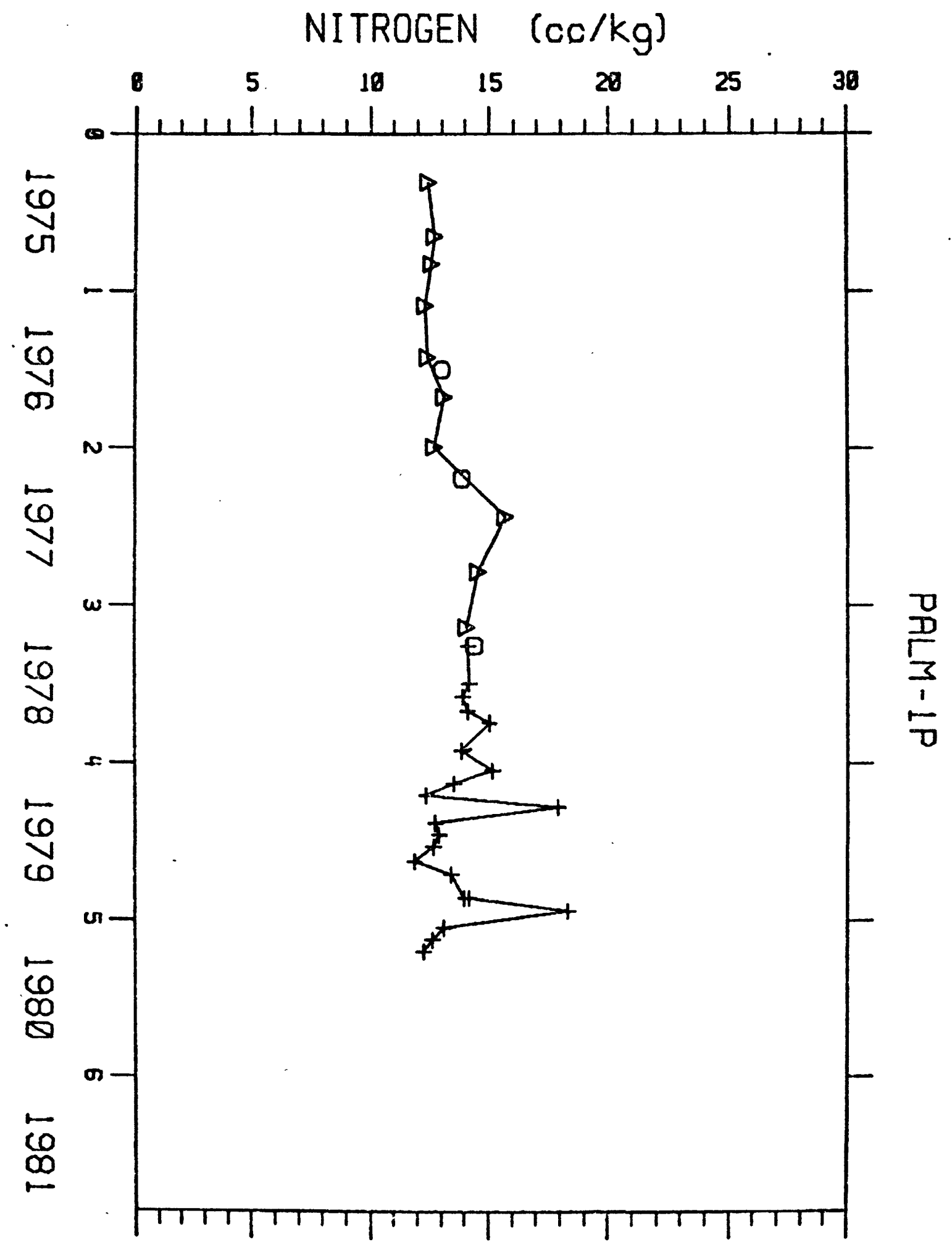




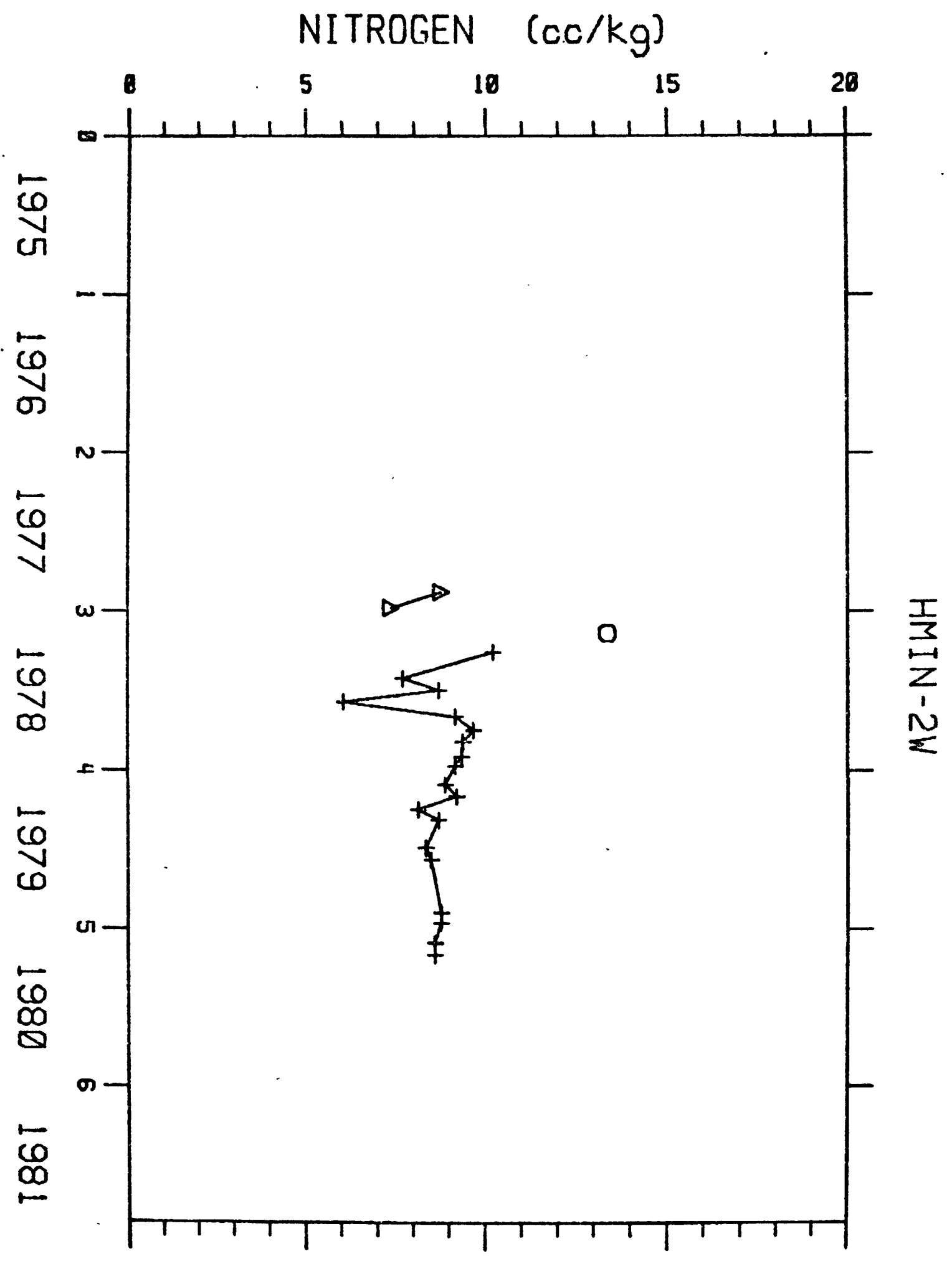




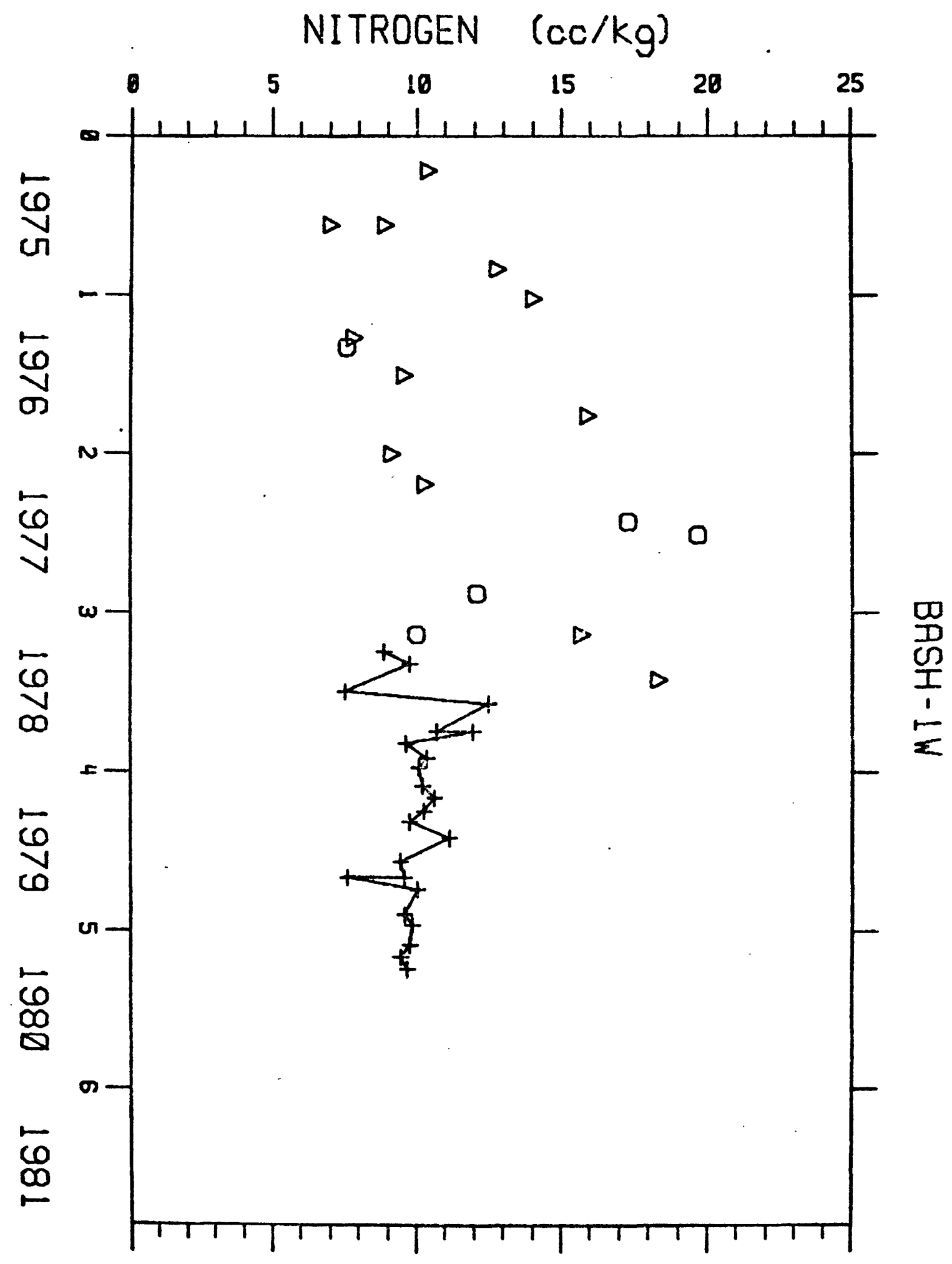




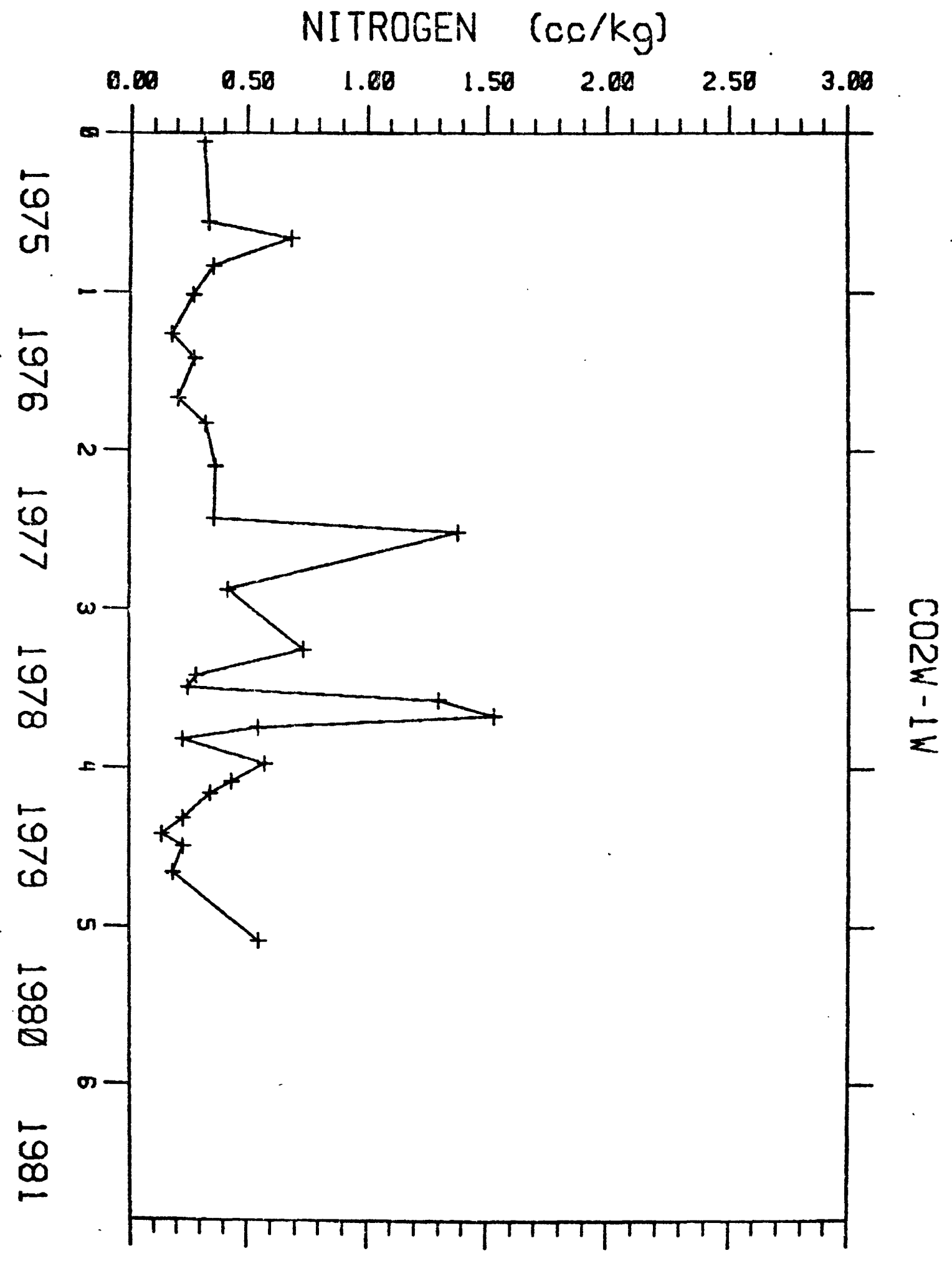




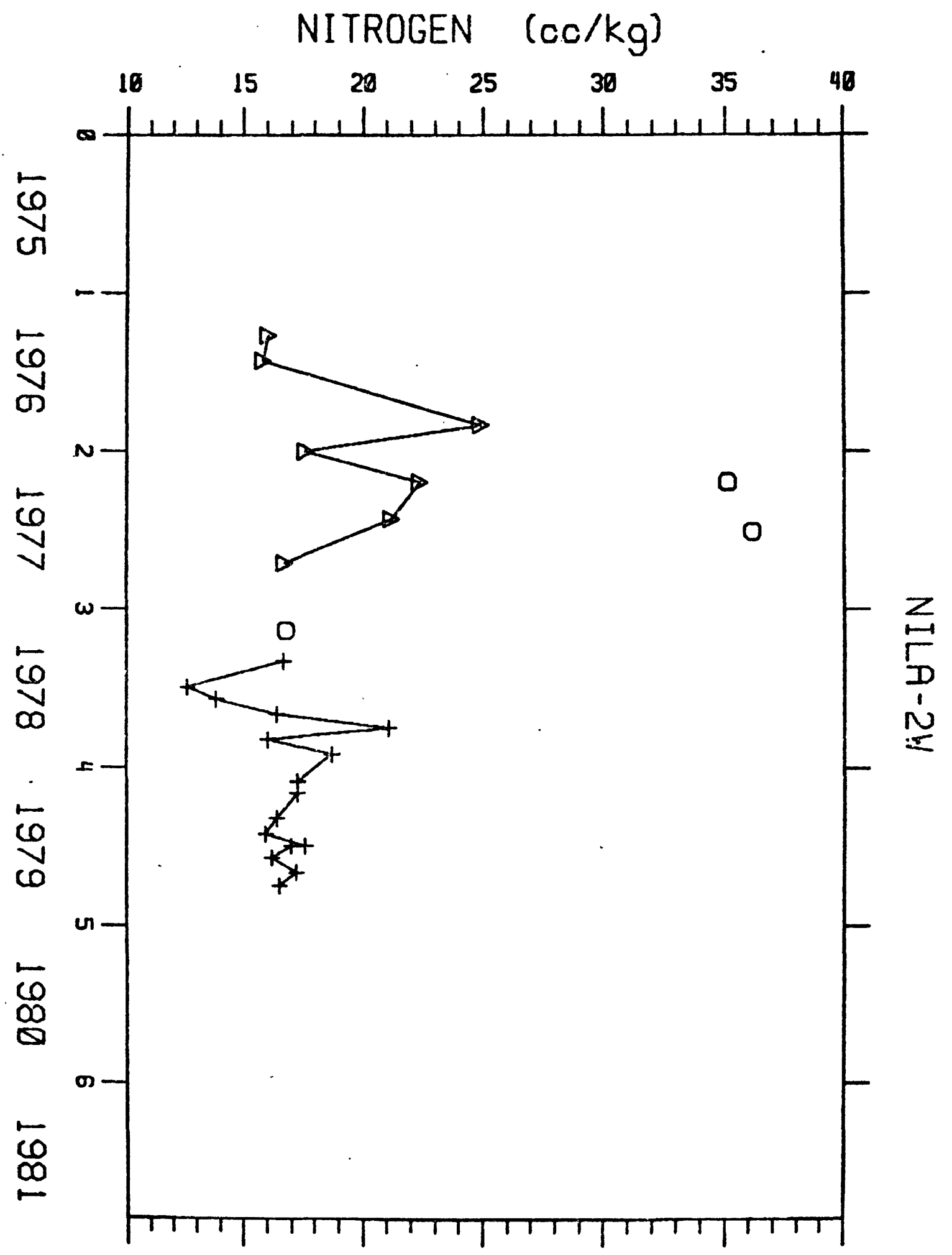


APPENDIX 4

METHANE VARIATIONS VS. TIME 
METHANE $(\mathrm{cc} / \mathrm{kg})$

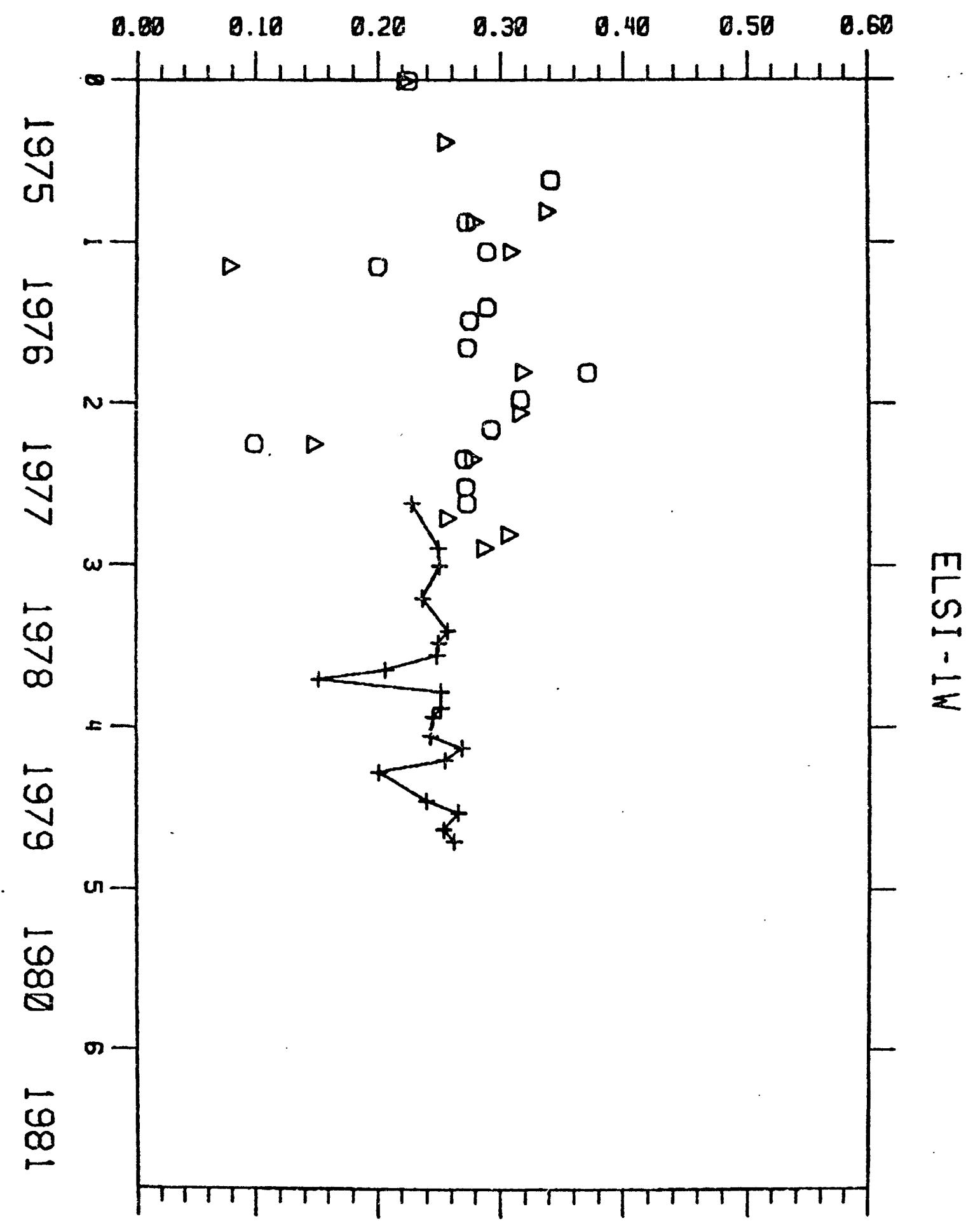




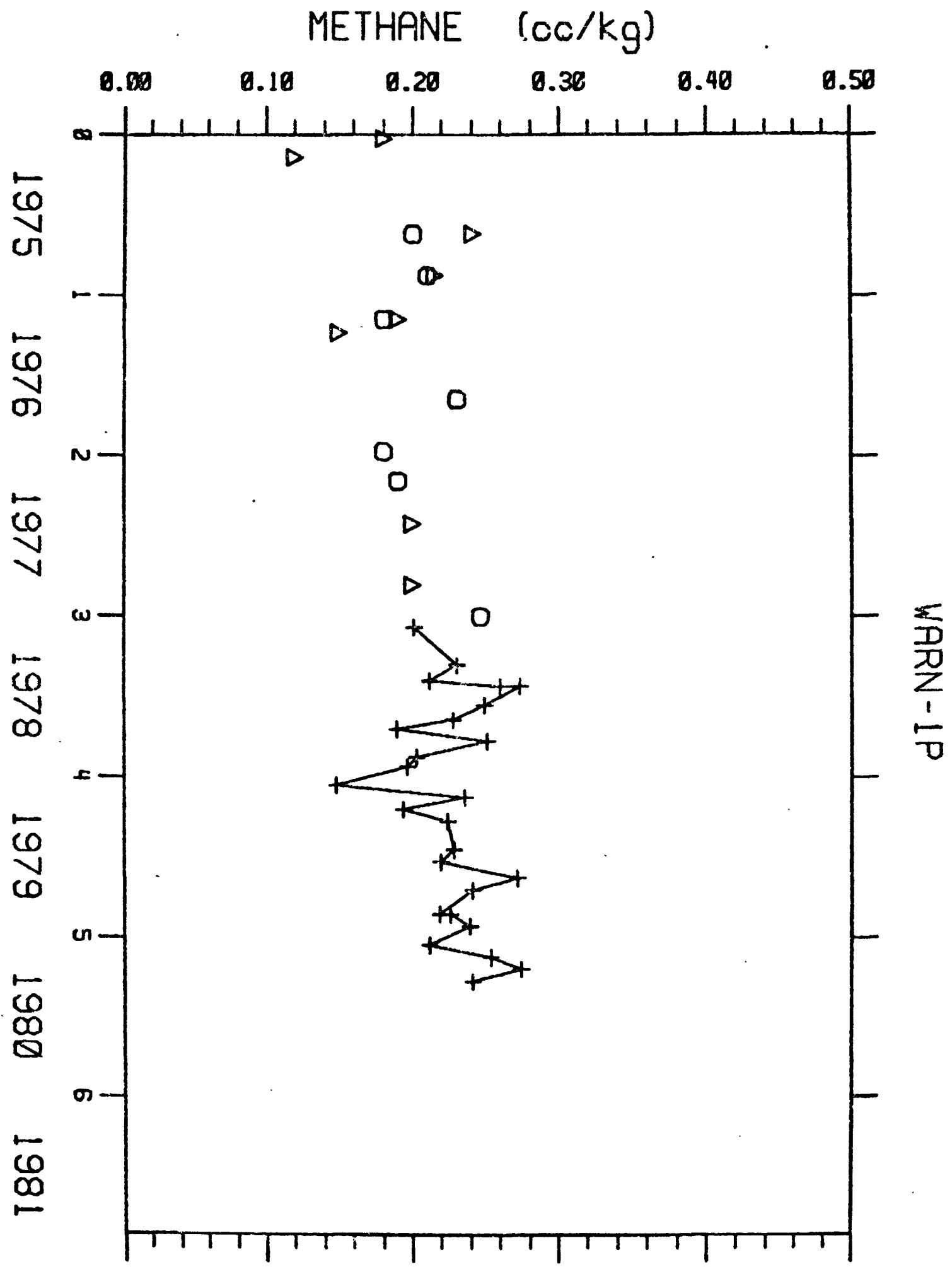




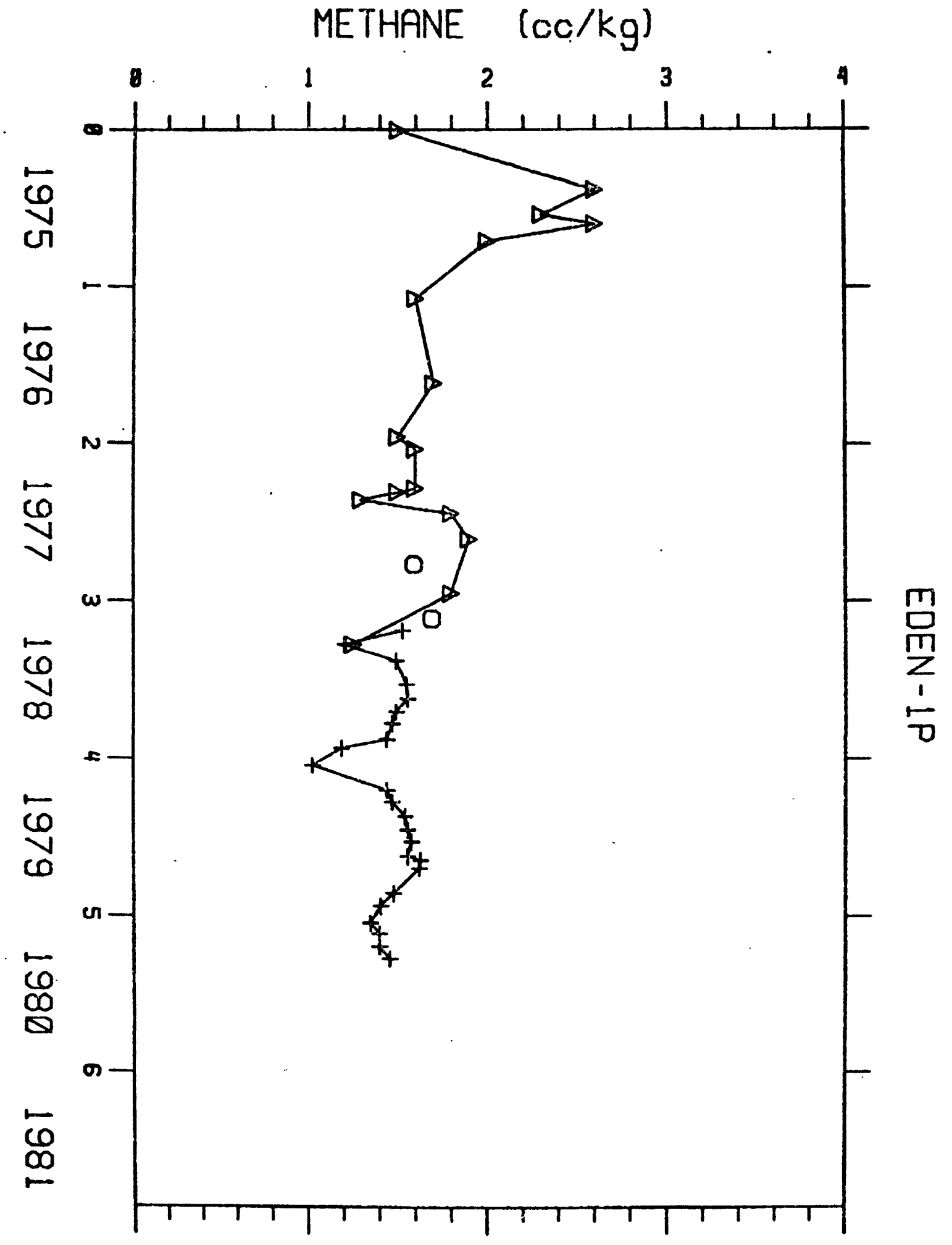




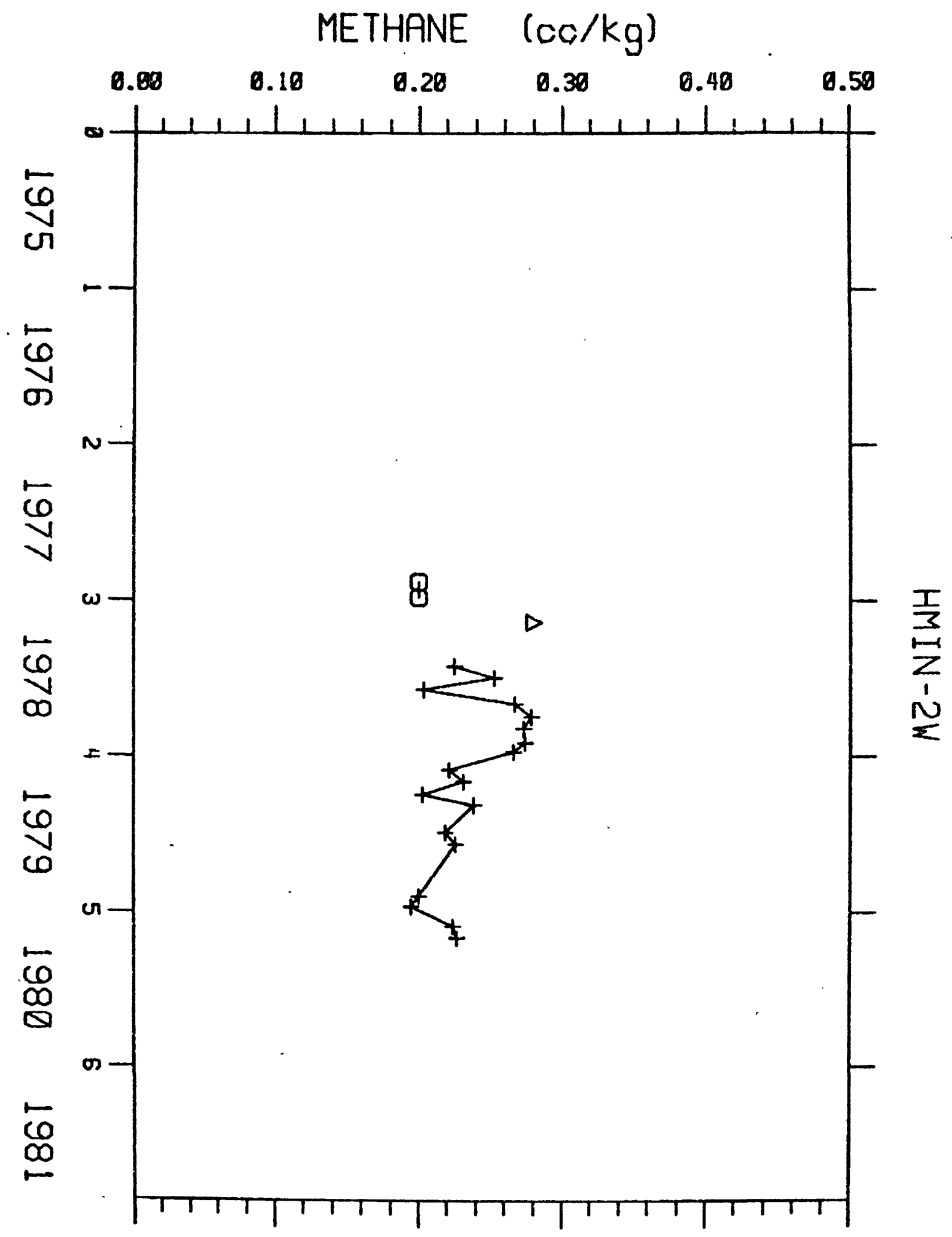




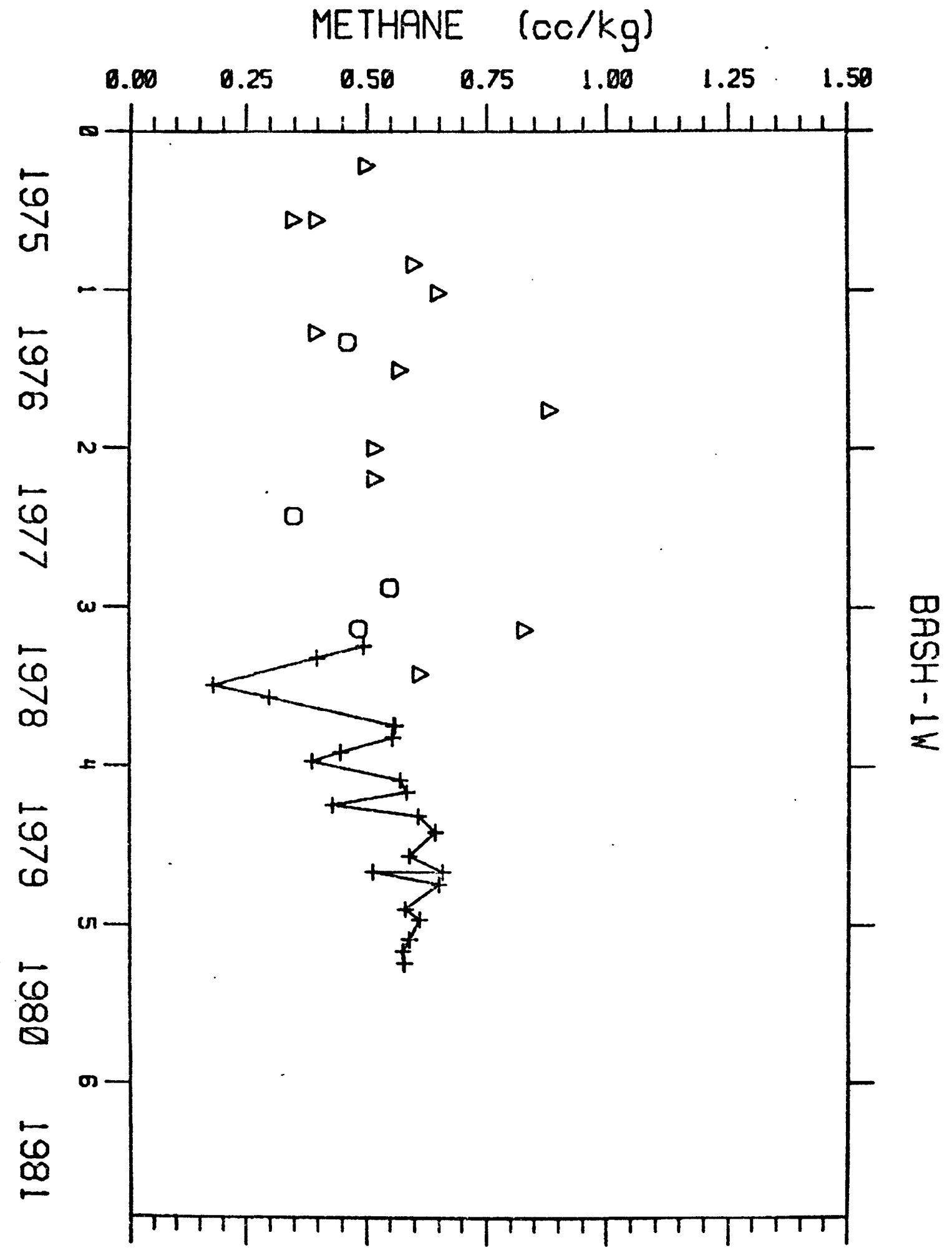




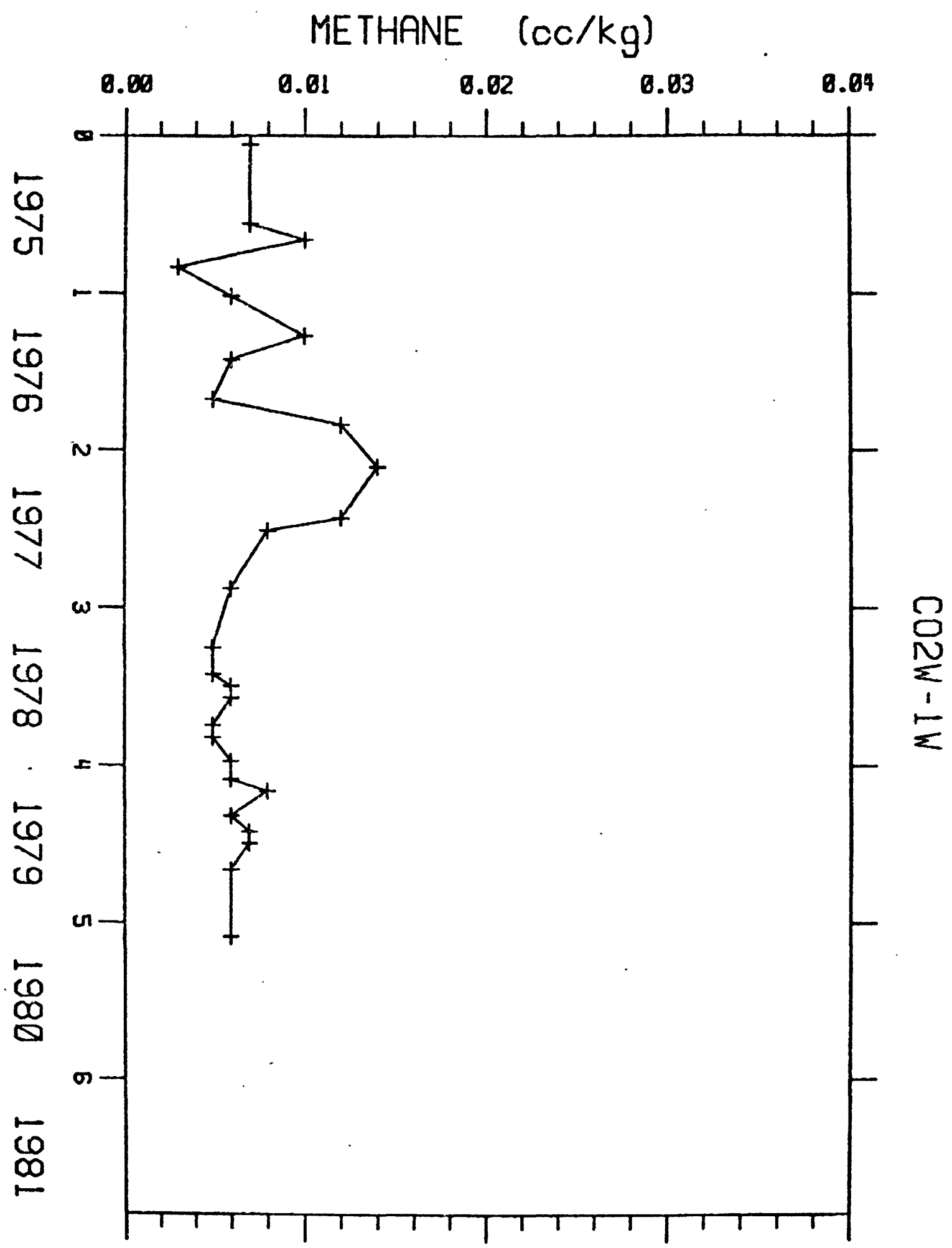




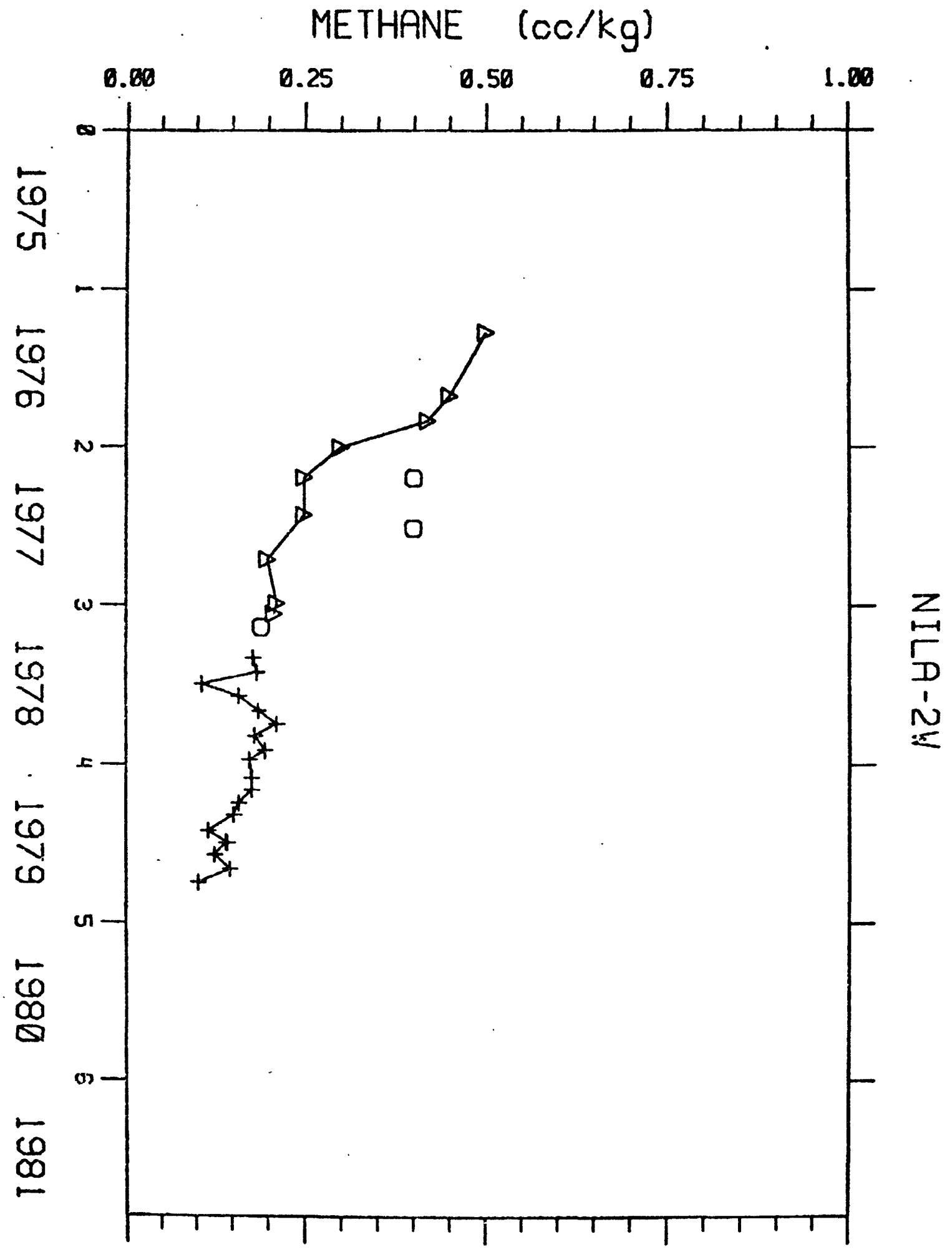




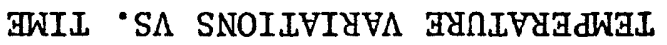

ऽ XIANGddV 


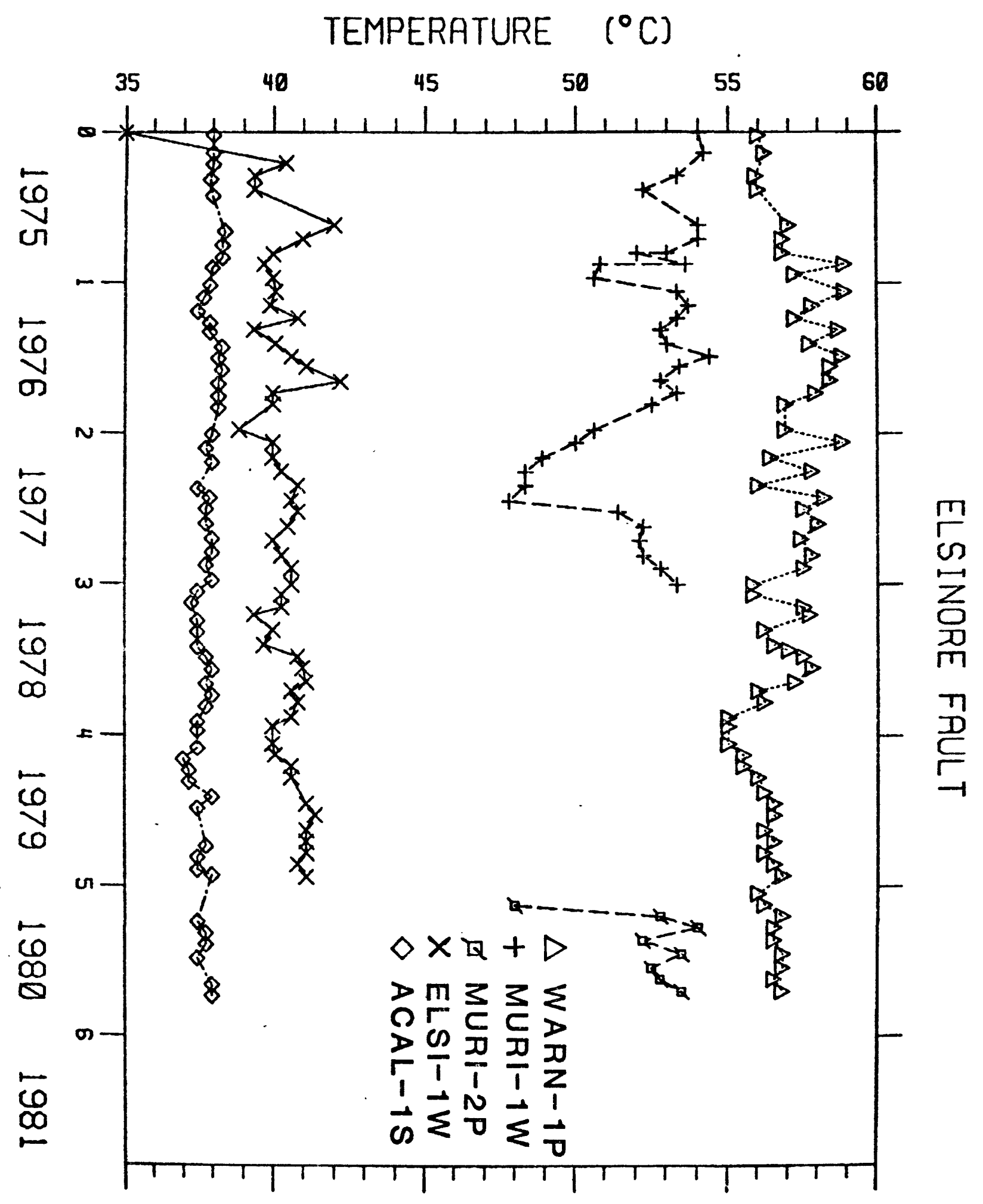




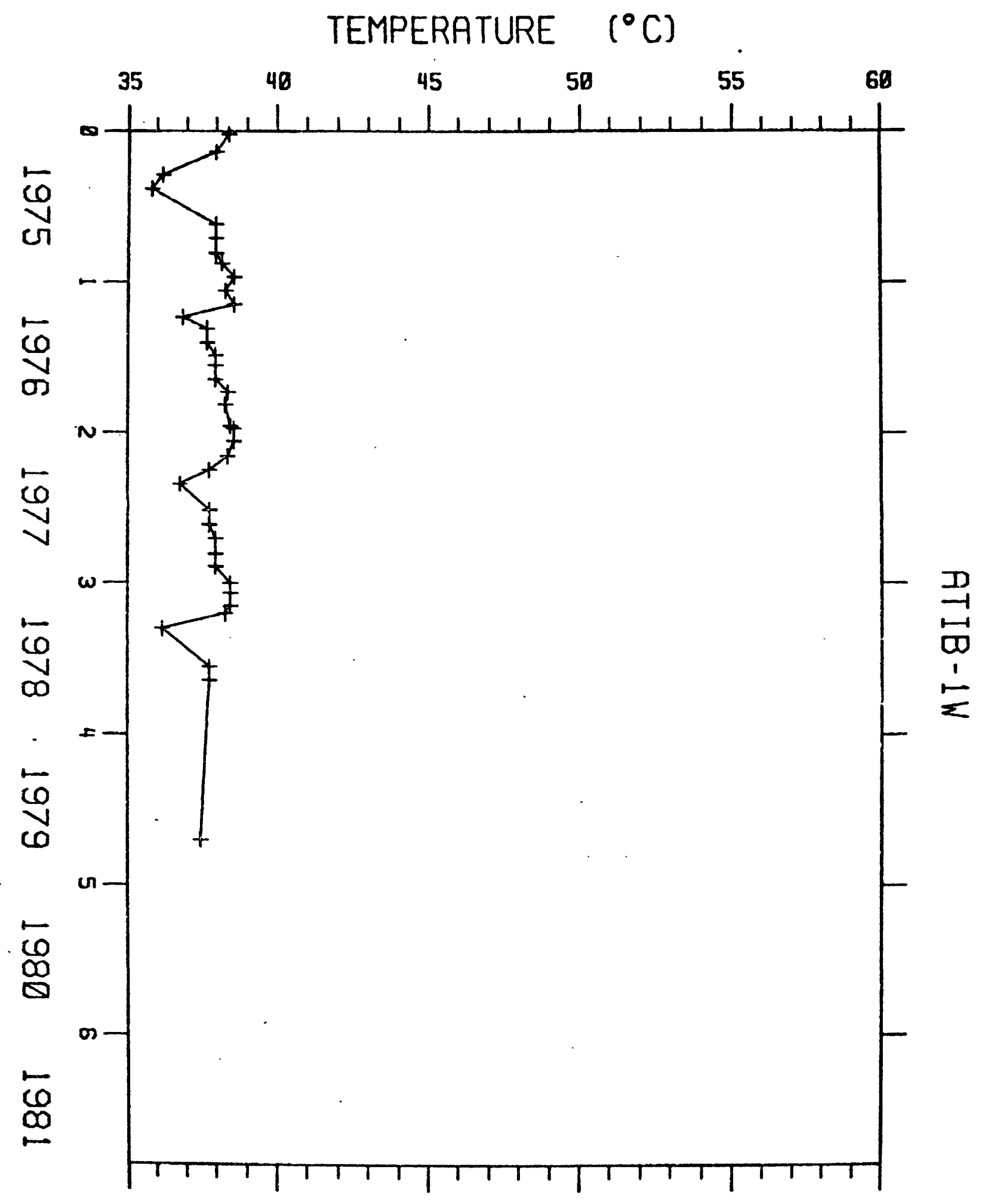




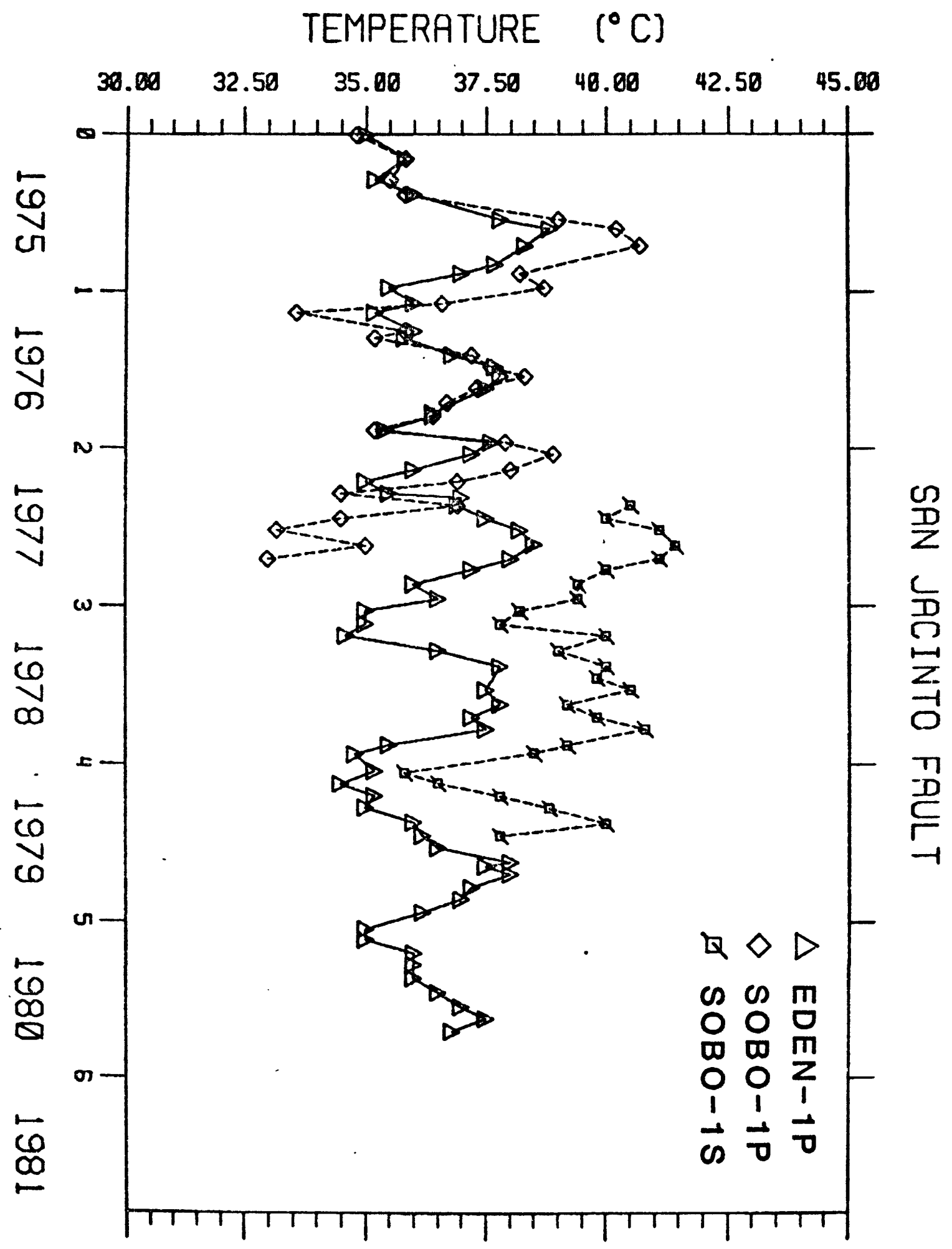




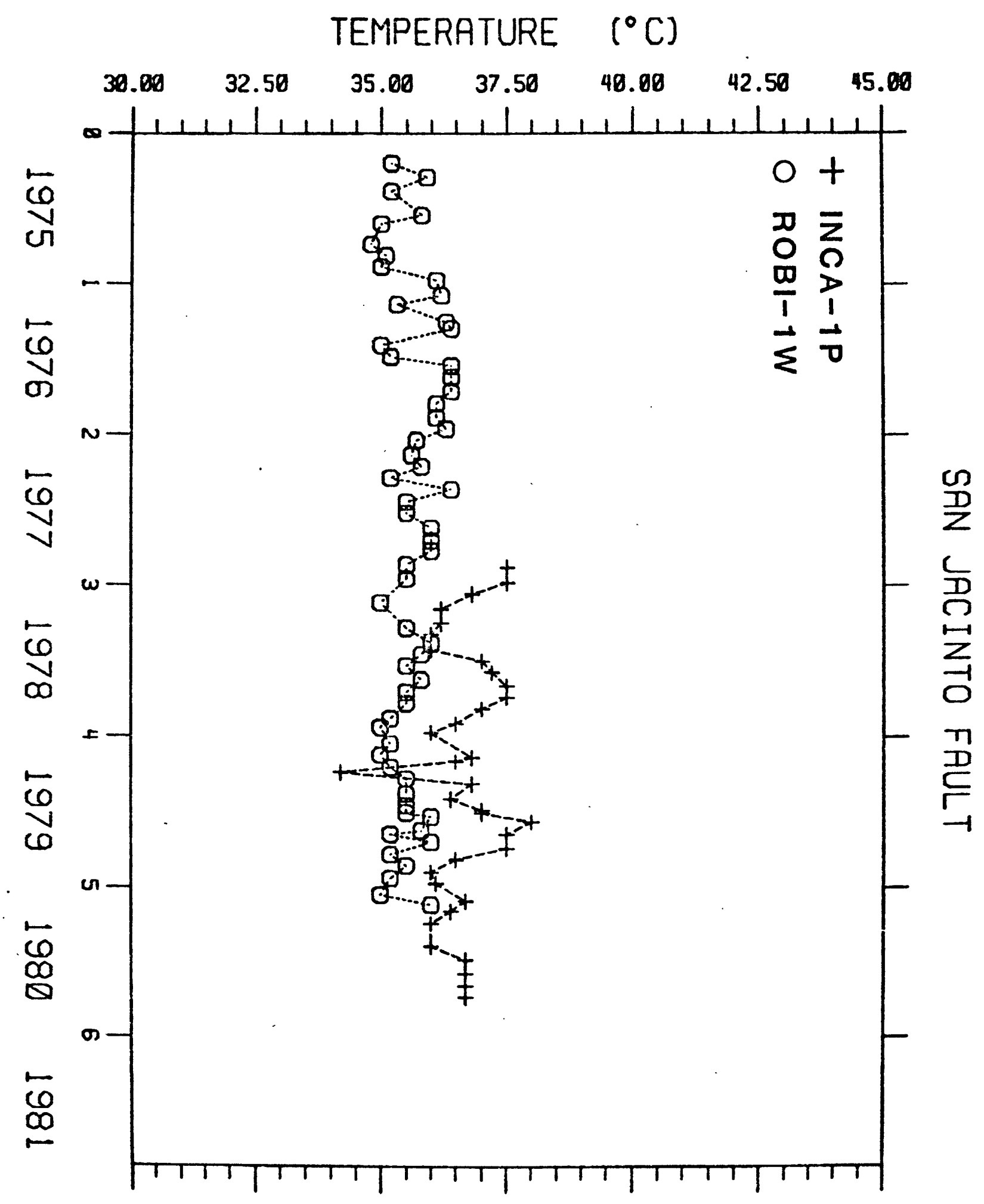




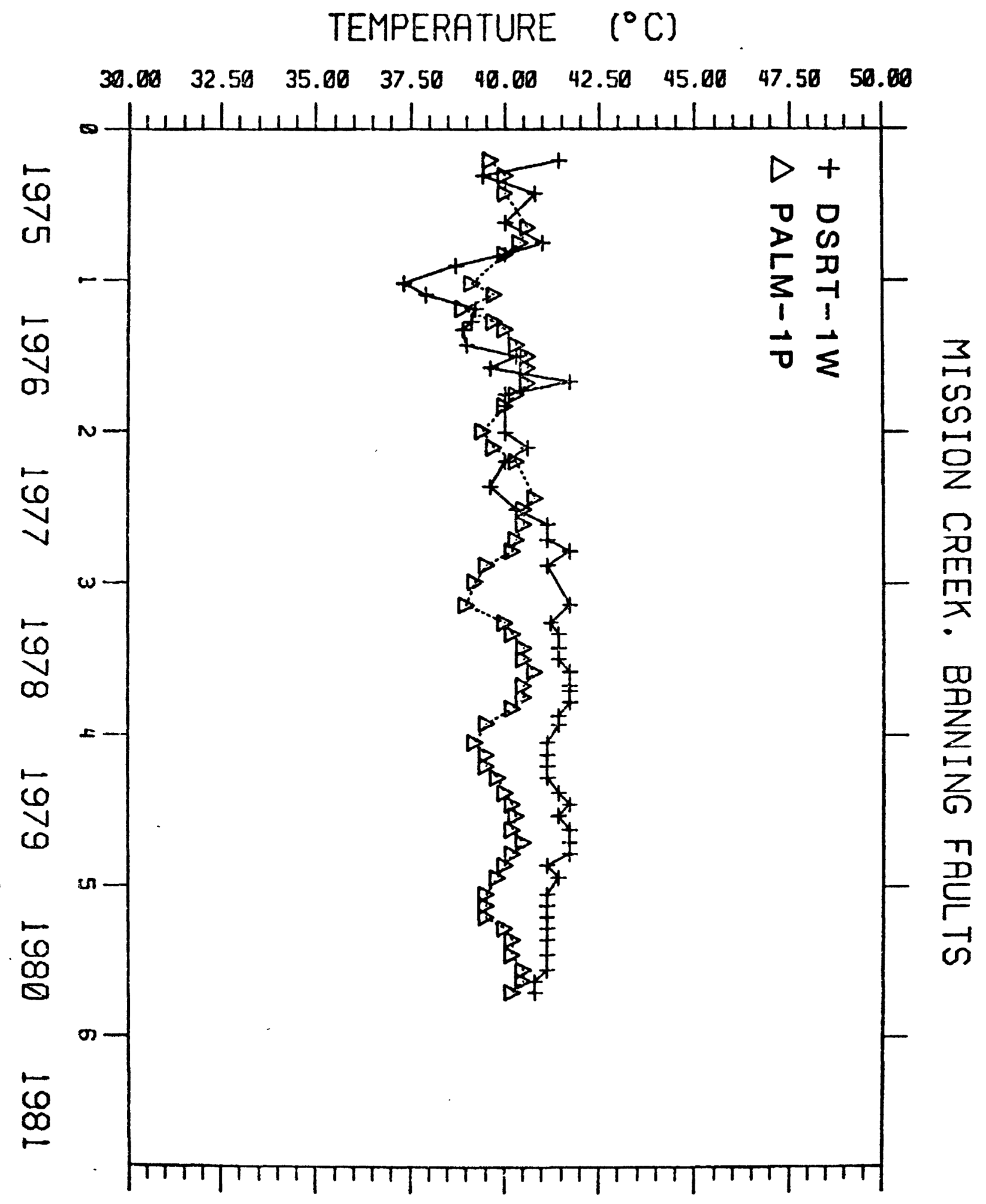




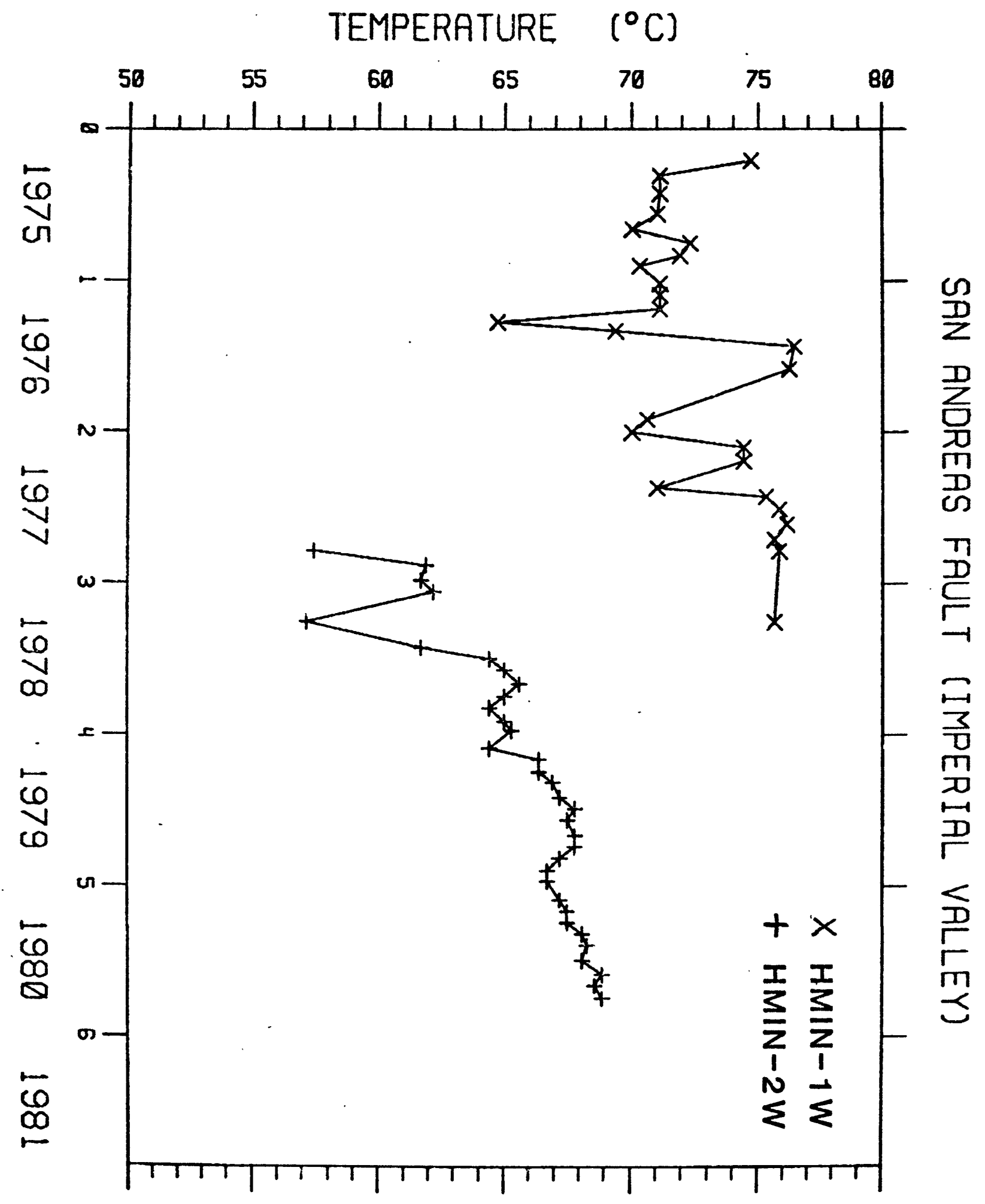




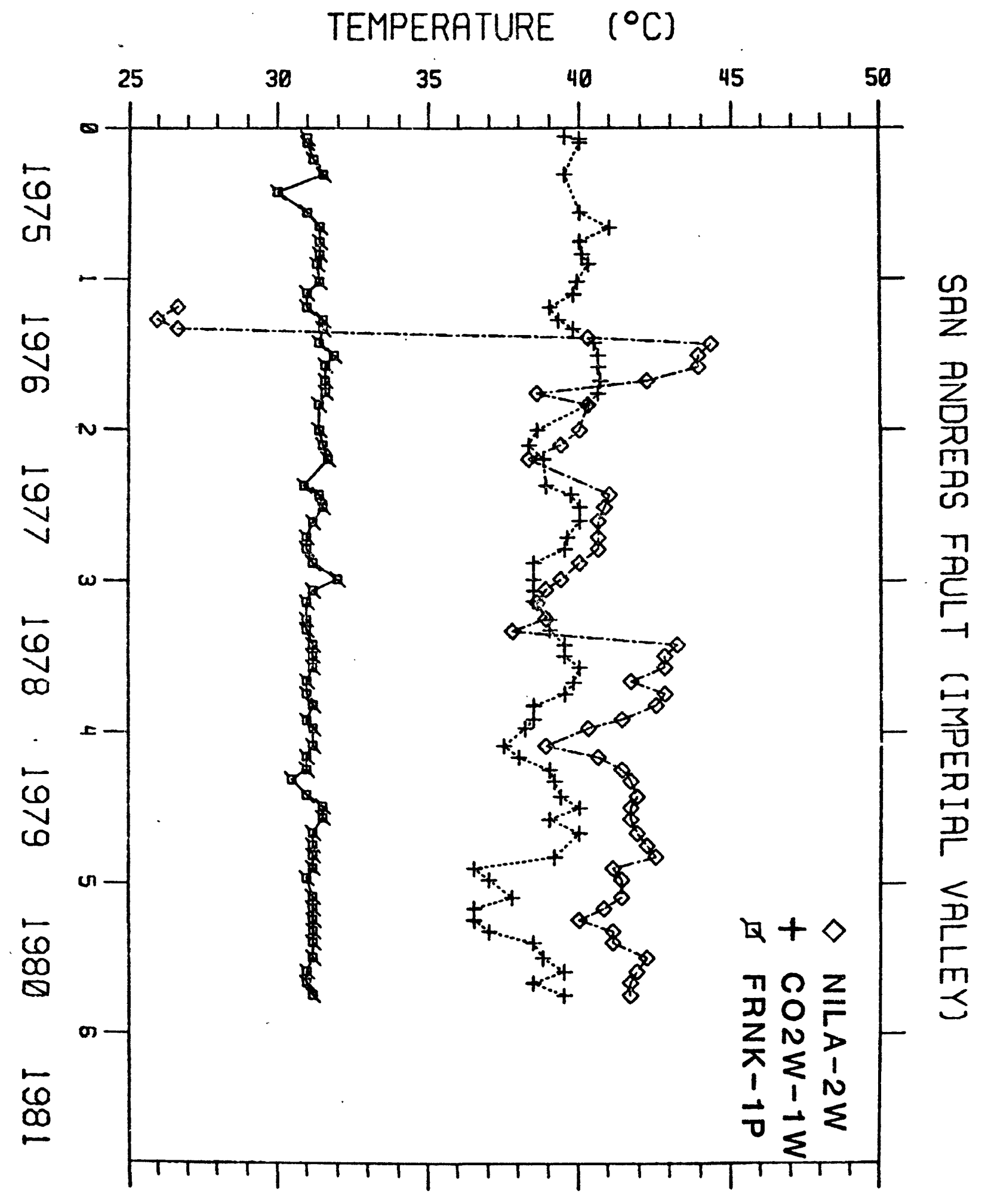


JWIL •SA SNOILVIYVA XIIAIIJOANOO

9 XIबNGddV 


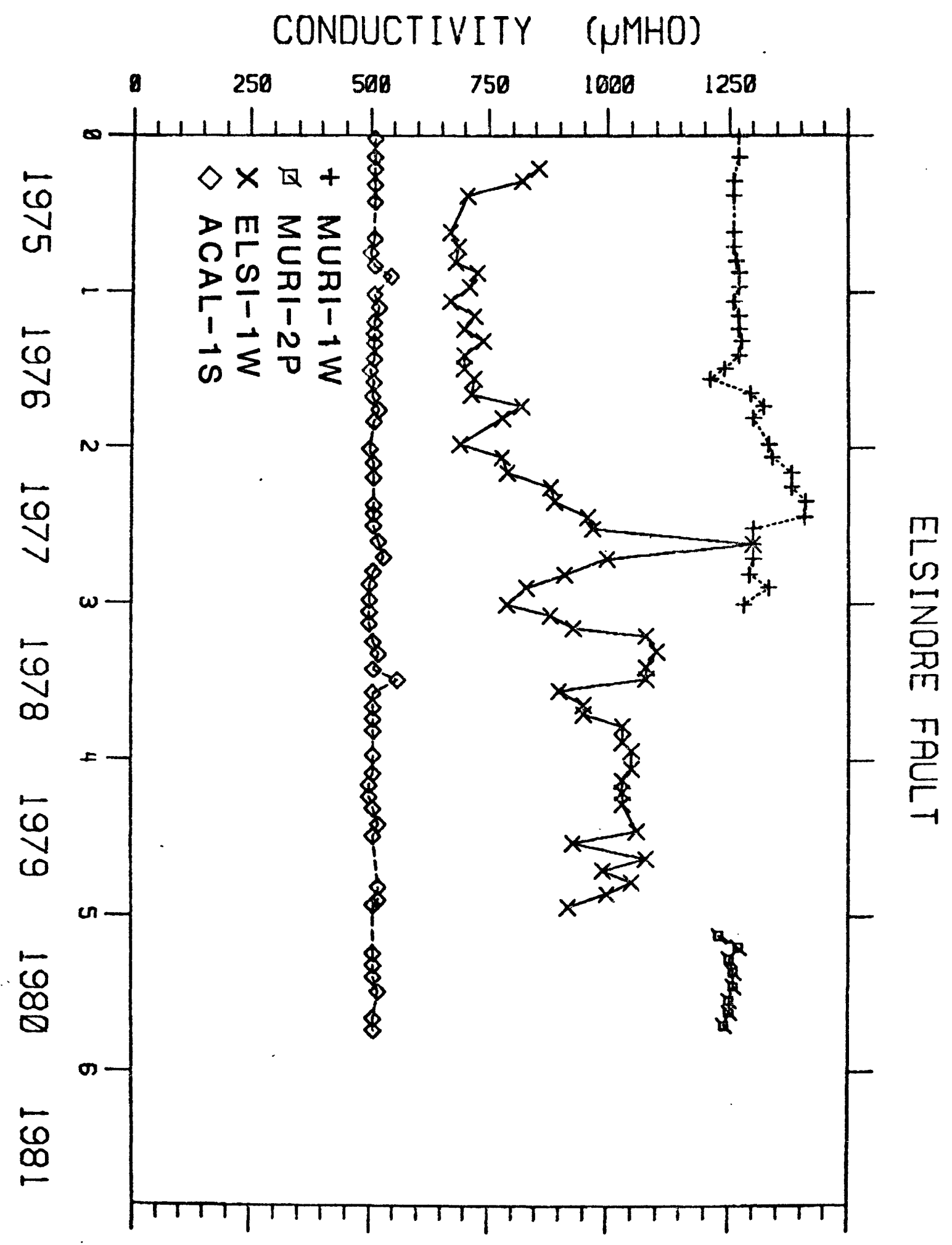




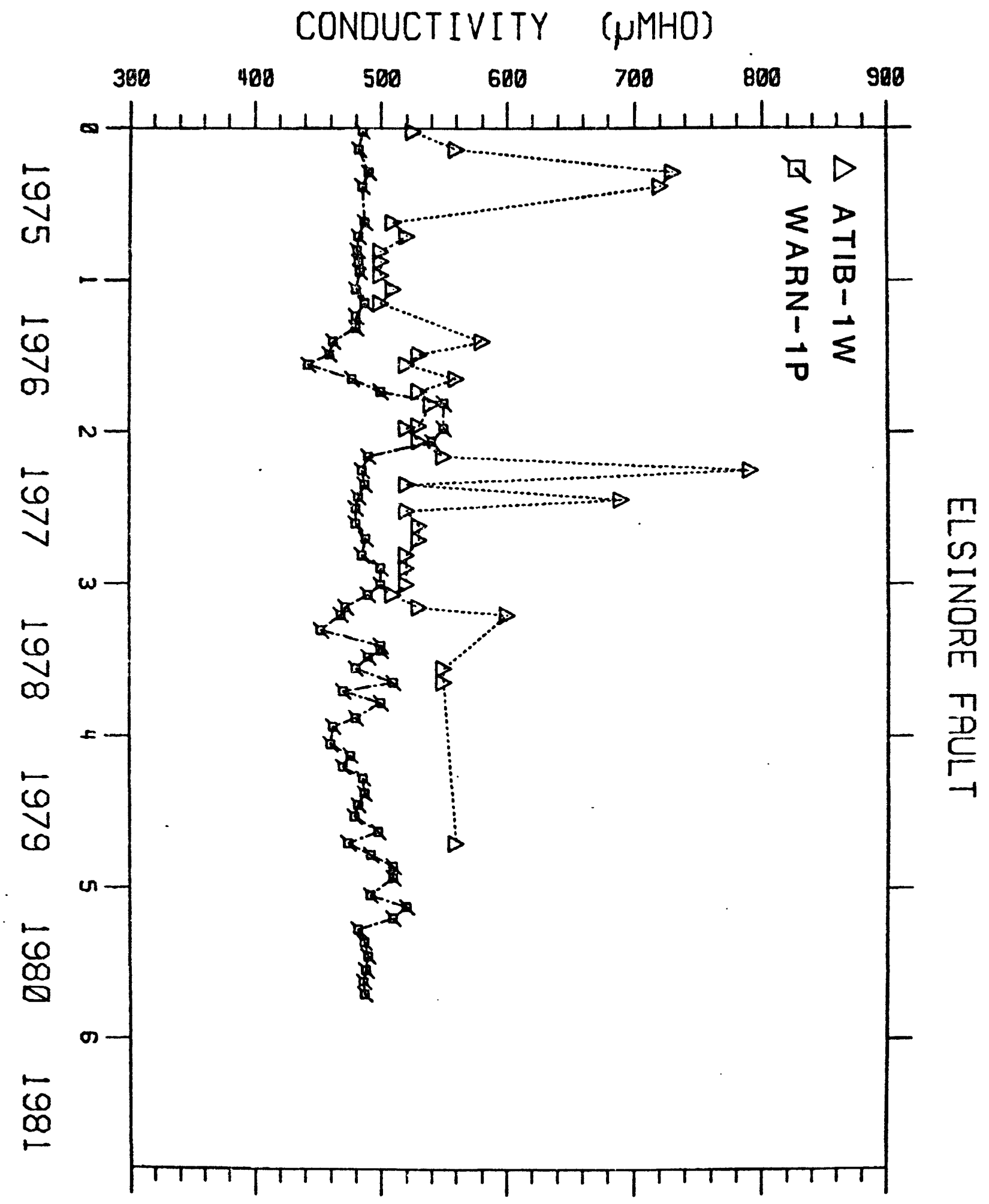




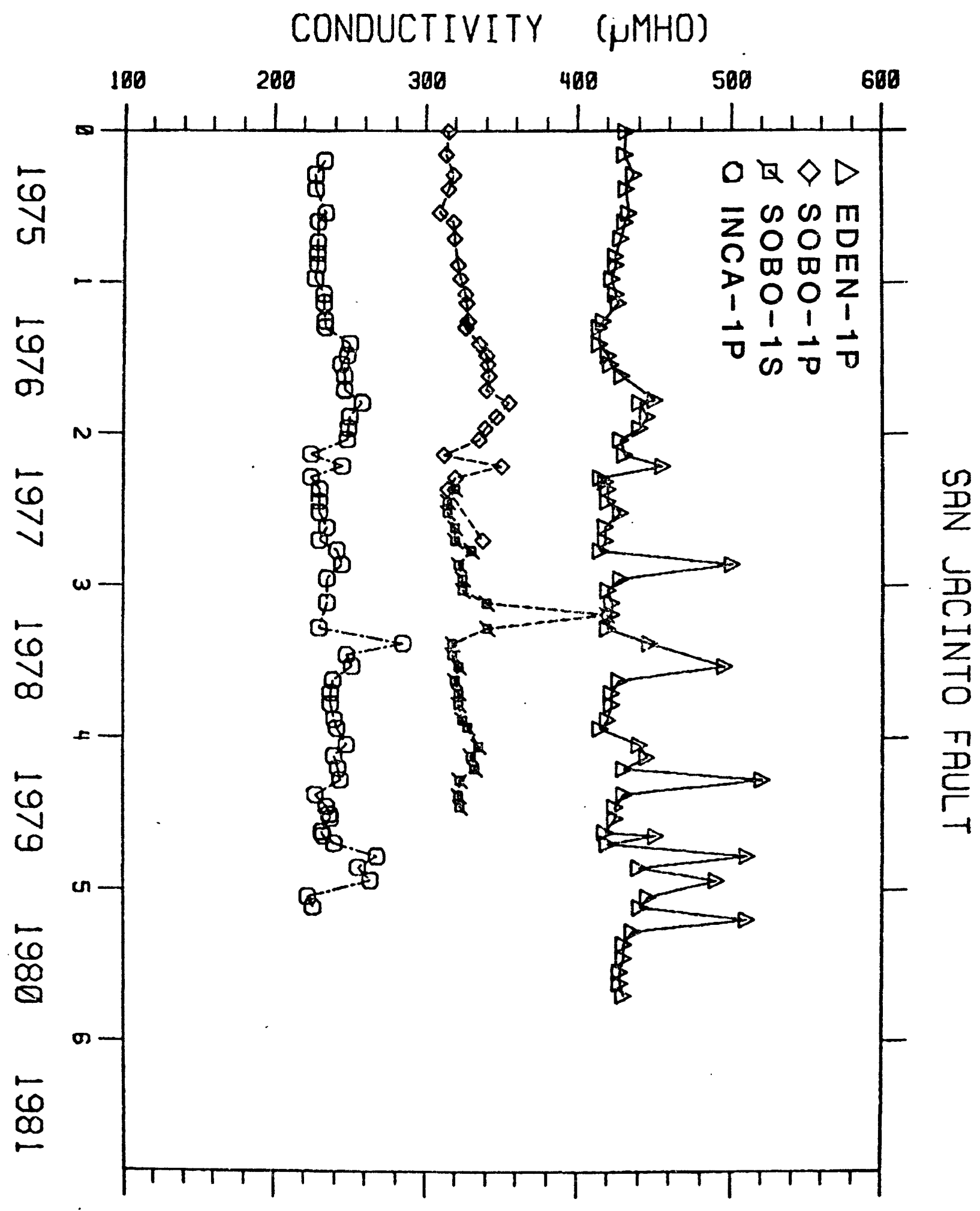




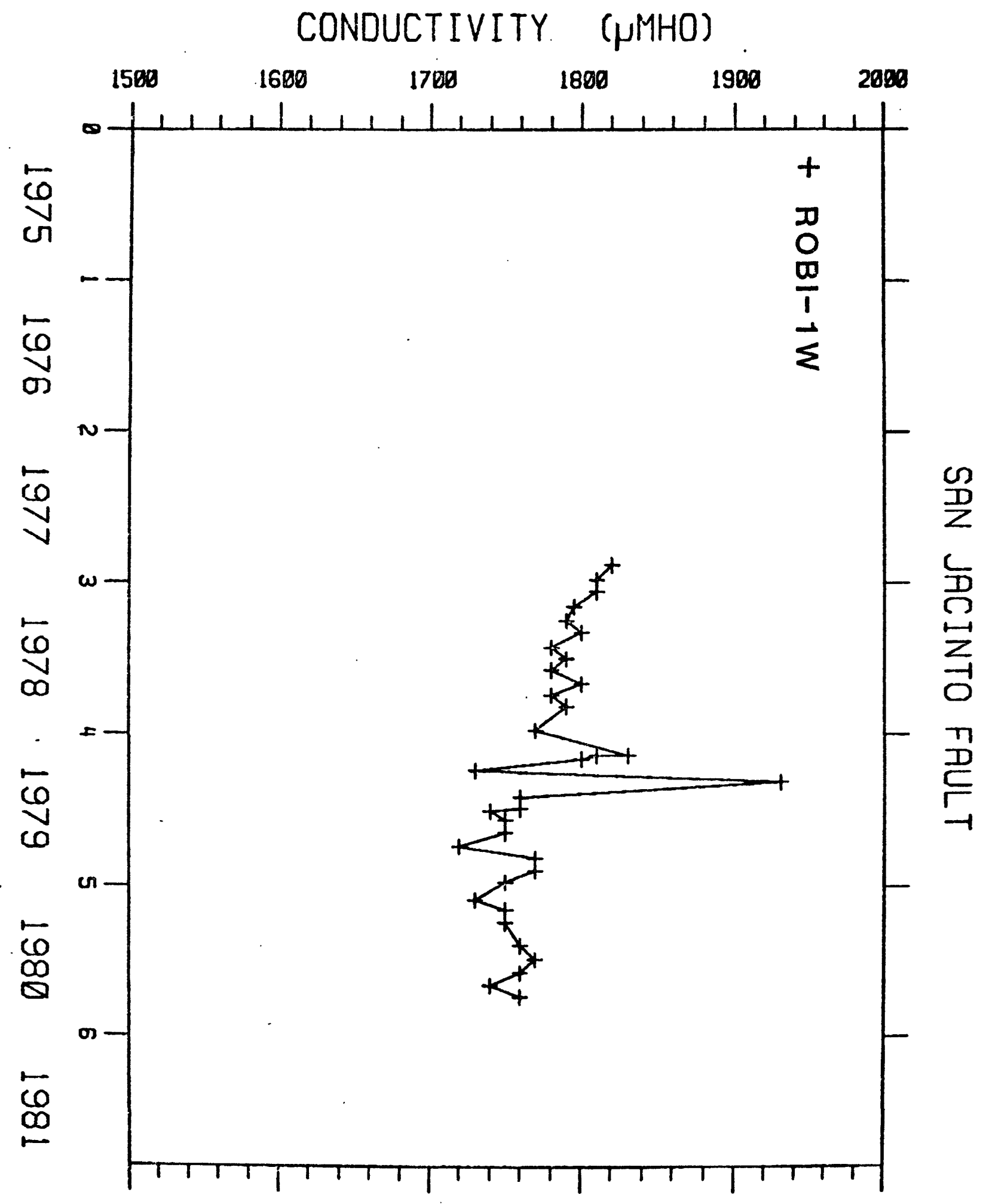




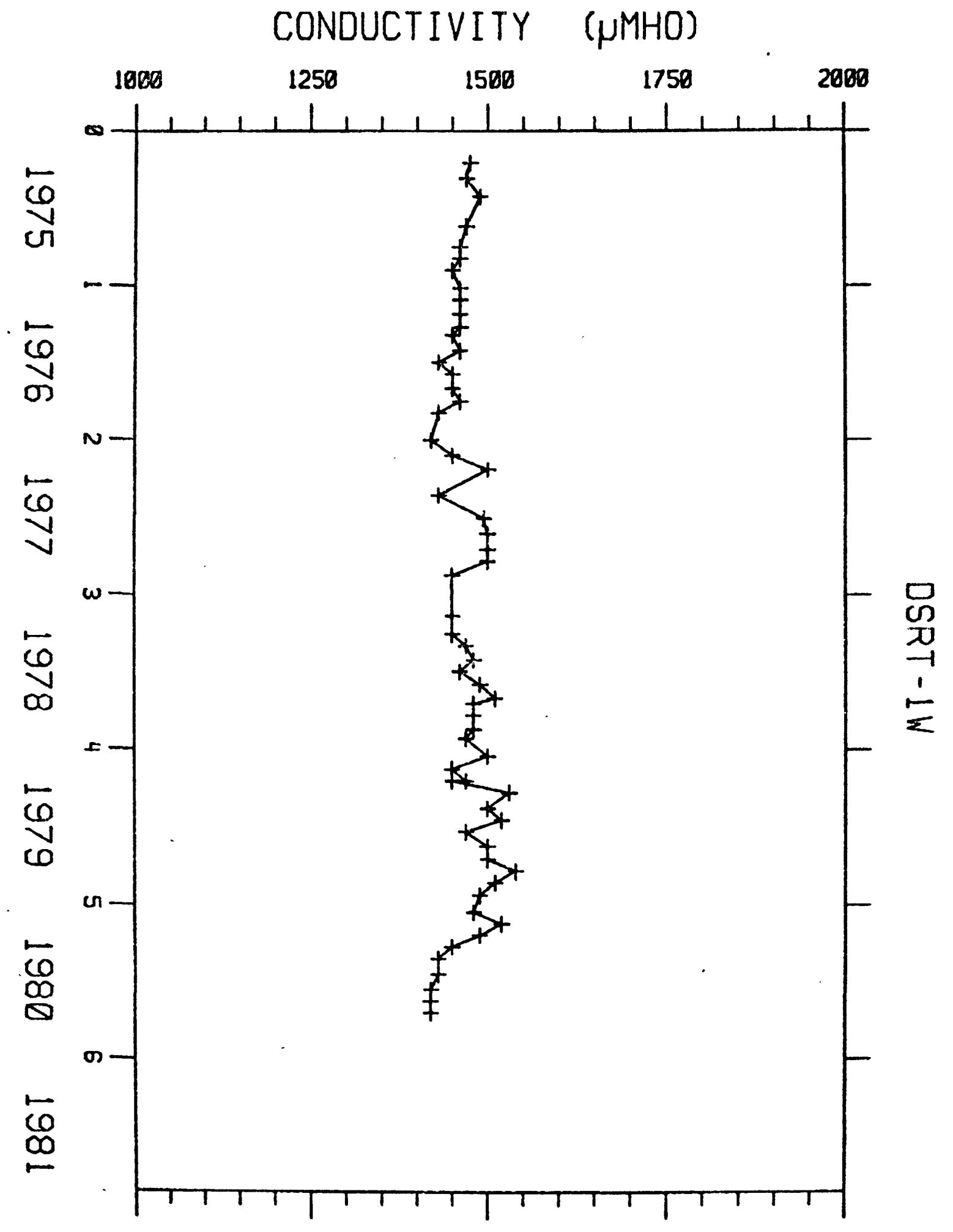




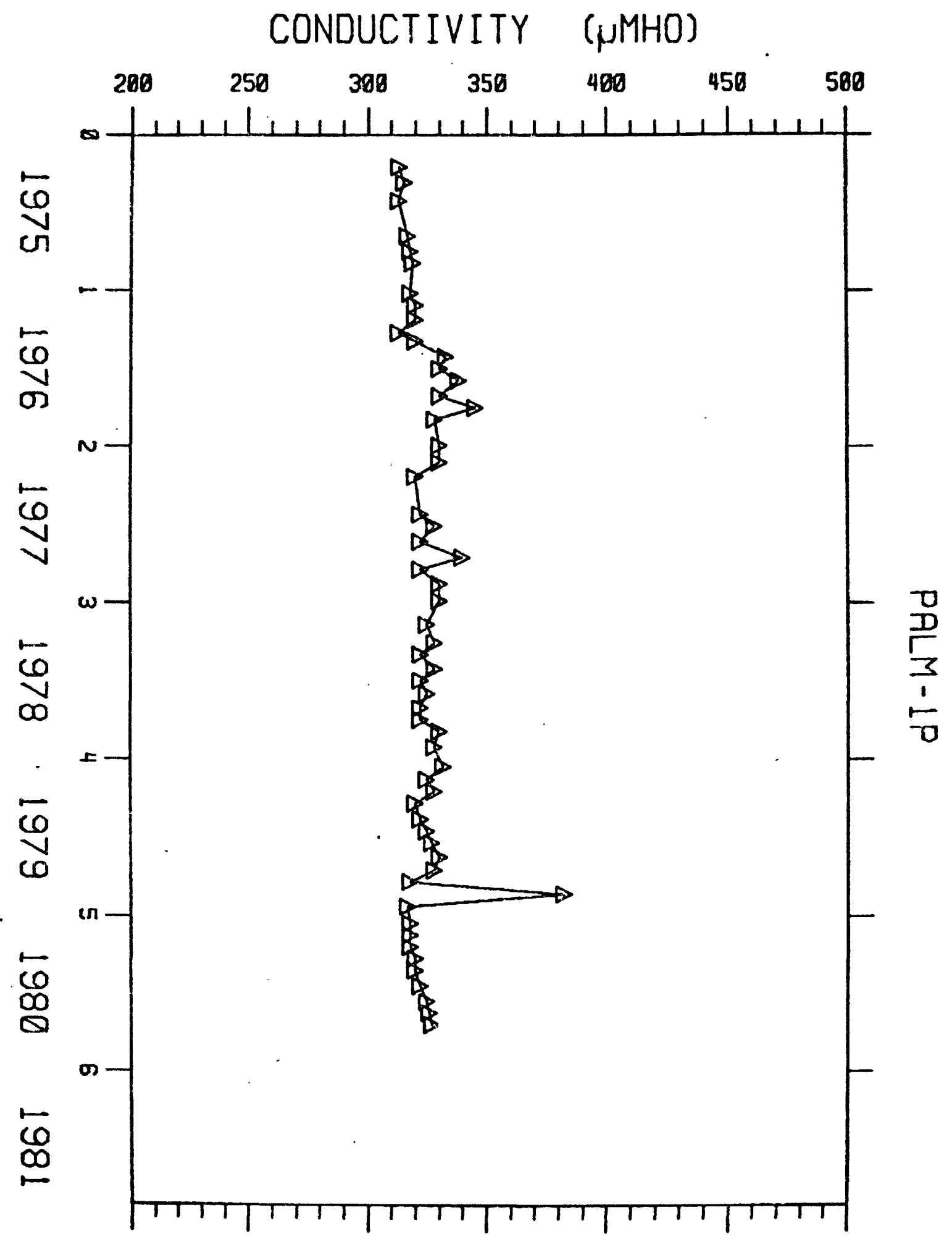




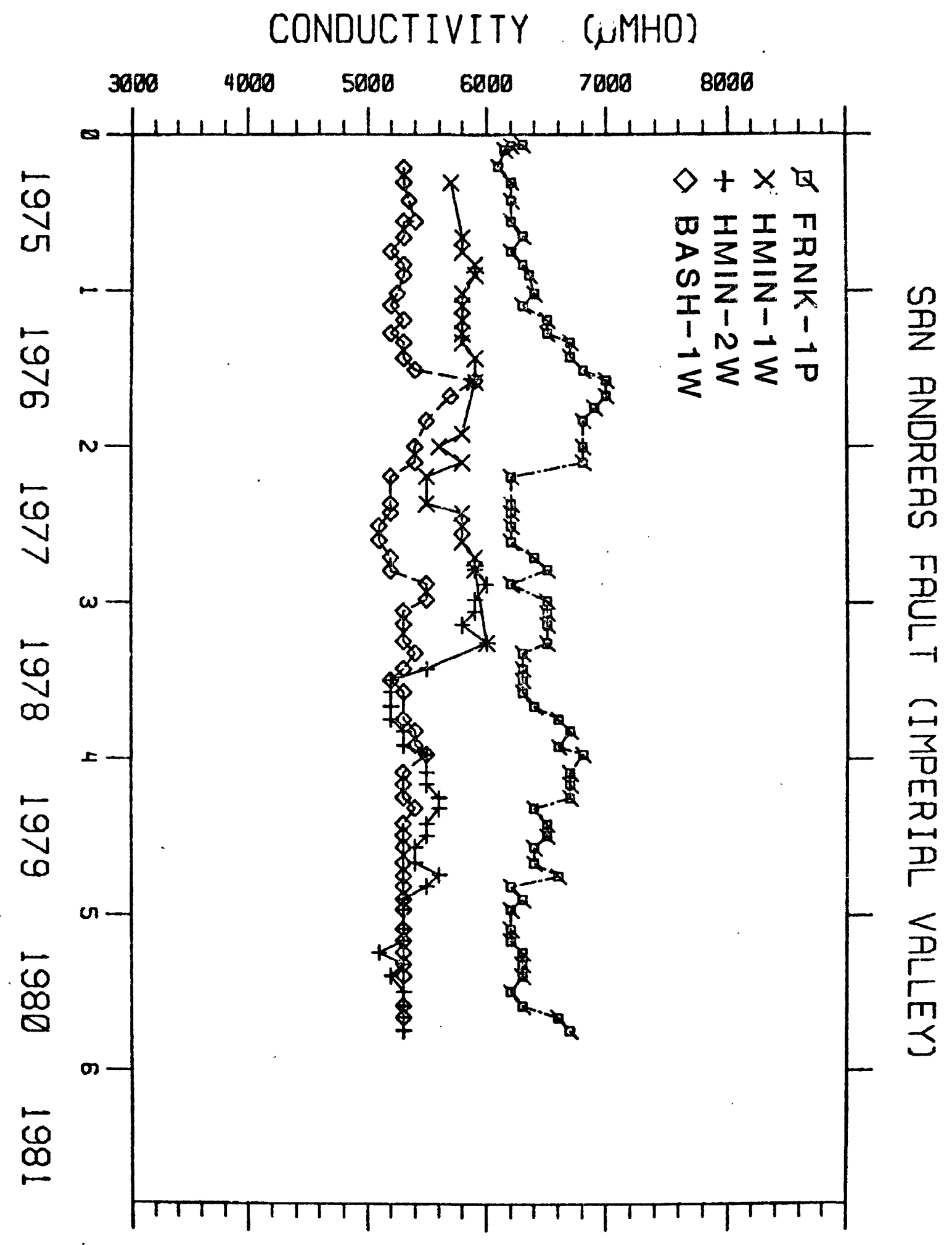




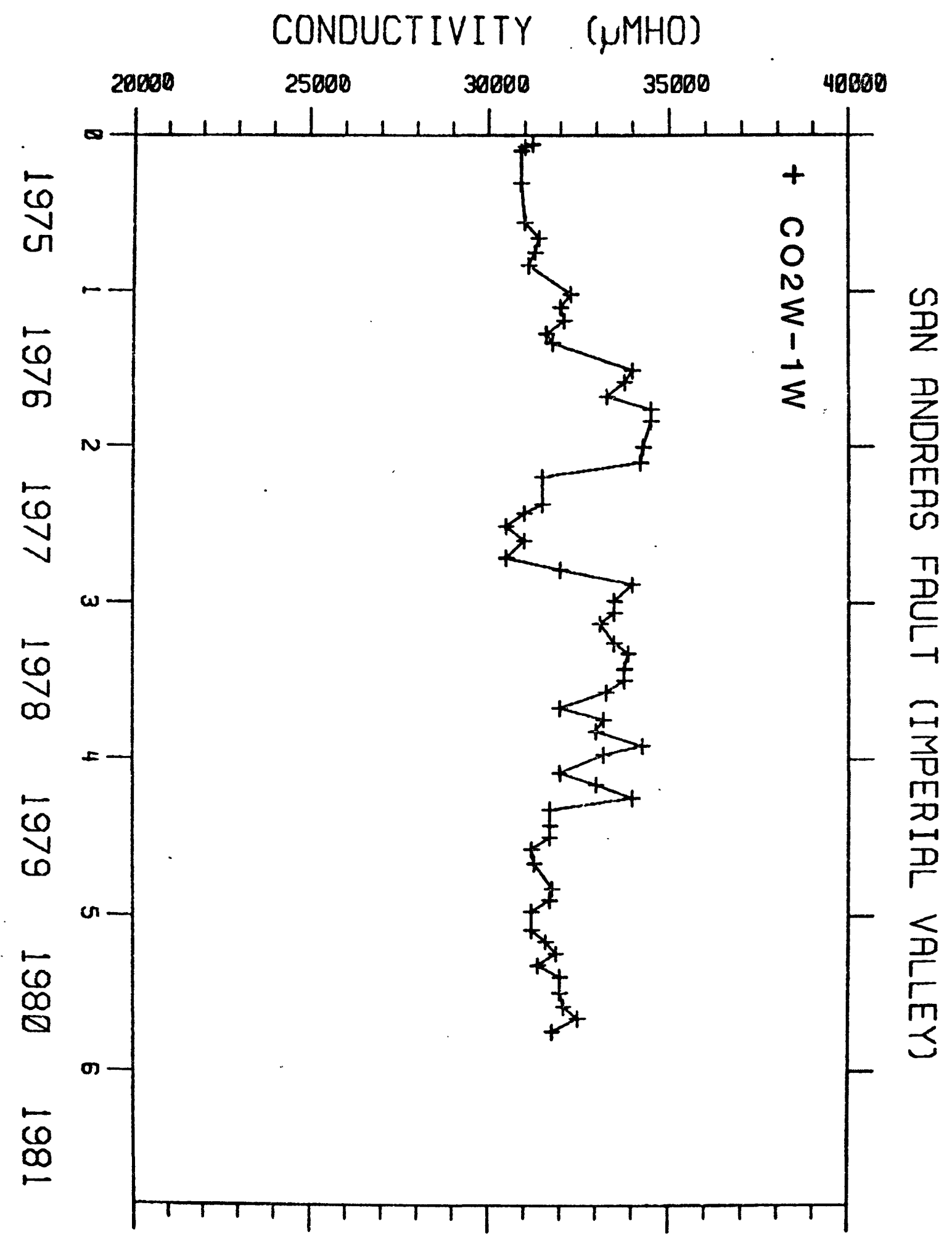




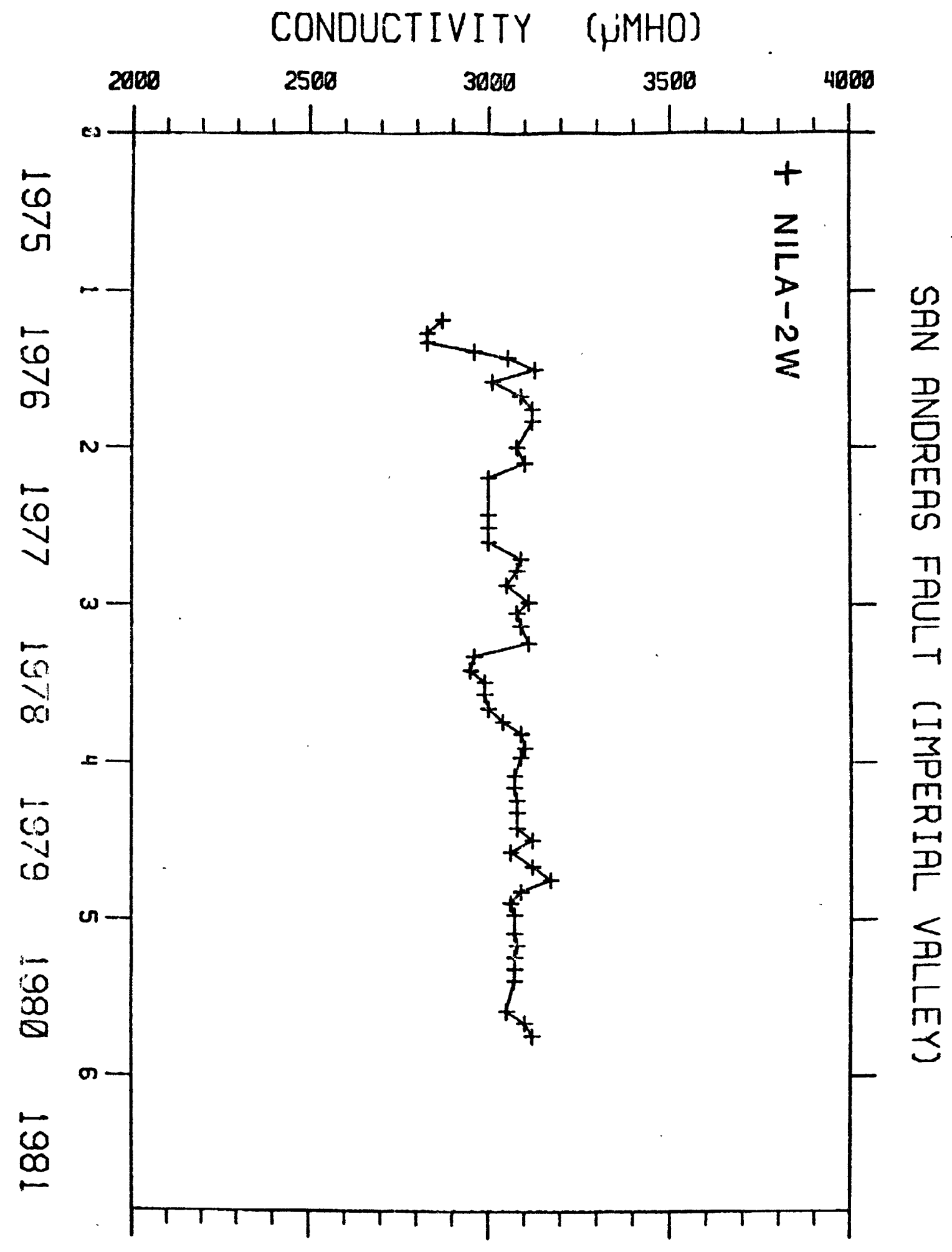

